Portland State University

PDXScholar

$1-1-1986$

\title{
Analysis of problemsolving groups with feedback intervention using a systematic multiple level observation of groups
}

Donna Buchanan Schantz

Portland State University

Follow this and additional works at: https://pdxscholar.library.pdx.edu/open_access_etds Let us know how access to this document benefits you.

\section{Recommended Citation}

Schantz, Donna Buchanan, "Analysis of problemsolving groups with feedback intervention using a systematic multiple level observation of groups" (1986). Dissertations and Theses. Paper 573. https://doi.org/10.15760/etd.573

This Dissertation is brought to you for free and open access. It has been accepted for inclusion in Dissertations and Theses by an authorized administrator of PDXScholar. Please contact us if we can make this document more accessible: pdxscholar@pdx.edu. 
ANALYSIS OF PROBLEMSOLVING GROUPS WITH FEEDBACK INTERVENTION USING A SYSTEMATIC MULTIPLE LEVEL OBSERVATION OF GROUPS

by

DONNA BUCHANAN SCHANTZ

A dissertation submitted in partial fulfillment of the raquirements for the degree of

DOCTOR OF PHILOSOPHY

URBAN STUDIES

Portland State University

(C) 1986 Donna Buchanan Schantz 
TO THE OFFICE OF GRADUATE STUDIES AND RESEARCH:

The members of the Committee approve the dissertation of Donna Buchanan Schantz preserited December 12, 1986.
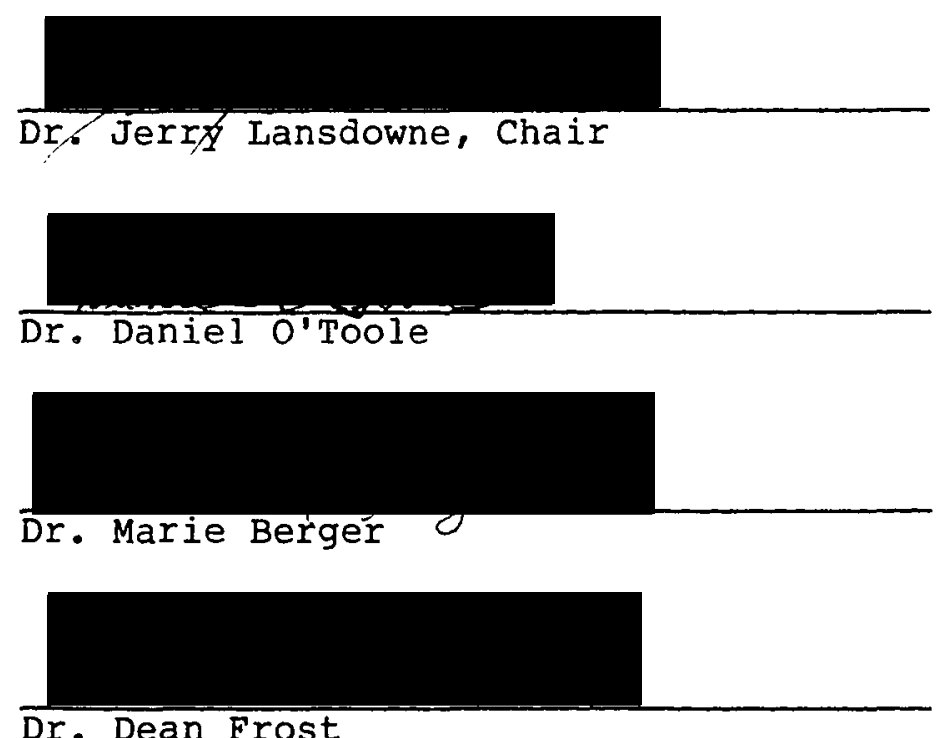

APPROVED:

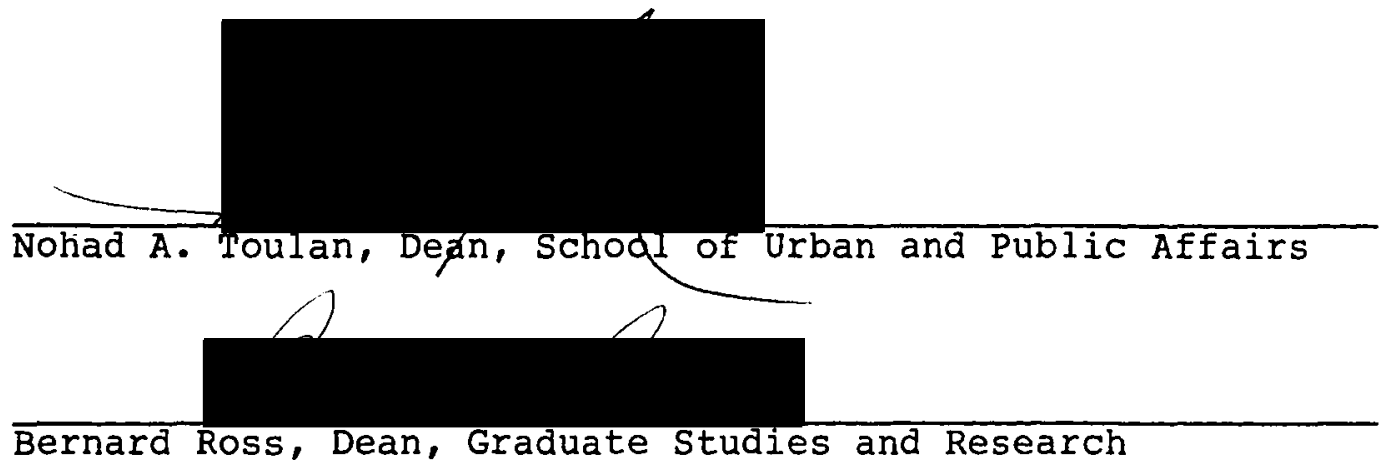




\section{ACKNOWLEDGEMENTS}

Thank you to my family, friends and colleagues who have been loving and supportive throughout the dissertation process.

Thank you to my committee which gave me the inspiration, encouragement and guidance to complete this project: to Dean Frost, who was available and willing to spend hours assisting me with data analysis; to David Wrench, who stretched my mind into the "fourth" dimension; to Marie Berger, who assisted me in making the complex elegantly simple; to Dan O'Toole, who provided insight into new ways of thinking about old ideas; and to my major professor and advisor, Jerry Lansdowne, who never waivered in his support of what I was attempting to do.

A special thank you to Barbara Stewart for her assistance in methodological issues and to Donna Jensen who assisted me in data collection and in the use of microcomputers.

To these persons and many more I am grateful for their support in what became for me a "magnificent obsession." 
TABLE OF CONTENTS

PAGE

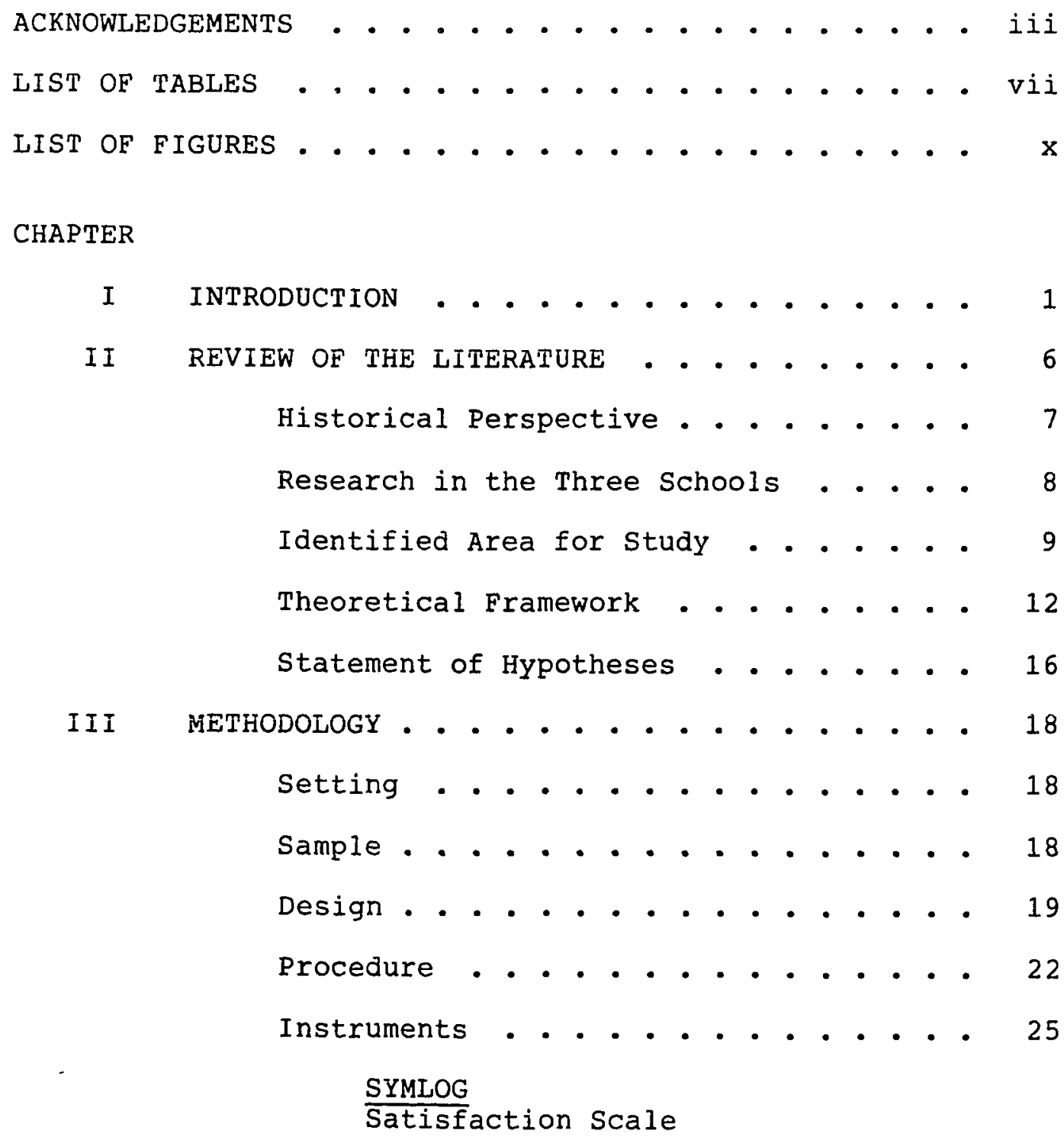


Internal Validity Checks . . . . . . 38

Equivalence of Tasks Group vs. Individual

Findings Related to the Group Change Hypothesis . . . . . . . . . . 43

Findings Related to the Group Satisfaction Hypothesis . . . . . 44

Findings Related to the Self-Perception Hypothesis . . . . . . . . . 49

Findings Related to the Ieadership Hypothesis... . . . . . . . 56

V

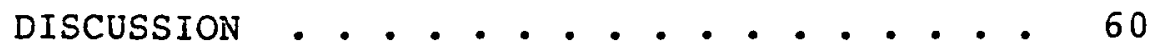

Individual Movement vs. Group Movement • 61

Feedback Groups . . . . . . . . 63

No-Feedback Groups . . . . . . . . 82

No-Show Groups . . . . . . . . 83

The Winning Group . . . . . . . . 88

VI SUMMARY, RECOMMENDATIONS, AND CONCLUSIONS • • 94

Summary • • • • • • • • • • • . 94

Recommendations for Future Research • . 98

Conclusions • . • . . . . . . . . 99

BIBLIOGRAPHY • • • • • • • • • • • • • • • . 101 
A: SYMLOG Adjective Rating Sheet . . . . 109

B: "Who Gets the Kidney" and "Luna" Tasks . . 111

C: Sample Packet Field Diagrams . . . . . 118

D: Course Syllabus . . . . . . . . . 125

E: Satisfaction Questionnaire . . . . . . 135

F : Raw Scores . . . . . . . . . . . 137

G: PFS File........ . . . . . . 139

H: Variable List . . . . . . . . . . 145

I: Satisfaction Frequencies . . . . . . . 148

J: Leader Movement . . . . . . . . . 152 


\section{LIST OF TABLES}

TABLE

PAGE

I Study Model by Group and Task . . . . . . . 41

II Results of a $t$-Test Comparing the Mean

Pretest scores on the Up-Down (U-D),

Positive-Negative $(\mathrm{P}-\mathrm{N})$, and Forward-

Backward (F-B) Dimensions for the

"Kidney" and "Luna" Tasks . . . . . 40

II Differences Among the Twelve Groups on the Average Up-Down (U-D), Positive-Negative $(\overline{-N})$, and Forward-Backward $(\mathrm{F}-\mathrm{B})$

Dimension at Pretest . . . . . . . 41

IV One-way analysis of Variance, Using Absolute Difference Scores for Feedback and NoFeedback Groups, on the Up-Down (U-D), Positive-Negative (P-N), and ForwardBackward (F-B) Dimensions . . . . . 42

$V$ Results of a $\underline{t}$-Test Comparing Feedback and No-Feedback Using Absolute Difference Scores on the Up-Down (U-D), Positive-Negative $(\mathrm{P}-\mathrm{N})$, and ForwardBackward (F-B) Dimensions . . . . . . 44 
VI Group Satisfaction Questionnaire Mean Scores

VII One-Way Analysis of Variance with Feedback, No-Feedback and No-Show Groups ....

VIII Results of $t$-Tests Comparing Feedback, No-Feedback and No-Show Groups ... . 48

IX Correlations of Self with Group Average for the Feedback, No-Feedback and No-Show Groups on the Up-Down Dimension . . . 53

$x$ Correlations of Self with Group Average for the Feedback, No-Feedback and No-Show Groups on the Positive-Negative Dimension ........... . 54

XI Correlations of Self with Group Average for the Feedback, No-Feedback and No-Show Groups on the Forward-Backward Dimension . . . . . . . . 55

XII Results of a $t$-Test on the Average Change Scores Used as Leader Means, by Feedback and No-Feedback Groups on the Up-Down $(\mathrm{U}-\mathrm{d})$, Positive-Negative $(\mathrm{P}-\mathrm{N})$ and Forward-Backward (F-B) Dimensions . . 57 
XII Directional Change Scores as Means for

Leaders Experiencing Either Feedback or

No-Feedback on the Up-Down (U-D),

Positive-Negative $(\mathrm{P}-\mathrm{N})$, and Forward-

Backward (F-B) Dimensions . . . . 58 


\section{LIST OF FIGURES}

1. The Positive-Negative (P-N), Forward-Backward

$(F-B)$, and Up-Down (U-D) Combinations in

the SYMLOG Space . . . . . . . . 27

2. Sample Field Diagram of SYMLOG depicting

Individuals Located in the Three

Dimensions of Positive-Negative (P-N),

Forward-Backward (F-B), and Up-Down (U-D) 31

3. Sample Field Diagram with Polarization-

Unification Overlay . . . . . . 33

4. Graphic Representation of the Three Bipolar

Dimensions of SYMLOG . . . . . . 37

5. Perceptions of Rater \#002 on Self and Others

in the Group . . . . . . . . . 51

6. Average Group Perceptions of :002's Behavior 52

7. Average Field Diagram of Group \#5, Term I

(Feedback) at Pretest ........ 65

8. Average Field Diagram of Group \#5, Term I

(Feedback) at Posttest ........ 66

9. Individual Field Diagram of Ann (\#001) at

Pretest . . . . . . . . . . 69 
10. Individual Field Diagram of Ann (\#001) at Posttest ........... 70

11. Individual Field Diagram of Bea (\#002) at Pretest . . . . . . . . . 72

12. Individual Field Diagram of Bea (\#002) at Posttest . . . . . . . . . 73

13. Individual Field Diagram of Jo (\#003) at Pretest ............ 74

14. Individual Field Diagram of Jo (\#003) at Posttest . . . . . . . . 75

15. Individual Field Diagram of Mo (\#004) at Pretest . . . . . . . . . 77

16. Individual Field Diagram of Mo (\#004) at Posttest . . . . . . . . 78

17. Individual Field Diagram of Mary (\#005) at Pretest . . . . . . . . . 79

18. Individual Field Diagram of Mary (\#005) at Posttest ............. 80

19. Average Field Diagram for Group \#4, Term II

(No-Feedback) at Pretest . . . . . 84

20. Average Field Diagram for Group \#4, Term II

(No-Feedback) at Posttest . . . . . 85

21. Average Field Diagram for Group \#7, Term II

(No-Feedback) at Final Examination . . 87 
xii

FIGURE

PAGE

22. Average Field Diagram for Group \#6, Term II

(Winning Group) at Pretest . . . . 90

23. Average Field Diagram for Group \#6, Term II

(Winning Group) at Posttest . . . . . 92 
AN ABSTRACT OF THE DISSERTATION OF Donna Buchanan Schantz for the Doctor of Philosophy in Urban Studies presented December $12,1986$.

Title: Analysis of Problemsolving Groups with Feedback Intervention Using a Systematic Multiple Level Observation of Groups.

APPROVED BY MEMBERS OF THE DISSERTATION COMMITTEE:
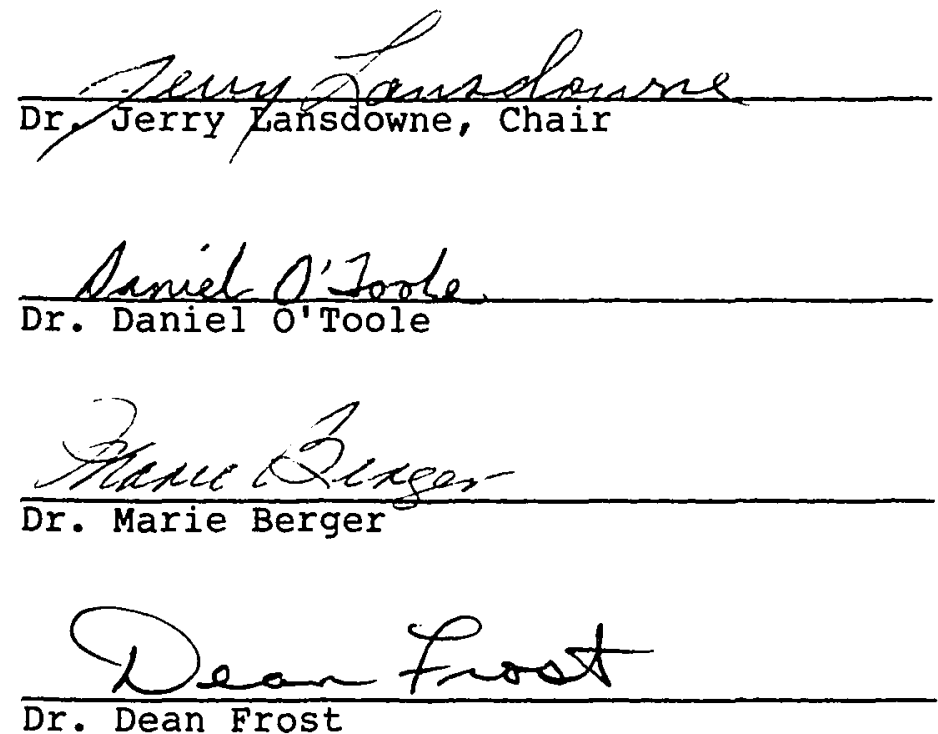

Considerable research has been devoted to problemsolving groups. Attention has also been paid to feedback as a way to increase effective communication and hence performance. The purpose of this study was to 
determine the effects of a feedback cycle on problemsolving groups.

A formal method, A Systematic Multiple Level Observation of Groups (SYMLOG) was employed for the analysis of behavior in such groups. The system, which codes on multiple levels of communication, served both as a theoretical and an explanatory approach. Problemsolving groups which included a feedback session on group process were compared with problemsolving groups which were not given feedback. The study used primary data from SYMLOG field diagrams to determine whether group movement, leader movement, self-perceptions, and group satisfaction would be affected by feedback intervention.

The study sample consisted of sixty-seven students in a professional school placed into fourteen small groups. These groups were divided into eight subgroups, four of which received feedback and four of which did not. Two additional control groups labeled "no-shows" also participated in the study.

The study was a field experiment using a quasiexperimental design. Members were randomly placed into small groups which were subsequently designated either feedback or no-feedback groups. A pretest, following a problemsolving small group exercise, was administered to all students in attendance. Those students not attending class 
became the no-show group. Feedback was then given in the experimental groups, followed by a second small group exercise and a posttest for all groups. Those data from the pretest and the posttest, obtained by use of SYMLOG general adjectives rating sheets, were employed to address the working hypotheses. Posttest data from the two additional no-show groups were only utilized in the research question pertaining to group satisfaction and subsequently for descriptive purposes.

Quantitative techniques were employed to answer the research questions. Case study techniques involving the SYMLOG field diagrams were used to discuss the results in a descriptive manner. The groups were analyzed on multiple levels of group space using the bipolar three-dimensional model of SYMLOG: task-orientation vs. emotionally expressive, dominant vs. passive, and positive vs. negative.

The findings indicated that the feedback cycle played a central role in both group satisfaction and leadership behavior but had little effect upon group movement over time and did not appear to change self-perceptions in any substantial manner.

The major findings were those surrounding the concepts of leadership and group satisfaction, both of which were found to be influenced by the intervention of feedback. The designated leaders from the groups receiving feedback made 
more movement in the group space than those leaders from groups not receiving feedback. In addition, members in the feedback groups were more satisfied with the group work than were leaders from the no-feedback groups. The remaining two hypotheses were not supported in this research. First, the movement of groups as a function of feedback was only marginal. Secondly, self-perceptions did not correlate more highly with others' perceptions as a result of feedback intervention in this study. These research findings have implications for the fields of Oregnization Behavior and Leadership Development. Use of feedback with SYMLOG field diagrams will aid in the continuing effort to develop leadership skills and increase satisfaction in group work. 
CHAPTER I

\section{INTRODUCTION}

Whether or not use of groups rather than individuals is the most effective way to reach a goal is a continuing debate, but the fact remains that small groups are being used by people in powerful positions to make significant decisions. In fact, one of the themes of Kurt Lewin's applied study in group work, social action through group action, is becoming a reality in current organizations (Schellenberg, 1978, p. 81). Small groups are being used by managers, therapists, educators and policymakers to accomplish goals through collective reasoning; the combined energy of individuals may supply a variety of inputs or strategies for any given problem (Swap, 1984).

The way in which individuals communicate when they are interacting in a group can have an effect on how the group's goals are accomplished. The more effective the communication, the more likely goals are to be met (Davis, 1981). Likewise, the more indivduals become aware of their behavior in a group setting, the more effective is their communication (Wang and Hawkins, 1980).

For scientists whose research is directed toward the analysis of small group work, feedback on individual 
behavior or on group progress is a consistent theme (Berlo, 1960; Davis, 1981; Hersey and Blanchard, 1977; Johnson, 1981; Miller, 1966). As far back as 1946, Lewin assisted in setting up training camps (which would later become "Tgroups") by introducing feedback as a helpful way for the staff to analyze self-behavior (Marrow, 1969). Although researchers generally agree that behavior feedback is essential in the communication process, they continue to search for definitive measures by which behavior may be reflected in a way which will aid self-analysis and, if desired, initiate behavior changes.

Building on Lewin's field theory, Robert F. Bales and his colleagues proposed a "new" field theory and a method for measuring group behavior. Bales applied to a group a similar kind of field theory analysis which Lewin applied to individuals. Application of field theory analysis to a group was Lewin's life-long dream; it was never realized because of the complexity of combining his individual life spaces to chart a total social field. In 1979, Bales and his colleagues proposed a theoretical framework and a measurement tool called SYMLOG: A System for the Multiple Level Observation of Groups which could record empirical data for the analysis of both individuals and groups (Bales, Cohen and Williamson, 1979). Analysis could be accomplished through retrospective rating of group behavior by the 
group members themselves. The theory was constructed over several decades by observers watching, recording and videotaping groups of Harvard undergraduates in a laboratory setting. Using empirical data and inductive reasoring, a set of laws was constructed about membership behavior which, Bales maintained, could be generalized to all small groups. In addition, the method provided a feedback cycle which occurred when the members rated one another on a SYMLOG rating sheet and the results were given back to the members for discussion. The feedback process guided the interpretation of interpersonal behavior occurring in groups at one point in time and modified certain aspects of behavior during a subsequent point in time.

The question of whether behavior can be modified has been raised in relation both to leader behavior and to group behavior. French \& Raven (1980) state that through knowledge and information leaders gain power. In that case, would feedback increase information and power to the extent that leaders and groups would make more behavioral changes over time than those groups not receiving feedback? The current study investigates that question. In addition, results of studies have shown that generally most people see themselves as others see them (Bales, Cowen, Koenigs, 1986). This study also investigates whether self-perceptions change as a result of feedback 
given in problem-solving work groups.

Finally, group satisfaction has long been inversely associated with job turnover, burnout, absenteeism and low productivity. This study determines whether the introduction of feedback into work groups increases the satisfaction level perceived by members of these groups.

In summary, then, this study seeks to determine what effect feedback intervention has over time on both individual leader and group behavior, self-perceptions, and levels of satisfaction as applied both to groups and to individual group leaders. The data are analyzed using Bales' System for the Multiple Level Observation of Groups (SYMLOG), which provides a three-dimensional model of heuristic group space. Bales acknowledged that the three dimensions would need to be demonstrated through experimental trials to provide useful evidence for his "new field theory" and system for quantification and analysis. The current study hopes, in part, to accomplish such a demonstration. To ground the study in a relevant area of practice, concepts from the field of leadership and management are also employed to assist in guiding the research process.

Since much of human activity is conducted in small groups, the study of group phenomena seems appropriate. It is hoped that results of the current study will provide 
managers: educators : and policy analysts with information that will be useful to them in their work with small groups. 
CHAPTER II

REVIEW OF THE LITERATURE

HISTORICAL PERSPECTIVE

Much of what is known about small groups stems from Lewin's theoretical constructs developed in 1939. His notions of "life space" and "group dynamics" provided a framework for small group research that continues to this day. In addition, Lewin legitimized the study of "groups" by being one of the first social psychologists to place the emphasis of study on the group as a phenomenon (Deutsch, 1954)。

In contrast to Lewin, Jacob Moreno approached the theory and application of social interaction from the individual perspective, introducing the school of "sociometry" (Moreno, 1953). His work stimulated research directed toward the individual and in particular toward the use of psychodrama as a therapeutic tool.

A third approach to the study of social interaction was that of Robert Bales, who began his work in 1950 with the reporting of a network of categories to describe the group process as a social system (1950). Although Bales coined the term "small group" to describe a unit of analysis, he 
and his colleagues have since shifted to also include in that unit of analysis the individual for, more specifically. individual personalities). This shift resulted in the current use of three dimensions for the analysis of interpersonal behavior, labeled multiple level field theory (Bales, Cohen \& Williamson, 1979).

These three schools--group dynamics, sociometry, and small groups--dominated the social interaction field of study which was prevalent until the $1970^{\prime} \mathrm{s}$. Differences among the schools were more differences of emphasis than of concept (Hare, 1982). The research emanating from these three schools was prolific during the 1950's and $1960^{\prime} \mathrm{s}$. Strodtbeck's (1954) classic paper describing the proliferation of research activity in the field was indicative of the times as he advertised the new scientific "best seller" to be Cartwright and Zander's (1953) collection of papers from all three schools of small group research.

Although research in small groups diminished in both sociology and psychology during the 1970's (Crandall, 1975; Steiner, 1974), primarily because it was felt that the field was saturated using the data analysis techniques available at that time, research has begun again in the 1980 's. Research based on the broad concepts of Lewin's theory continues, while Moreno's sociometry has more or less 
been designated a "classical" theory. The most recent introduction of Bales" "new field theory" has stimulated international research in its application and development (Hare, 1985).

RESEARCH IN THE THREE SCHOOLS

Recorded studies over the years in all three schools of group behavior have tested hypotheses or observed behaviox occurring at the moment in a face-to-face group setting such as a classroom, a meeting, and a therapy session (Tubbs, 1978). The findings have suggested ways in which groups are formed (Bradford, 1982), illustrated how groups mature (Gibb \& Gibb, 1967), shown how the introduction of new members affects the group (Fine, 1976), demonstrated leader-member relations (Fiedler, 1967; Stogdill, 1974), discussed optimal small group size (Bales, 1954), and presented normative group behavior (Allport, 1924; Sherif, 1936; Festinger \& Aronson, 1968). The problemsolving small group has been given by far the greatest attention in textbooks of group discussion (Barnlund \& Haiman, 1959; Collins \& Guetzkow, 1964; Harnack \&Fest, 1964; Gulley, 1968; Sattler \& Miller, 1968; Bormann, 1969; Patton \& Griffin, 1973; Appelbaum, at al., 1974; Brilhart, 1974; Gouran, 1974; Goldberg\& Larson, 1975; Hersey \& Blanchard, 1982, and Lippitt, 1981). In addition, small group research has given insight into group conformity 
(Leavitt, 1964), encounter groups (Lieberman, 1973). effective work groups (Likert, 1961), and many others. The research is exhaustive and provides a generous pool of knowledge about how groups are formed, the process of group work and a variety of outcome measures. Depending upon the therapeutic or problemsolving purpose of the group, a great deal of information is available to the practitioner, be it educator, therapist, or manager, for the applied use of small group research.

\section{IDENTIFIED AREA FOR STUDY}

One area which has received less attention in small group research is the quantification of the effects of feedback (Middleman and Goldberg, 1983). Although feedback is generally accepted as being helpful and useful in small group work, there is little recorded information on the precise measurement of feedback intervention effects.

In addition to measurement, an identified framework of the communication process which includes concepts in communication theory is relevant to the present study. This framework is useful in both developing the use of feedback as it relates to communication theory and providing a sense of guidance into the more pragmatic world of leadership and management as a way of application. This guidance, 
emanating from communication theory, is embedded in the communication process.

Communication involves both a sender and a receiver. According to Johnson (1981) it is a means for one person to relay a message to another, expecting a response. The communication prcess involves five basic steps: identifying the reason for communication, (2) encoding the information (putting the ideas into words), (3) transmitting the message, (4) decoding the message, and (5) providing feedback to the sender (Davis, 1981).

The goal of any communication is congruence between the sender's intended message and the receiver's perceived message. Validation of this process is important because people perceive messages in relation to their own values, educational level, and experiences (Berlo, 1960).

Validation of messages during the communication process occurs by use of feedback. Wang and Hawkins (1980) suggest that effective communication requires feedback to increase understanding about behavior. Feedback is also the "process of adjusting future actions based upon information about past performance" (Haynes, Massie, and Wallace, 1975, p. 243)

There are many methods for receiving and giving feedback. For example, the study of Quaker decisionmaking by Hare (1973) demonstrates an instance in which, with 
feedback as part of the process, informal interactions facilitated group decisionmaking. Simple statements about performance of even a nod also constitute feedback in an informal way. At the other end of the scale, formal feedback performance appraisals at six-month intervals are commonplace in management practice.

Several tools have been developed to assist practitioners in conducting feedback sessions. Partially because of Napier and Gershenfeld's research (1973) and that of others which reported that feedback is a high-risk activity for followers, the National Training Laboratory (NTL) suggested guidelines for useful feedback:

1. It is descriptive rather than evaluative;

2. It is specific rather than general;

3. It takes into account the needs of both the receiver and giver of the feedback;

4. It is directed toward behavior which the receiver can do something about;

5. It is solicited, rather than imposed;

6. It is well-timed;

7. It is checked to ensure clear communication.

(Mill, 1971)

The notion of introducing feedback into the group process (also called "intervention") has intrigued researchers over the years (Gibb, 1967; MCCaskey, 1976). 
Berger (1981) introduced into a series of small working groups a survey feedback model for the purpose of increasing trust behavior. Feedback to small groups about their behavior was also utilized by Bales in his early work to enhance the growth and development of groups (Bales, 1956). In his recent work, SYMLOG, Bales has devised a method for giving feedback to leaders and groups that is more explicit than his early work and is consistent with NTL guidelines for effective feedback.

What Bales offers in his new system for group observation is an opportunity to view behavior from a threedimensional model which more clearly differentiates and captures the movement of individuals and groups in a unit of real time. Through this system, a more detailed view into the life of small groups may be possible. It is this method that the present study uses to determine the effect of feedback on group behavior.

\title{
THEORETICAL FRAMEWORK
}

\author{
MCGrath (1984), after reviewing small group \\ research from several fields and discussing general \\ contribution, concluded that future research was needed, but \\ with the "guiding hand of theory." In 1979, Bales and \\ colleagues proposed a "new field theory" that was designed \\ to provide a framework for behavior in small groups, an
}


jnstrument that could measure this behavior, and a set of meanings that explained the behavior of both individuals and groups (Bales, Cohen \& Williamson, 1979). By incorporating Lewin's field analysis of group space using vectors and valences and the symbolic interaction concepts from Parsons, a new method for group observation, analysis and feedback was constructed. The uniqueness of this method was its ability to record behavior in a threedimensional conceptual space. Earlier methods contained long lists of categories; in Bales' method, the observer need only classify twenty-six. SYMLOG; A System for the Multiple Level Observation of Groups (Bales, Cohen \& Williamson, 1979) is a multilevel and multi-method system. That it is multi-level is its revolutionary aspect (Polley, 1984). Along with verbal behavior, values and images, nonverbal behavior can be coded within three dimensions. In addition, these data may be obtained by act-to-act observations or scoring, or by retrospective ratings on an adjective check list. (Appendix A contains a sample of SYMLOG's general adjective rating sheet.)

Bales utilized natural meanings in his representation of the three physical dimensions, for example the UpwardDownward (U-D) dimension he assigned to the behavioral meaning of "Dominant-Submissive," corresponding to most 
people's perception of dominant as upward and submissive as downward. Likewise, the Positive dimension (P) implies "Friendliness," while the negative dimension (N) implies "Unfriendliness." Similarly, the Forward direction (F) implies "Task-oriented" or "Instrumentally controlled," while the Backward direction (B) is associated with "Emotionally-expressive" behavior (Bales, Cohen and Williamson, 1979).

Although meanings associated with each space are attached for quantification, Bales makes it explicit that there are no values attached to the location of any individual or to any particular space. In other words, productivity is not necessarily attached to the Forward direction. Polley (1983), in his work which extends Bales' theory, states that the Backward direction is "essential to almost every task."

The SYMLOG space seen in the field diagrams operates within vectors similar to those described by Lewin (1951). Bales set out to provide a concrete conceptual framework for the attraction and repulsion of vectors in space, something Bales did not do. Iikewise, Moreno's sociograms plot the interrelationships of people in space, but they are not positioned with any meaning other than relative positions in the interrelationships. SYMLOG provides a model for examining both the interrelationship network and the 
explicit conceptual space. Since the SYMLOG theory and method are used for hypotheses testing in this study, more explicit information about the method is presented in the "Instrument" section of Chapter III.

Research in testing Bales' multiple field theory is now appearing in the literature. Hare (1985) assesses two different ways in which SYMLOG can be used in the study of group dynamics. Jesuino (1985) used SYMLOG in a study of early detection of emerging leaders in a Portuguese military academy. In addition, applications-focused studies are now being reported. Fine (1976), for example, reported on the addition of a new group member and its affect on group process in the first experimental study using SYMLOG. Hattink (1985) translated the adjective rating questionnaire for use in a Dutch elementary school to provide teachers with an instrument for perceptions of problematic classroom interaction. Lansdowne introduced a creative application of SYMLOG in his observation of a theatrical group (1986). The recorded research is slowly emerging in national and international journals demonstrating the use of SYMLOG across cultures and in different circumstances.

Although research using SYMLOG is now well underway, there is a recognized need to continue what Kohler (1986) describes as the need for "concrete experiments" and what Hare (1982) suggests as empirical evidence of SYMLOG's 
efficacy and usefulness in pracicice.

The present study applies the formulations of Bales' working hypotheses and uses feedback as the independent variable.

\section{STATEMENT OF HYPOTHESES}

This study seeks to determine whether a feedback session for small groups contributes to the group's being more positive, more task-oriented, and better unified than when feedback is not employed. It also tests whether groups which have experienced feedback describing individual and group perceptions of behavior may be more satisfied with their group work than those who have not been exposed to the feedback cycle.

Two specific hypotheses were formulated:

- Intervention of a feedback cycle on a group following a specific problemsolving assignment will lead to a significant change in the positioning of the group space on the field diagram of SYMLOG.

Positioning, in the above definition, refers to the point of reference in a three-dimensional space which gives a visual picture of an individual's location within a group. Feedback cycle occurs when the members rate one another on the Simiog rating sheet and the data are summarized, returned to the members, and results are discussed (Bales, Cohen and williamson, 1979, p. 303). The problemsolving task is a problem given to all of the groups to accomplish 
witnin a designated time frame and independent from the classroom teacher.

- Group satisfaction with problemsolving assignments will be significantly higher following the intervention of a feedback cycle than when there is no feedback.

Self-perception is likely to be closer to the perception of the others in the group for the same behavior if the group has had the opportunity to practice together and to receive feedback. In addition, those groups which have experienced the feedback cycle will most likely see a change in leadership behavior within the group. Two additional hypotheses were proposed to test this notion:

- Self-perception of behavior within a group will be more highly correlated with the perception by others in the group when the group has experienced a feedback cycle than when it has received no feedback.

- Leadership behavior within a group exhibits greater positional change on the field diagram following a feedback cycle than if the group receives no feedback. 
CHAPTER III

METHODOLOGY

SETTING

The setting was a regularly-scheduled required leadership-management class of senior students in a baccalaureate school of nursing located on a Health Sciences University campus. The class was conducted for three hours, once a week, for twelve weeks.

\section{SAMPLE}

The sample for this study included 67 senior nursing students who were enrolled in the required leadershipmanagement class over a period of two academic terms; 60 of the students were females, and 7 were males. Thirty-seven students were enrolled in Term I, and 30 students were enrolled in Term II. The classes were held in the winter and spring terms consecutively.

\section{DESIGN}

The study was quasi-experimental and contained three conditions: feedback (the experimental condition), no feedback and "no-shows" (the two control conditions). 
it the beginning of each term, students were randomly placed into small groups $(6-7$ persons). The original sample included six groups per term; however, because of the noshows at the first group exercise, the final size of the small groups used for the study ranged from 3-7 persons, and the number of groups increased to seven per term to include an additional group containing these no-shows.

During Term I, six groups received feedback, and the one group of no-shows experienced neither practice time in groups nor any feedback. During Term II, two groups received feedback, four groups received no feedback, and one group of no-shows experienced neither practice time in groups nor feedback.

During Term II, the assignment to feedback or nofeedback conditions was not random, but rather was related to the student's choice of class activities. Students were given the opportunity to attend a micro-computer session during regular class time, since one of the course objectives relating to the term paper stated that all students were expected to use the word processor. Sixteen individuals expressed a desire to attend that class. Those sixteen persons were randomly placed into four small groups; those four groups became the no-feedback groups in the study.

The total sample for the two terms (six months) 
consisted ổ eight feedback groups, four no-feedback groups and two no-show groups. The sample of 67 students was used throughout the study. One student was not present at the first group session and was asked to join the no-show group. She elected not to do so, but instead came to the feedback session and continued on with her originally-assigned group. The only inclusion of data pertaining to her is in posttest scores.

One of the class requirements of the leadershipmanagement class was working together in small groups to complete problemsolving tasks. During each of the terms of study, groups were given two problemsolving tasks to complete: one practice problemsolving task at midterm which was used to obtain pretest measures and another graded problemsolving task at the end of the term which was used to obtain posttest measures. To control for task order effects, the tasks were reversed in sequence during the second term of study. Except for the reversal of task sequence, all other variables were held constant over the two terms. The group of no-shows did not have experience in the small groups until the end of the term when posttest measures were obtained for these subjects. Immediately following the small group practice task at midterm, data were gathered by asking students in the groups to rate their own behavior and that of others in the group 
using Bales' SYMLOG Adjective Rating Sheet. These pretest data were displayed on field diagrams for each student, and a feedback session to interpret the diagrams took place in the next class session for the students in the feedback groups. An equivalent data-gathering procedure occurred at the end of the term following the second problemsolving group work to obtain the posttest measures.

Two problemsolving tasks were presented, one of which will be hereinforth referred to as the "Kidney Task" and the other as the "Luna Task." (See Appendix B for specifics of the relative task assignments.) The two tasks depicted situations wherein students were asked to make judgments in their small groups and present their recommendations to the total group. Table I shows the order of tasks in this study.

TABLE I

STUDY MODEL BY GROUP AND TASK

\begin{tabular}{|c|c|c|c|c|c|c|}
\hline TERM I & Winter) & & TERM IT & (Spring & & \\
\hline \multirow[b]{2}{*}{$\begin{array}{l}\text { Groups } 1 \ldots 6 \\
\text { (feedback) }\end{array}$} & Kidney & \multirow{2}{*}{$\begin{array}{l}\text { Luna } \\
02\end{array}$} & \multirow[b]{2}{*}{$\begin{array}{l}\text { Groups } 1 \ldots 4 \\
\text { (no-feedback) }\end{array}$} & \multirow{2}{*}{$\begin{array}{c}\text { Luna } \\
02\end{array}$} & \multicolumn{2}{|c|}{ Kidne } \\
\hline & $01 x$ & & & & $x$ & 01 \\
\hline \multirow[t]{2}{*}{$\begin{array}{l}\text { Group } 7 \\
\text { (no-show) }\end{array}$} & & 02 & $\begin{array}{l}\text { Groups } 5 \ldots 6 \\
\text { (feedback) }\end{array}$ & 02 & $x$ & 01 \\
\hline & & & $\begin{array}{l}\text { Group } 7 \\
\text { (no-show) }\end{array}$ & & & 01 \\
\hline
\end{tabular}


PROCEDURE

1. In the third week of the academic term students were randomly placed into small groups of no more than seven students per group.

2. In the fifth week of the term, the groups were given the first problemsolving task, "Who Gets the Kidney," and given one hour to complete the task. In addition, each group was asked to designate a leader to represent the group in communicating the results of the task.

3. Pretest data were collected immediately following completion of the task. No grade was awarded for this exercise since it was designated as a practice session. Students were asked to complete the SYMLOG adjective rating sheet, rating both themselves and the others in their group. This task was accomplished before the group presentation and selection of "Who Gets the Kidney," based upon verbal reports from each group. For purposes of computer identification, students were asked to place their own first name on the right side of the adjective rating sheet and the name of person they were rating on the left side.

4. Data from the general adjective rating sheets were coded and enterd into an IBM-PC using Polley's software computer package to quantify the SYMLOG data (Polley, 1984). These data provided the pretest scores for this study. 5. For the eight feedback groups, each student 
received a folder containing all of the field diagrams for their group (Appendix $C$ ). In addition, to maintain confidentiality, each student was given an identification number and asked to pencil the number on the front page of the packet. Students were told that they would only be able to identify themselves by their code number (Term I, group \#3, person 003 , for example).

A two-hour feedback session took place in which the SYMLOG diagrams were discussed. Feedback was given which interpreted the diagrams for the students in both Term I and Term II. The four no-feedback control groups (all in Term II) were not present and did not receive the field diagrams or any form of feedback. These no-feedback groups were attending the optional class on the use of micro-computers.

6. Following the pretest and the subsequent feedback session, classroom activities continued throughout the term with lecture-discussion of leadership and management concepts.

7. The final group problemsolving task was assigned on week ten of the term. The no-show group was included in this assignment. Each group was also asked at that time to designate a group leader who would be responsible for presenting the final oral report on the project. It was the designated leaders from this assignment who became the twelve subjects in the leadership hypothesis. 
Students were asked to work on the assignment of "A Satellite Health Program for Luna" during out-of-class time using their small groups. In addition, they were asked to submit a one-page summary of their project and be prepared to present an oral argument defending their recommended solution to the problem for their final examination. This summary was given to an outside reviewer to grade using guidelines specified to students in the course syllabus (Appendix D). The groups understood that they would be competing with each other in their presentations and would be represented by their designated leader.

8. Posttest data were collected after students completed the "Luna" task but before they presented it at the final class session. Students were again asked to complete the SYMLOG general adjective rating sheet for themselves and for others in the group. In addition, a questionnaire was administered to determine the students' satisfaction level in terms of their group work (Appendix E).

9. The group reports of the project were presented by the designated group leader to two expert reviewers who judged the projects. The winning group was announced and awarded an "A" grade.

10. The data from the adjective check sheets were coded and run on the IBM-PC, producing the field diagrams of 
SYMLOG.

11. The procedure for Term II was similar to that for Term I, with the exception of the change in the sequence of small group assignments. (For example, the "Kidney" assignment was the pretest in the first term, but was changed to the posttest the second term.l These assignments were switched to control for task order effects.

\section{INSTRUMENTS}

The four dependent variables for this study were satisfaction vs. dissatisfaction, dominance vs. submissiveness, friendliness vs. unfriendliness, and instrumentally controlling vs. emotionally expressive. Satisfaction with the group process was measured using a tool developed by the researcher (see Appendix F). The other three variables were measured using the SYMLOG method developed by Bales, Cohen \& Williamson (1979). Movement or change from the pretest to the posttest on the last three variables was measured using both directional difference scores and absolute difference scores. The SYMLOG and satisfaction instruments are described below.

\section{SYMLOG}

SYMLOG, A System for the Multiple Level Observation of Groups was developed by Bales and Cohen (1979). The system was designed after thirty years of study and ten years of 
experimentation with self-analytical groups in the Harvard University laboratories (Bales, 1950, 1970; Bales, Cohen, and Williamson, 1979). This system is useful in the study of groups in that it dissects overt interpersonal interactions, then combines them into discrete parts which can be graphed in three dimensions to create a profile of the actions occurring within a group. Although the system was first tested with self-analytical groups of students to guide their insights into their own behavior and the behavior of others, the system is now being tested and utilized as a consultant tool in organizations (Polley, $1984)$ and in therapy groups, classroom groups, and with families (Bales and Isenberg, 1982).

The SYMLOG three-dimensional space contains vectors or lines representing both magnitude and direction in the theoretical force field. The space may be conceptualized as an analytic space comprised of three orthogonal, bipolar factors. The model used to depict the vectors in the three dimensions of space is a cube, as shown in Figure 1. This cube allows a visual rotation of vectors in Euclidean space showing the classes of directions or location, defined by combinations of the six named reference directions. The reference directions are represented by three lines passing through the cube and intersecting in the center. Polarity changes when location on the line moves away from the point 


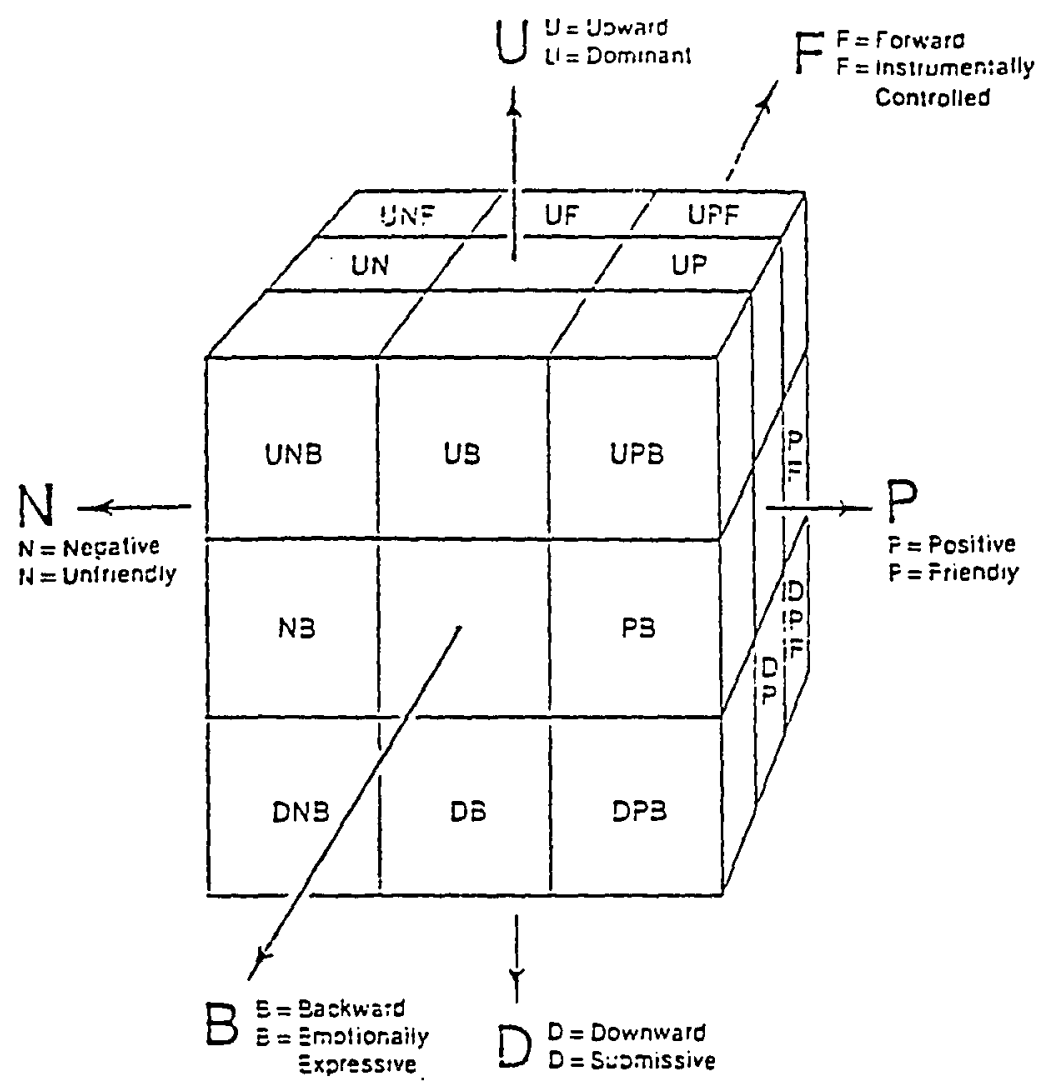

Figure 1. The positive-negative $(\mathrm{P}-\mathrm{N})$, Forward-Backward

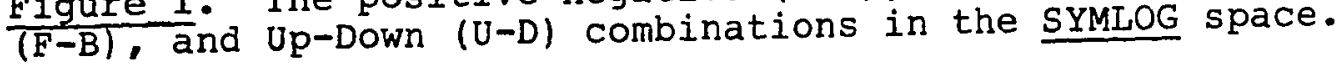


of intersection in any direction. The pairs of opposing vectors are named to suggest direction in three-dimensional space. The horizontal direction from left to right is designated Negative-Positive $(N-P)$, and the vertical direction is labeled Forward-Backward $(F-B)$. The dimension labeled Up-Down (U-D) comprises the third dimension.

In each of the three dimensions, $U-D, F-B, P-N$, vectors are divided into three cubes which give a relatively precise location on the line of reference. All in all there are 27 equal parts of the vectors within the cube $(3 \times 3 \times 3=27)$. Each of the vectors is named to represent its location within the cube. If the location is half way between the vectors $\mathrm{N}$ and $\mathrm{B}$, the vector is named NB and is at zero point of U-D. The zero point is neither $U$ or $D$ and is located in three equal parts or dimensions comprising the one vector in the center. Therefore, for mathematical purposes in plotting, there are 26 vectors.

Construct validity and reliability have been satisfactorily demonstrated to determine that the factors represent $85 \%$ of the variance in measuring behaviors in individuals and groups and that the factors consistently emerge in test-retest studies. Factor analysis, which, according to J. Myers (1972), is a powerful method for establishing construct validity, has been employed in this study. By reducing hundreds of measures of behavior into a 
smaller number of measures called factors, Bales (1970) was able to determine which ones cluster. The six identified factors isolated for SYMLOG have been pretested, tested, and retested for agreement and disagreement with value statements, determined through act-by-act classification of values and behaviors by groups and tested through post-meeting ratings of behavior by observers and members of the group to test for reliability.

Bales, Cohen, and Williamson (1979) developed an instrument to capture and measure variables that entered into the three identified factors. This was done by collapsing act-to-act observations into 26 items which measured the 26 vectors as precisely as possible. The items were factor analyzed and refined using current data from groups, resulting in a reliability coefficient for the $\mathrm{P}-\mathrm{N}$ dimension of .95 , for the F-B dimension of .80 , and for the U-D dimension of .77 (Bales, 1979). The instrument, called the Adjective Rating Form, is illustrated in Appendix A. Although Bales and colleagues developed subsequent rating forms which reflect values as well as desired behavior, the present study was confined to determining behaviors within a group at one point in time.

Asking each member of a group to complete the adjective rating form at the conclusion of problemsolving Tasks 1 and 2 in the present study allowed for retrospective rating of 
behavior for the rater and for members of the group. The responses gave numerical indicators for the items which were added, subtracted, and multiplied to produce a score for each of the three dimensions. These three scores were then located on the vectors of the three dimensional space for each individual to form a field diagram of the group. A sample field diagram is shown in Figure 2.

As can be seen in Figure 2, each circle represents an individual within a small group and the location or vector where the individual has been placed in the two dimensions of task orientation: emotionally expressive $(F-B)$ or negative-positive $(\mathrm{N}-\mathrm{P})$. The size of the circle surrounding the individual represents the third dimension of dominantsubmissive $(U-D)$ behavior. The larger the size of the circle, the more dominant the person. These three dimensions represent on the field diagrams individuals' behavior occurring during one group meeting.

Bales superimposes in the SYMLOG space polarizationunification as it applies to small groups. Earlier research in polarization was focused on defining group decisionmaking as opposed to individual decisionmaking. Moscovici and Zavalloni (1969) coined the term "group polarization" to describe this phenomenon. Bales departed from this single explanation of group thinking by dividing the group entity into two widely separated locations in the conceptual space. 


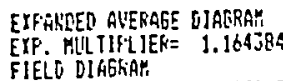

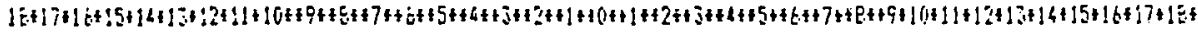


Figure 3 is an iliustration of the polarizationunification of a sample small group. By using the overlay to conceptualize the opposing poles on the field diagram, a determination can be made about the group's relative unification or polarization. The circle which appears to contain the most influential members is the referent circle. In the example, the field is unified, and all of the members are in the referent circle.

\section{Satisfaction Scale}

The satisfaction tool was developed to measure perceived satisfaction by any group members of the group work. Eleven questions were directed toward both the process and the content of the group work. Students were asked to complete the questionnaire at the end of the term using scaled responses ranging from 1 (not satisfied) to 4 (very satisfied) to register their degree of satisfaction with the group work. Cronback's alpha statistic was used to detrmine the satisfaction tool's reliability. This was accomplished by taking the average correlations of any pair of the eleven satisfaction items. The tool can be seen in Appendix E. 


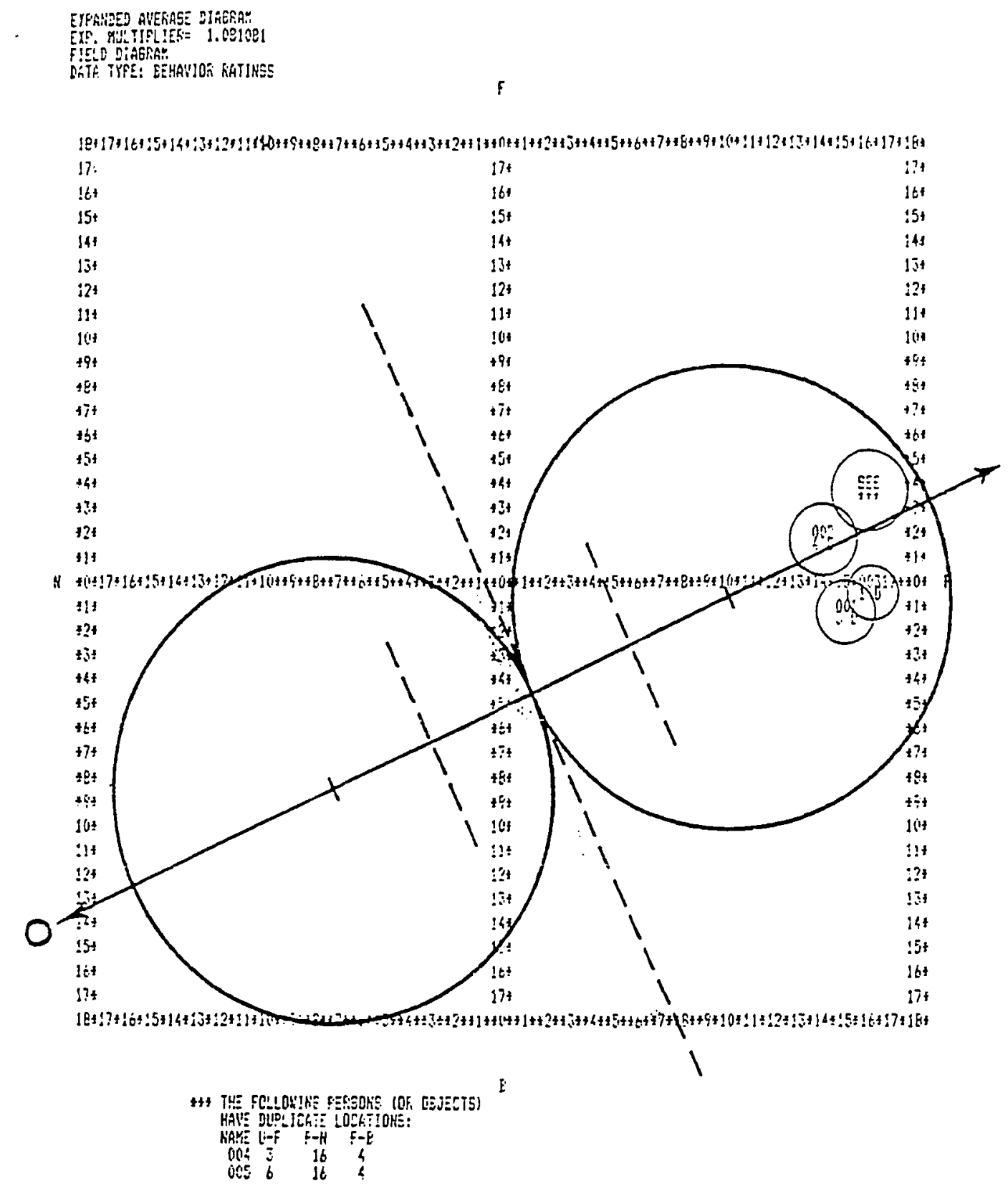

Figure 3. Sample field diagram with polarizationunification overlay. 


\section{ANALYSIS PROCEDURES}

\section{Software}

A computer software package developed by Rick Polley (1983) was used to assist in quantifying data and displaying the field diagrams. Raw data were entered into an IBM-PC, and scores from each individual $(\mathrm{N}=67)$ were used to plot the location on each dimension in the field diagram. A sample of rating scores from one group $(\mathrm{N}=5)$ is shown in Appendix $F$ to illustrate how raw scores were transformed into the field diagrams. The average diagrams were used in comparing all fourteen groups to one another and in analyzing leader behavior. The individual diagrams were used to test the research hypothesis pertaining to selfperceptions.

Data from these initial ratings were transcribed to an IBM Personal File System (PFS) as a preliminary step in preparation for using the IBM-XT, SPSS package. (See Appendix G for the PFS used for this study.) A variable list was created to assist in the comparison of groups using SPSS. The complete variable list can be found in Appendix H.

\section{Hypothesis Testing}

The unit of analysis for the first hypothesis was the group. To test the change in the positioning of the twelve 
groups from pretest to posttest, an ANOVA was applied to the absolute change scores of the average field diagrams and was calculated on all three dimensions $(U-D, P-N, F-B)$ by both the feedback and the no-feedback groups.

The second hypothesis addressed satisfaction with the group process, which was measured at the end of the term. This hypothesis stated that satisfaction would be higher for the feedback group than for the no-feedback groups. A one-way analysis of variance (ANOVA) was used to compare students in the eight feedback, four no-feedback and two noshow groups on relative levels of satisfaction.

The third hypothesis was concerned with the effect of feedback on the correlation between the self-rating and group rating of individuals on the three dimensions (U-D, $\mathrm{P}-\mathrm{N}$, and $\mathrm{F}-\mathrm{B})$. The group rating of an individual was computed by averaging the ratings of each person by all other persons in that group. This group rating was correlated with the score of the self-rating on each of the three dimensions. For example, the variable name given to the group rating of an individual on the $U-D$ dimension was CAUD, and the variable name for the self-score was SUD. These two scores on all of the dimensions were correlated across subjects separately for the feedback groups, for the no-feedback groups, and for the no-show groups. The correlations were then transformed using Fisher's $\mathrm{Z}$ and 
compared across groups using a $\underline{t}$ -

The fourth hypothesis addressed the leadership

question, using a $t$-test which compared the average change scores of leaders who received feedback with those who did not. This comparison was performed on all of the three dimensions.

Field diagrams were displayed throughout the study to depict the movement of both groups and individuals. The polarization-unification overlay was used to identify how individuals and groups in this study were unified as opposed to polarized.

Finally, a graph was constructed to assist the reader in the results section of this study. The graph is a visual guide to the three dimensions of SYMLOG and can be seen in Figure 4 . 
F (Forwardi)

instrumentally

controlling

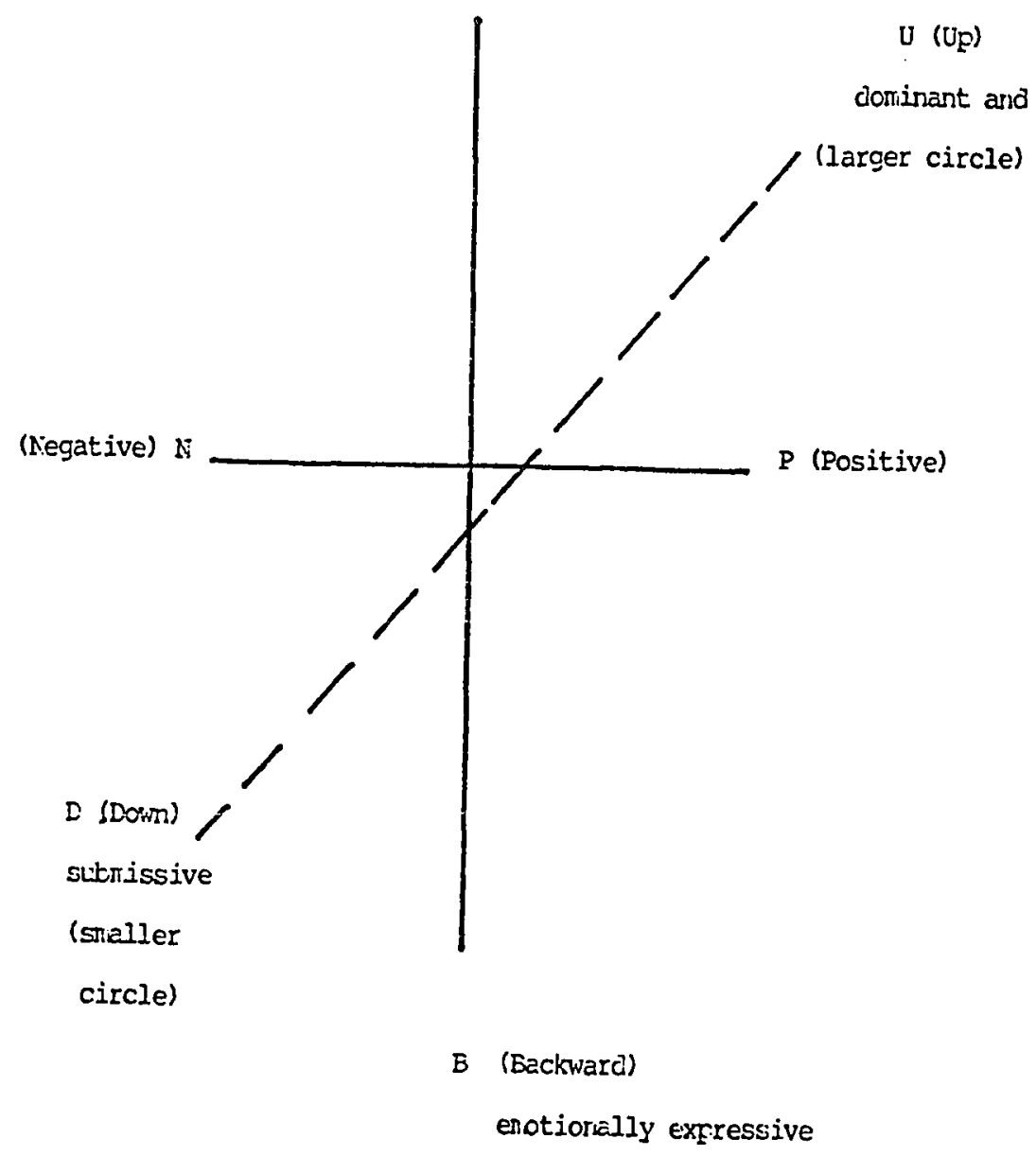

Figure 4. Graphic representation of the three bipolar dimensions of SYMLOG. 
CHAPTER IV

RESULTS

The data from this study were analyzed and will be presented by relating the findings to each specific research hypothesis stated in the previous chapter. A discussion of the findings will be integrated throughout the results section since the interrelationships of the threedimensional model in the group space is a central theme and requires comment for the sake of clarity.

Prior to the data analysis, two checks were made on measures of internal validity, one to determine whether the tasks were equivalent and the other to determine whether the unit of analysis should be the group or the individual. These results will be presented first, followed by findings related to the central hypotheses.

\section{INTERNAL VALIDITY CHECKS}

\section{Equivalence of Tasks}

Since the study was conducted over two academic terms (six months) and involved two different problemsolving tasks each term, the order of the tasks was reversed during the second term of data collection to reduce the task ordering effect. Since the "Kidney Task" was administered at time 1 
and the "Iuna Task" at time 2 in the first term, these tasks were reversed in the second academic term. The nature of the design used in this study required that scores obtained from the "Luna" and "Kidney" tasks be interchangeable or equivalent. Therefore, a $t$-test was performed, using the mean pretest scores of each individual on each of the three bi-polar dimensions $(U-D, P-N, F-B)$, to test for differences in the mean pretest scores at Term I ("Kidney") and Term II ("Luna"). Because it was desirable to support the equivalence of means, a large significance level $(p=.20)$ was chosen. The two no-show groups were not included in this test since these two groups did not accurately represent the central study groups.

Results indicated significant differences between the "Kidney" and "Luna" tasks on mean pretest scores for the three SYMLOG dimensions. Mean pretest scores on each dimension for Term $I$ and Term II can be found in Table II. Because there was no significant difference in scores at $p=<.20$, the two tasks were considered to be roughly equivalent.

Group vs. Individual

The second question concerned whether the scores of individuals could be considered independent observations and thus used in statistical analyses or whether they must necessarily be related to the particular group to which they 
TABLE I I

RESULTS OF A t-TEST COMPARING THE MEAN PRETEST SCORES

ON THE UP-DŌWN (U-D), POSITIVE-NEGATIVE (P-N), AND

FORWARD-BACKWARD (F-B) DIMENSIONS FOR THE

"KIDNEY" AND "LUNA" TASKS

\begin{tabular}{lcccc}
\hline SYMLOG & $\begin{array}{c}\text { Term I } \\
\text { "Kidney" } \\
(\mathrm{n}=29)\end{array}$ & $\begin{array}{l}\text { Term II } \\
\text { Luna" } \\
(\mathrm{n}=26)\end{array}$ & $\underline{t}$ & $\begin{array}{c}\text { P } \\
\text { (2-tailed) }\end{array}$ \\
\hline U-D & $\begin{array}{r}2.31 \\
(3.8)\end{array}$ & $\begin{array}{c}2.00 \\
(4.2)\end{array}$ & .30 & .76 \\
P-N & $\begin{array}{l}13.93 \\
(2.9)\end{array}$ & $\begin{array}{r}12.91 \\
(3.3)\end{array}$ & 1.23 & .23 \\
F-B & 2.50 & $\begin{array}{r}3.50 \\
(3.5)\end{array}$ & 1.25 & .22
\end{tabular}

Note: Standard deviations are included in parentheses below their respective means.

belonged. To answer this question, two sets of analyses of variance were computed. The first set of three ANOVA's compared the mean pretest scores of the twelve groups leight feedback and four no-feedback) on each of the SYMLOG dimensions. Because the movement of groups from pretest to posttest is an important dependent variable, the second set of six ANOVA's employed the absolute difference score from pretest to posttest as the measure of movement. Of the six ANOVA's, three compared the mean movement scores of the 
eight feedback groups on each of the three SYMLOG dimensions, and the remaining three ANOVA's compared the mean movement scores of the four no-feedback groups on each of the three SYMLOG dimensions. Again, a.20 level of significance was employed because it was desirable to show that the groups were not significantly different, even with a large alpha level.

As shown in Table III, significant differences among the twelve groups on the pretest occurred on the positivenegative and forward-backward dimensions $(p<.01)$, but not on the up-down dimension $(p=.35)$.

\section{TABLE III}

DIFFERENCES AMONG THE TWELVE GROUPS ON THE AVERAGE UP-DOWN (U-D), POSITIVE-NEGATIVE (P-N), AND FORWARD-BACKWARD (F-B) DIMENSIONS AT PRETEST

\begin{tabular}{ccccc}
\hline SYMLOG & $\begin{array}{c}\text { Means Square } \\
\text { Between groups } \\
(\mathrm{df}=11)\end{array}$ & $\begin{array}{c}\text { Means Square } \\
\text { Within Groups } \\
(\mathrm{df}=43)\end{array}$ & $\begin{array}{c}\mathrm{F} \\
\text { Ratio }\end{array}$ & $\mathrm{p}$ \\
\hline $\mathrm{U}-\mathrm{D}$ & 16.90 & 14.72 & 1.15 & .35 \\
P-N & 18.41 & 7.14 & 2.58 & .01 \\
F-B & 16.55 & 6.40 & 2.58 & .01 \\
\hline
\end{tabular}

As Table IV demonstrates, of the six ANOVA's computed for absolute difference scores, significant group differences 
TABLE IV

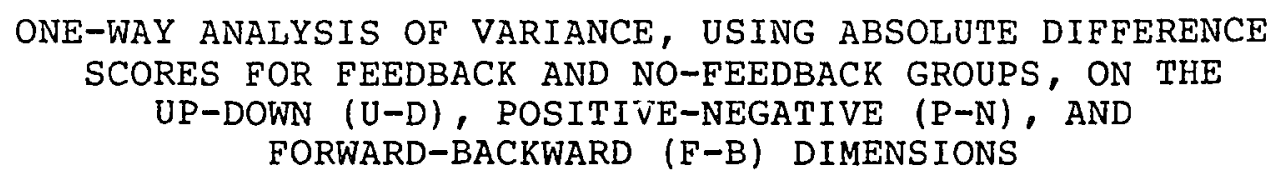

\begin{tabular}{lcccc}
\hline SYMLOG & $\begin{array}{c}\text { Means Square } \\
\text { Between groups }\end{array}$ & $\begin{array}{c}\text { Means Square } \\
\text { Within Groups }\end{array}$ & $\begin{array}{c}\text { F } \\
\text { Ratio }\end{array}$ & $\underline{p}$ \\
\hline F-D & .91 & 1.55 & .59 & .76 \\
P-N & 4.46 & 2.40 & 1.86 & .11 \\
F-B & 4.69 & 1.71 & 2.74 & .02
\end{tabular}

df for means square between groups $=7$

df for means square within groups $=31$

\begin{tabular}{|c|c|c|c|c|}
\hline \multicolumn{5}{|c|}{ NO-FEEDBACK } \\
\hline$U-D$ & .99 & 5.75 & .91 & \\
\hline $\mathrm{P}-\mathrm{N}$ & .15 & 2.10 & .07 & $n, s$. \\
\hline$F-B$ & .90 & 2.30 & .39 & \\
\hline
\end{tabular}

were found on the forward-backward dimension $(p=.02)$ and on the positive-negative dimension $(\mathrm{p}=.11)$. By showing a difference between the groups on the pretest (prior to any 
feedback), the group becomes the unit of analysis for the $\mathrm{P}-\mathrm{N}$ and $\mathrm{F}-\mathrm{B}$ dimensions. This finding relates to the first hypothesis regarding group movement occuring as a result of the feedback intervention. Instead of $\mathrm{n}=55$, which would reflect the total membership in these groups, $n=8$ for feedback groups, and $\mathrm{n}=4$ for no-feedback groups became the units of analysis.

FINDINGS RELATED TO THE GROUP CHANGE HYPOTHESIS

The intervention of a feedback cycle on a group following a specific problemsolving assignment will lead to a significant change in the positioning of the group space on the field diagram of SYMLOG.

The sample was separated into the feedback and nofeedback groups to address the hypothesis regarding group movement following a feedback intervention. An analysis of variance using the absolute difference scores from the pretest to the posttest on each of the three dimensions was conducted to determine whether any of the groups showed a change as a result of feedback.

As can be seen in Table $V$, the results showed no significant differences between the feedback and no-feedback groups on any of the three dimensions. The results of this study thus do not support the group change hypothesis. On all three of the dimensions, feedback did not appear to have a substantial effect on the movement of these groups. 
TABLE V

RESULTS OF A t-TEST COMPARING FEEDBACK AND NO-FEEDBACK USING ABSOLUTE $\bar{E}$ DIFFERENCE SCORES ON THE UP-DOWN (U-D), POSITIVE-NEGATIVE (P-N), AND FORWARD-BACKWARD $(\mathrm{F}-\mathrm{B})$

DIMENSIONS

\begin{tabular}{|c|c|c|c|c|c|c|c|}
\hline \multirow{2}{*}{ Di $\frac{\text { SYMLOG }}{\text { mensions }}$} & \multicolumn{3}{|c|}{ Feedback } & \multicolumn{3}{|c|}{ No-Feedback } & \multirow{2}{*}{$\frac{p}{(2-\operatorname{tai} 1)}$} \\
\hline & $n$ & & $\bar{X}$ & $\overline{\mathrm{n}}$ & & $\bar{X}$ & \\
\hline$U-D$ & 39 & (indiv.) & 1.00 & 16 & (indiv.) & 1.92 & \\
\hline $\mathrm{P}-\mathrm{N}$ & 8 & (groups) & 1.83 & 4 & (groups) & 1.25 & n.s. \\
\hline$F \sim P$ & 8 & (groups) & 1.87 & 4 & (groups) & 1.45 & \\
\hline
\end{tabular}

FINDINGS RELATED TO THE GROUP SATISFACTION HYPOTHESIS

Group sitisfaction with problemsolving assignments will be significantly higher following the intervention of a feedback cycle than when there is no feedback.

At the cluse of the two academic terms and prior to the announcement of the winning group, the standard course evaluation and the small group satisfaction questionnaire were administered. Because the small group satisfaction questionnaire was added, it was determined that a test for item reliability would be given before any further analysis. As a result, item \#11 was discarded because the responses did not relate to the intent of the question. For example, several persons responded "yes" to item \#11 which asked 
whether whey had been given a field diagram for review when in fact they had not.

Cronbach's alpha statistic was applied to the correlation coefficients of the ten remaining items, and the result was a reliability coefficient of $r .87$. The formula used to determine the reliability coefficient was the standardized alpha and is shown below:

$\frac{K r i j}{1+(K-1) r i j}=\frac{10 x .4151031}{1+9 x .4151031}=\frac{4.151031}{4.735927}=0.87$

This degree of reliability provided confidence in proceeding with measurements first to determine the level of expressed satisfaction and then to discriminate levels of expressed satisfaction among the feedback, no-feedback and control groups.

In general, students expressed satisfaction with the group experience, Fifty-three of the 67 participants in the study (798) responsed to the questionnaire. A representative sample was selected from each of the fourteen groups. On a likert scale ranging from 1 (dissatisfaction) to 4 (satisfaction), the mean score was 3.40 , and the standard deviation was .626. Item \#4, which asked whether group members contributed equally to the discussion, received the lowest score $(\bar{x}=2.79)$. The highest rated item was \#6 $(\bar{x}=3.60)$, which asked whether group members discussed their opinions openly without hiding personal 
feelings. (See Appendix I for detailed item frequencies and measures of central tendency.) As can be seen in Table VI, the mean scores range from 2.79 to 4.0 , indicating a high level of satisfaction with the group experience.

TABLE VI

GROUP SATISFACTION QUESTIONNAIRE MEAN SCORES $(N=53)$

\begin{tabular}{ll}
\hline \multicolumn{1}{c}{ Item } & $\begin{array}{c}\text { Mean } \\
\text { Score }\end{array}$ \\
\hline $\begin{array}{l}\text { 1. Group members understand the problems under } \\
\text { discussion. }\end{array}$ & 3.54 \\
2. Group members stayed on the topic. & 3.45 \\
3. Group members avoided premature closure on & 3.30 \\
discussion. & 2.79 \\
4. Group members contributed equally to the \\
discussion.
\end{tabular}


A review of mean scores showed that the feedback groups expressed more satisfaction with the group experience than either the no-feedback or the no-show groups. When a oneway analysis of variance was conducted to compare the groups, a significant difference was found at the $p<.001$ level. The mean scores for each of the three groups presented in Table VII indicates that the feedback group was the most satisfied, while the no-show group was the least satisfied.

TABLE VII

ONE-WAY ANALYSIS OF VARIANCE WITH FEEDBACK, NO-FEEDBACK AND NO-SHOW GROUPS

\begin{tabular}{lccccc}
\hline \multicolumn{1}{c}{ Group } & $\mathrm{n}$ & Mean & $\begin{array}{l}\text { Standard } \\
\text { Deviation }\end{array}$ & $\begin{array}{c}\mathrm{F} \\
\text { Ratio }\end{array}$ & $\mathrm{p}$ \\
\hline Feedback & 30 & 3.58 & .35 & & \\
No-feedback & 15 & 3.26 & .31 & 7.83 & .001 \\
No-show & 8 & 3.02 & .62 & & \\
\hline
\end{tabular}

Results of a $t$-test performed on the means of these groups also revealed a significant difference between the feedback groups and the no-show groups $(p<.001)$, but no significant difference between the no-show groups and the no-feedback groups $(p=.17)$. Table VIII contrasts the three groups in terms of matrix, t-values and probabilities. 
TABLE VIII

RESUITS OF t-TESTS COMPARING FEEDBACK, NO-FEEDBACK AND NO-SHOW GROUPS

\begin{tabular}{ccc}
\hline Contrast Groups & t-value & t-probability \\
\hline Feedback vs. No-show & 3.56 & .001 \\
Feedback vs. No-feedback & 2.60 & .01 \\
No-show vs. No-feedback & 1.36 & .17 \\
\hline
\end{tabular}

The levels of satisfaction expressed by the feedback groups may reflect the increased attention paid to them compared with that given the participants who practiced group work but received no feedback on their behavior. The control group, which expressed the least satisfaction, experienced neither practice in group work nor feedback on their behavior. Although group movement did not appear to be affected by the intervention of feedback in the previous hypothesis testing, the mere fact that the feedback groups spent more time and received more attention in their group experiences appeared to make a difference in their levels of exprsssed satisfaction. This finding is consistent with the work of Luft (1970), who maintains that feedback increases the likelihood of group effectiveness.

The implications for organizational goals, based on levels of satisfaction, may also be a factor. March and 
Simon's (1958) motivation researcin maintained that the more satisfied a group, the more innovations will occur in the organization.

The no-show groups did accomplish effective group work, but their levels of satisfaction were lower than those of either of the other groups who had experience and had received feedback on their behavior. Bales says that groups under tension can hold a peak level of performance for a specific period of time and then need a resting period or time to express their feelings (Bales, Cohen and Williamson, 1979).

All of the groups expressed satisfaction wtin their small group experience. However, the groups receiving feedback expressed significantly more satisfaction than either the no-feedback or the no-show groups. Based on the results of this study, the group satisfaction hypothesis was accepted.

FINDINGS RELATED TO THE SELF-PERCEPTION HYPOTHESIS

Self-perception of behavior within a group will be more highly correlated with the perceptions by others in the group when the group has experienced a feedback cycle than when it has received no feedback.

The third hypothesis was directed toward selfperceptions of group members to determine whether a feedback cycle had an effect on those perceptions.

Each group member was asked to use the SYMLOG rating 
sheets to rate self-behavior in the group work. That score was compared with the average score for that same person as rated by all other members of the group. The self-score became SUD, or Self, on the Up-Down dimension, and CAUD became the representation of the average score for the person as perceived by others. Figures 5 and 6 are the field diagrams for Group 3, Term II and illustrate how the self-perceptions compare with the perceptions recorded by others for the same behavior. For example, Figure 5 is the individual field diagram of one person, \#001, and shows the perception of self in the group work. This person perceives self as very positive in the group session. Figure 6, by contrast, is the average field diagram of the same group and shows that other members of the group do not perceive \#002 in quite the same way. These two illustrations present a visual description of what the hypothesis is testing. The first step taken in analyzing this hypothesis was to display the correlations on each of the dimensions as an overview of self-perceptions compared with group perceptions. Individuals' self-ratings and those by others in the group were correlated for each dimension to determine whether a positive relationship existed between the two. Using Pearson's Product-Moment Correlation, the feedback and no-feedback groups both exhibited a high positive correlation between perceptions of self and perceptions of 


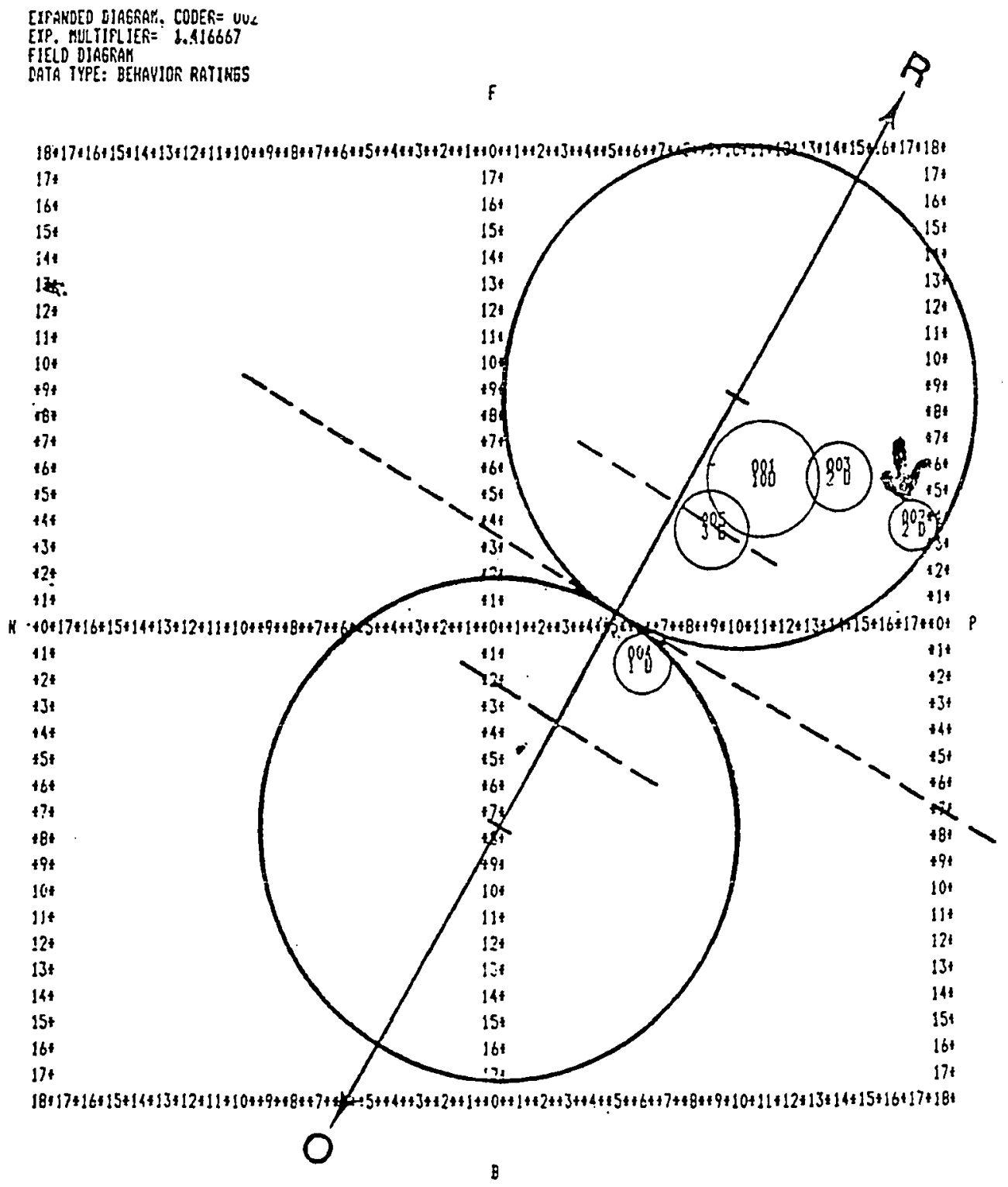

Figure 5. Perceptions of rater \#002 on self and others in the group. 


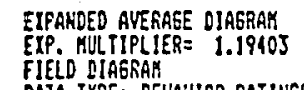

DAIA TYPE: BEHAVIOR RATIHGS

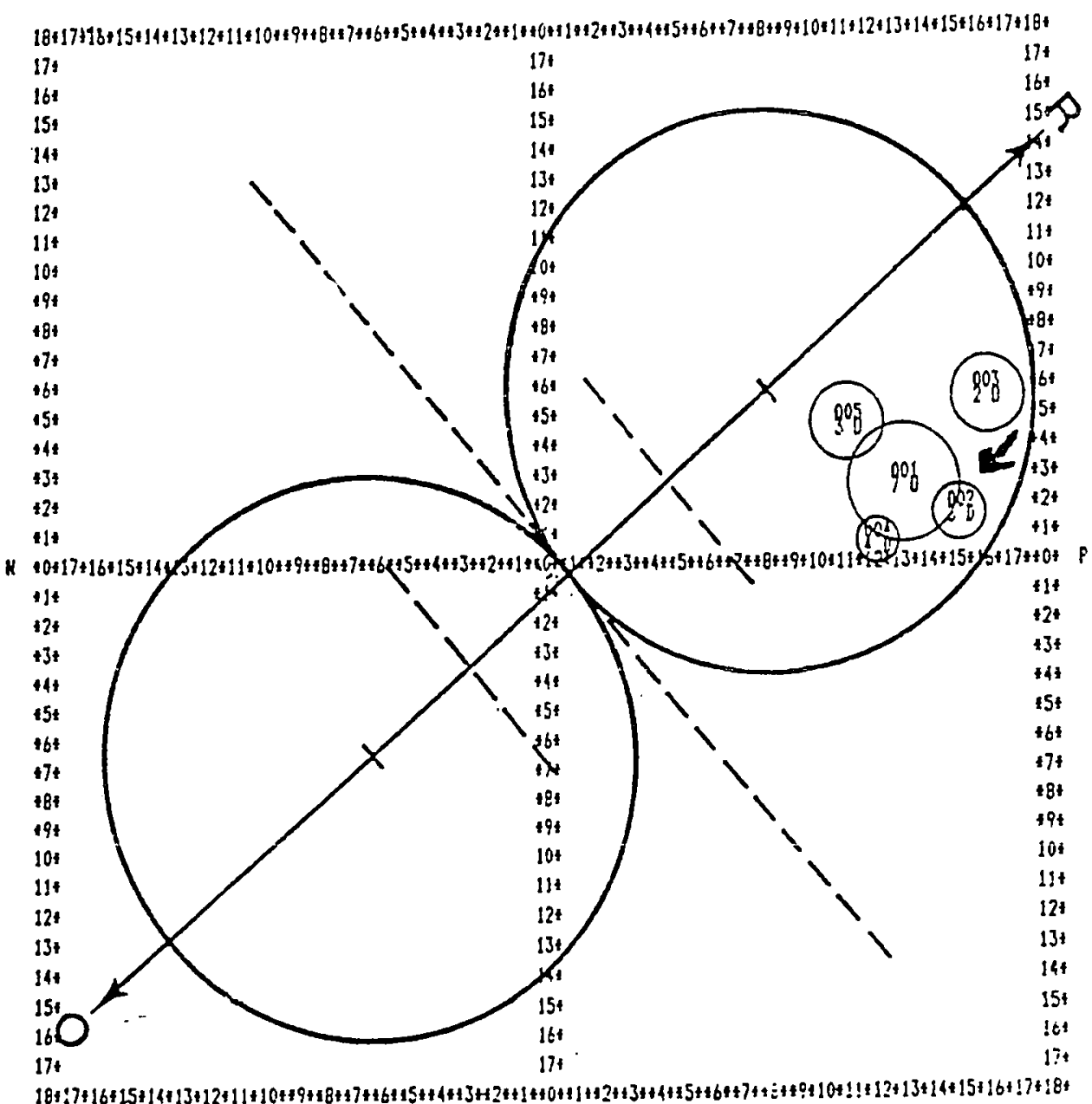

B

Figure 6. Average group perceptions of \#002's behavior. 
others at both pretest and posttest. The no-show group reported a positive level of association, but one which was not statistically significant. As can be seen in Table IX, the correlations on the U-D dimension were high and positively correlated for both the feedback and no-feedback groups, while the control groups did not show a significant relationship in the perception of self to others.

TABLE IX

CORRELATIONS OF SELF WITH GROUP AVERAGE FOR THE FEEDBACK, NO-FEEDBACK AND NO-SHOW GROUPS ON THE UP-DOWN DIMENSION

\begin{tabular}{lcccccc}
\hline Test & \multicolumn{3}{c}{$\begin{array}{c}\text { Feedback Group } \\
(\mathrm{n}=40)\end{array}$} & $\mathrm{No-Feedback}$ & Group & \multicolumn{2}{c}{ No-Show Group } \\
& $\mathrm{r}$ & $\mathrm{p}$ & $\mathrm{r}$ & $\mathrm{n}=16)$ & $\mathrm{r}$ & $\mathrm{p}$ \\
\hline Pretest & .61 & .000 & .68 & .002 & -- & -- \\
Posttest & .63 & .000 & .74 & .001 & .35 & .15 \\
\hline
\end{tabular}

As can be seen in Table $\mathrm{X}$, for the $\mathrm{P}-\mathrm{N}$ dimension the association between self-perception and that of others was low and nonsignificant for all groups in the study; for the no-show group the direction was negative.

On the F-B dimension, there was a strong correlation between the perceptions of self and perceptions of others at both pretest and posttest; and similar to the previous dimensions, the control group showed no systematic relationship between self and others $(x .02, \mathrm{p}<.48)$. The 
TABLE X

CORRELATIONS OF SELF WITH GROUP AVERAGE FOR THE FEEDBACK, NO-FEEDBACK AND NO-SHOW GROUPS ON THE POSITIVE-NEGATIVE DIMENSION

\begin{tabular}{|c|c|c|c|c|c|c|}
\hline \multirow[t]{2}{*}{ Test } & \multicolumn{2}{|c|}{$\begin{array}{c}\text { Feedback Group } \\
(n=40)\end{array}$} & \multicolumn{2}{|c|}{$\begin{array}{c}\text { No-Feedback Group } \\
(\mathrm{n}=16)\end{array}$} & \multicolumn{2}{|c|}{$\begin{array}{c}\text { No-Show Group } \\
(\mathrm{n}=11)\end{array}$} \\
\hline & $r$ & $\mathrm{p}$ & $\mathbf{r}$ & p & $r$ & $p$ \\
\hline Pretest & .14 & .19 & .26 & .17 & -- & -- \\
\hline Posttest & .05 & .38 & .26 & .17 & -.44 & .09 \\
\hline
\end{tabular}

intervention of feedback did not seem to have an effect on the strength of the associations. In fact, the correlations for both the feedback and no-feedback groups lessened over time. As can be seen in Table XI, the correlations between self and others are high for both the feedback and nofeedback groups, while the no-show groups evidenced no systematic relationship.

Displaying the correlations on all three dimensions was a portion of the results which led to the actual hypothesistesting; i.e., determining whether there was a difference among the correlations of the three groups. A ztransformation for independent correlations was used to compare the correlations for each pair of groups: feedback to no-feedback to no-shows. In addition, a t-test was performed on the independent correlations of the three 
TABIE XI

CORRELATIONS OF SELF WITH GROUP AVERAGE FOR THE FEEDBACK, NO-FEEDBACK AND NO-SHOW GROUPS ON THE FORWARD-BACKWARD DIMENSION

\begin{tabular}{|c|c|c|c|c|c|c|}
\hline \multirow[t]{2}{*}{ Test } & \multicolumn{2}{|c|}{$\begin{array}{l}\text { Feedback Group } \\
(n=40)\end{array}$} & \multicolumn{2}{|c|}{$\begin{array}{c}\text { No-Feedback Group } \\
(\mathrm{n}=16)\end{array}$} & \multicolumn{2}{|c|}{$\begin{array}{c}\text { No-Show Grour } \\
(\mathrm{n}=11)\end{array}$} \\
\hline & $r$ & $\underline{\mathrm{p}}$ & $r$ & $\mathrm{p}$ & $r$ & $\mathrm{p}$ \\
\hline Pretest & .53 & .000 & .66 & .003 & -- & -- \\
\hline Posttest & .43 & .003 & .43 & .05 & .02 & .48 \\
\hline
\end{tabular}

groups to test the differences among the feedback, nofeedback and no-show groups. No significant differences were found among any of the three dimensions.

All three dimensions showed consistent themes. The specific intervention of a feedback cycle to selected members did not cause change in the associations of selfperception to others' perceptions. The correlations between self-perception and others' perceptions were approximately the same for the feedback and no-feedback groups on each dimension, but were proportionately lower in the no-show group on every dimension. Finally, the no-show groups appeared to display the greatest discrepancy between selfperceptions and others' perceptions. The findings thus did not support acceptance of the self-perception hypothesis. 
FINDINGS RELATED TO THE LEADERSHIP HYPOTHESIS

The leadership behavior within a group will exhibit more change following a feedback cycle than if the group receives no feedback.

The identified leaders' absolute change scores were used from pretest to posttest to answer the research question. A $\underline{t}$-test to determine whether there was a difference between the mean absolute change scores of the feedback leaders and the no-feedback leaders revealed significance on two of the three dimensions. On the U-D dimension, there was no significant difference in groups either receiving or not receiving feedback. All of the group leaders became more dominant over time. This finding is consistent with the work of Hollander (1978), who maintains that leaders gain what he terms "idiosyncratic credit" against a time when the expenditure of this credit in the form of dominant behavior may be necessary, On the other hand, the $\mathrm{P}-\mathrm{N}$ and $\mathrm{F}-\mathrm{B}$ dimensions showed $\mathrm{a}$ significant difference among the feedback and no-feedback leaders. Statistical significance on the $\mathrm{P}-\mathrm{N}$ dimension showed a $\underline{t-v a l u e ~ o f ~} 2.92(p=.01)$, and on the $F-B$ dimension it showed a $\underline{t}$-value of $3.27(p=.008)$. The mean change scores of leaders in the feedback and no-feedback groups on each dimension, displayed in Table XII, demonstrate that the feedback leaders' scores are higher on all dimensions 
following feedback.

TABLE XII

RESULTS OF A t-TEST ON THE AVERAGE CHANGE SCORES USED AS LEADER MEANS, BY FEEDBACK AND NO-FEEDBACK GROUPS ON THE UP-DOWN (U-D), POSITIVE-NEGATIVE (P-N) AND FORWARD-BACKWARD (F-B) DIMENSIONS

\begin{tabular}{lcccc}
\hline & \multicolumn{3}{c}{ Mean } & \\
\cline { 2 - 4 } Dimension & $\begin{array}{c}\text { Feedback } \\
(\mathrm{n}=8)\end{array}$ & $\begin{array}{c}\text { No-Feedback } \\
(\mathrm{n}=4)\end{array}$ & t-value & $\begin{array}{c}\mathrm{p} \\
(2-\text { tail })\end{array}$ \\
\hline U-D & 1.97 & 1.27 & 0.89 & .39 \\
P-N & 2.13 & .37 & 2.92 & .01 \\
F-B & 1.83 & .50 & 3.27 & .008 \\
\hline
\end{tabular}

Directional change scores las opposed to the absolute change scores previously used in computations) were employed to determine whether the leaders moved in any spcific direction in the feedback and no-feedback groups. Results showed that the direction of movement was not predictable since leaders appeared to move in their group space depending upon the situation and their individual diagnoses of group configuration. This finding is consistent with Fiedler's (1973) work on situational leadership and assists in explaining why these leaders are not directionally consistent. Fiedler maintains that leaders perform 
differently, depending upon the situation of the moment. Table XIII displays the directional means for all three dimensions, indicating no significant differences in directional movement by the leaders whether they received feedback or not.

TABLE XIII

DIRECTIONAL CHANGE SCORES AS MEANS FOR LEADERS EXPERIENCING EITHER FEEDBACK OR NO-FEEDBACK ON THE UP-DOWN (U-D), POSITIVE-NEGATIVE (P-N) AND FORWARD-BACKWARD (F-B) DIMENSIONS

\begin{tabular}{lcccc}
\hline & \multicolumn{3}{c}{ Mean } \\
\cline { 2 - 4 } Dimension & $\begin{array}{c}\text { Feedback } \\
(\mathrm{n}=8)\end{array}$ & $\begin{array}{c}\text { No-Feedback } \\
(\mathrm{n}=4)\end{array}$ & t-value & T-prob. \\
\hline U-D & 1.92 & 1.27 & .81 & \\
P-N & 1.01 & .32 & .73 & n.s. \\
F-B & .58 & .50 & .11 & \\
\hline
\end{tabular}

Results of the present study clearly show that the intervention of a feedback cycle using SYMLOG makes a difference in the amount of leader movement in the group space. Leaders who have experienced feedback demonstrate more movement than group leaders who have not, given the same amount of exposure to classroom teaching and to group practice time. The evidence in this study thus supports 
acceptance of the leadership hypothesis. 


\section{CHAPTER V}

\section{DISCUSSION}

The purpose of this research was to determine what effect feedback had on small groups using Bales' Multiple Level Observation of Groups (SYMLOG). The criterion variables used to test this model were group movement, increased satisfaction, change in self-perception and leadership movement in the group space.

Three types of small groups were studied: eight feedback groups, four no-feedback group and two no-show groups. The independent variable, a feedback cycle introduced into one of these types of groups, was the focal research issue. The findings indicate that the feedback cycle played a central role in both group satisfaction and leadership behavior but had little effect on group movement over time and did not appear to change self-perceptions in any substantial manner. In an attempt to interpret these findings in a meaningful way, the dynamics occurring within these groups were closely examined by utilizing SYMLOG analysis, which clearly illustrated the transactional process within the group.

The discussion will begin with comments directed toward the group movement hypothesis. This hypothesis was 
not supported in the study but warrants a more detailed discussion since there was significant group movement on one of the dimensions in the feedback group.

Following this discussion, illustrative case studies from the feedback, no-feedback and no-show groups will be presented. These case studies will describe, through the use of SYMLOG field diagrams, the interactive phenomena analyzed in hypotheses testing. The average and individual diagrams will be presented for the feedback group, and only the average diagrams will be shown for the no-feedback and no-show groups. In addition, the average field diagrams of one of the two "winning" groups will be presented (i.e., the Term II group which received an "A" for its final project grade). The groups presented are singled out not only because of their performance in relation to the hypotheses tested, but because they can be used in illustrating the need for further research.

\section{INDIVIDUAL MOVEMENT VERSUS GROUP MOYEMENT}

Feedback did not appear to be a statistically significant variable in group movement on any of the three dimensions. The only significant movement which occurred in either the feedback or the no-feedback groups was in the feedback groups on the F-B or task-oriented dimension. This movement was further analyzed to determine whether a factor 
other than feedback could have influenced the findings.

A display of frequencies for the feedback groups demonstrated tiat one group reported a mean score which was atypically high on the F-B dimension at pretest and low at posttest. On further examination it was noted that two male students had been randomly placed into this particular feedback group, and both scored high F-B at time 1 and low F-B at time 2. Every other group was either exclusively female or contained only one male. In calculating feedback group differences excluding the two-male group, no significant difference was found on the F-B dimension. The possibility that gender may have influenced these findings is a consideration for further study.

All of the problemsolving groups clustered toward the lower quadrant of the F-P vectors. This may be a reflection of the demographic data or of the specific characteristics of these groups. Eighty-nine percent of the population in this study was female, and all were nursing students. These students were skilled in problemsolving in clinical settings under highly stressful circumstances. Thus, the groups might be expected to form quickly and to accomplish the task in an expeditious manner; this, in fact, is what happened. All of the groups formed and performed their group work in a manner which was successful in terms of grading by the instructor. The groups did not aggregate in the high, or 
even in the middle, of the Forward and Positive vectors; rather they clustered in the low vector on task orientation and on the cusp of the Positive and Backward vectors, indicating submissive and emotionally expressive behavior characteristics.

\section{FEEDBACK GROUPS}

The eight feedback groups had two group work sessions and an intervening feedback cycle to mirror back images of self-perception and group positioning on the SYMLOG field diagram. Both terms, it was the feedback group which earned the "A" grade for the "winning" group project. While net movement of these groups was not significant over time, individual movement in the group space became more positive and more dominant. In addition, self-perception was positively correlated with the perception of others on all of the dimensions, with the least positive association at the $\mathrm{P}-\mathrm{N}$ dimension. Finally, the designated leaders in these groups reported more movement than the no-feedback groups, and the feedback groups were more satisfied with group work than either the no-feedback or no-show groups. Group \#5 was chosen to illustrate the three-dimensional movement which occurred over time. This group is representative of the feedback groups in terms of general positioning, self-perception, and leader movement, but each 
group had a life and drama of its own. Further, each group configured differently due to differences in actors and their perceptions of the environment. The notion of the differences among groups is conceptually compatible with Lewin's group equation: Behavior equals the function of the person interacting with the environment, or $B=f(P+E)$.

Figures 7 and 8 illustrate Group \#5 on the average field diagrams at pretest and then at posttest. Fictitious names are given to group members in these diagrams. The designated leader was Mary (\#005), who, at time 1, was closely aligned with Bea (\#002). At posttest (following feedback), the leader Mary had moved to a more dominant, positive and task-oriented Up-Positive and Forward (UPF) position, joining with the other members of the group and leaving Bea behind. Though most groups in the study became more unified at posttest, this group became more polarized within their established group space over time. Bea, even though perceived as the most dominant member of the group, remained more or less alone in the space while the other members of the group were unified into a more UPF subgroup. This observation is compatible with Janis' (1982) work which suggests that moderate cohesiveness in a group may be more optimal for good decisionmaking than a high level of cohesiveness. 


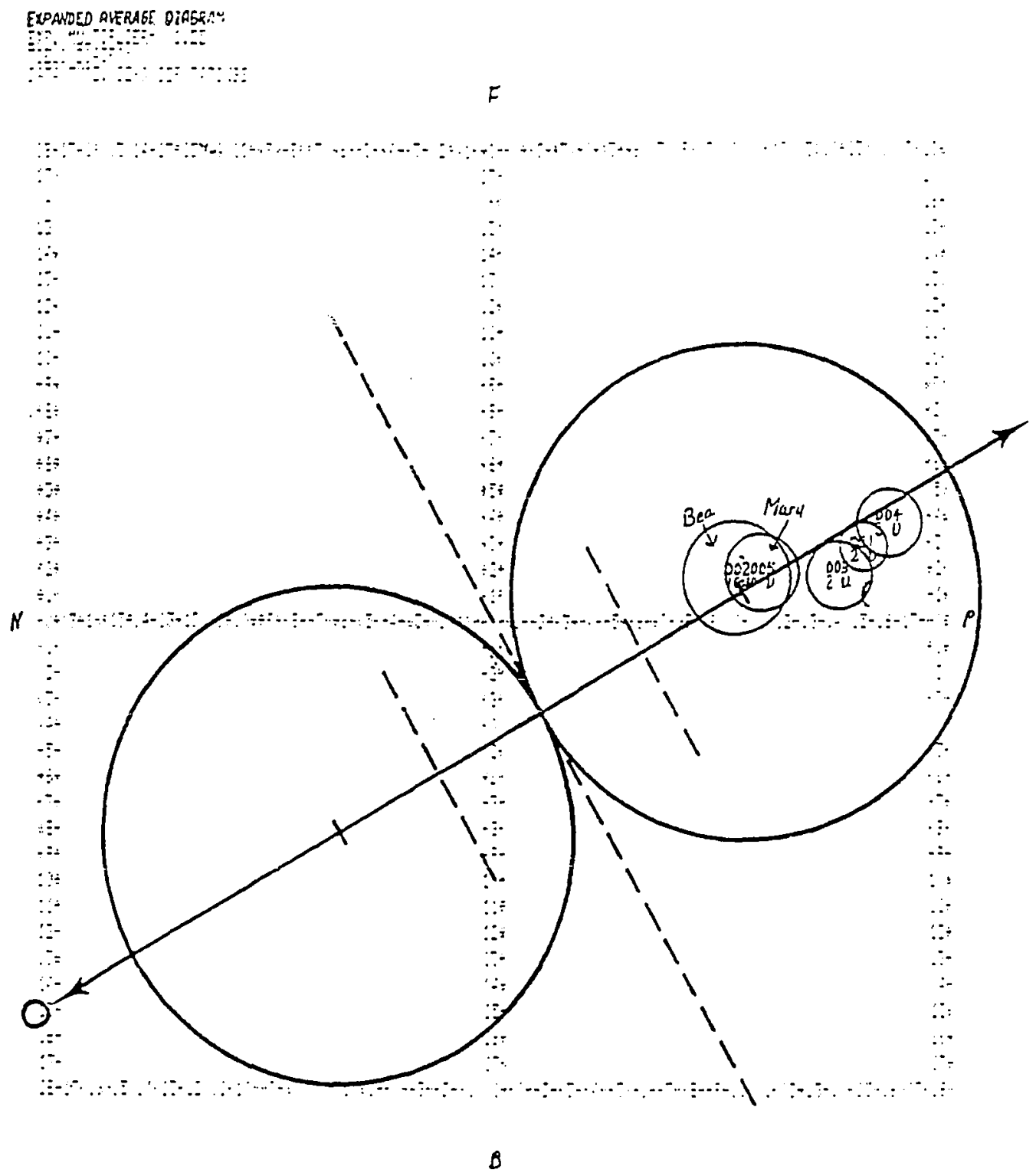

Figure 7. Average field diagram of Group \#5, Term I (feedback) at pretest. 


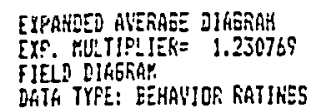

DGTF TYFE: EERAYJOR RATINES

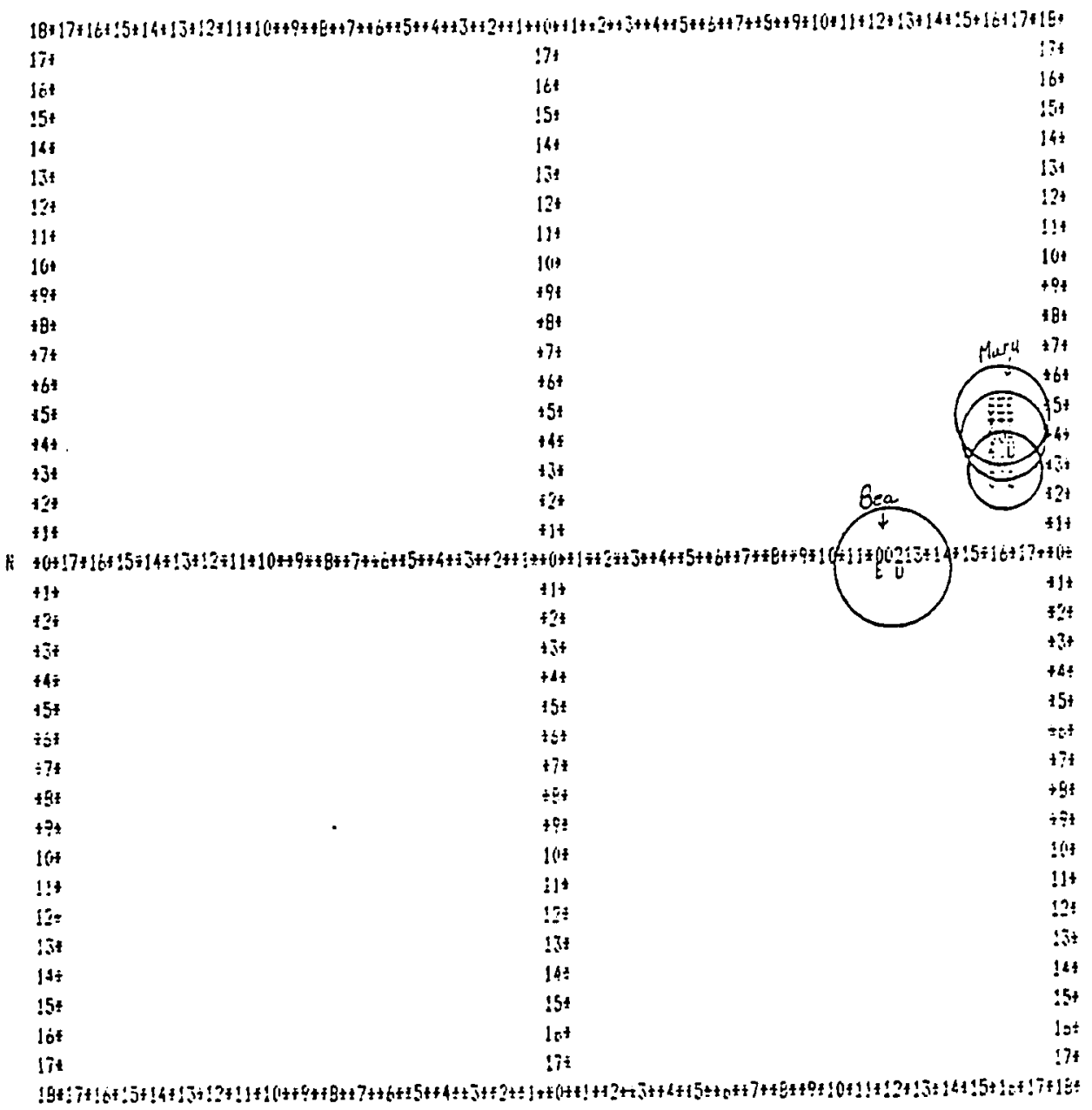

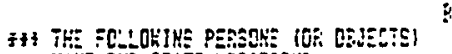

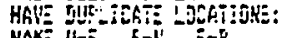

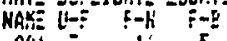

OC!

Figure 8. Average field diagram of Group \#5, Term 1 (feedback) at posttest. 
Although the group as a whole does not show net movement away from the originally-established group space in the lower F-P quadrant, the individual movement, particularly by leader Mary, is significant. At the practice session or pretest, Bea and Mary could be described as competing for the leadership role. Both indiriduals were dominant members of the group and polarized away from the other members. The designated leader became Mary, who moved to a more UPF position, joining the remainder of the group. On the other hand, Bea chose to remain in almost the same position throughout the study, dominant, but away from the majority of the group. Movement by Mary was substantial in the feedback groups, and this leader movement was consistent in all feedback groups in the study.

Leader movement from pretest to posttest can be seen in the abbreviated field diagrams contained in Appendix $\mathrm{J}$. These diagrams were helpful in demonstrating leader movement using only the low forward and positive vectors of the field diagrams. This movement is supported by research in leader behavior. Hollander (1969) maintains that the process of leadership requires social exchange between the leader and followers. This transactional process allows a leader to emerge within the context of a specific situation and to negotiate with group members for the leadership position. For example, Mary appeared to look to the followers for 
support; to achieve dominance she apparently needed to move away from Bea to a more influential space (Hollander, 1978). In this process, she became more dominant, more taskoriented and more positive.

Movement in the sense of exchanging places on the field diagram does not imply that the group is polarized in terms of Bales' concept of polarization-unification. All of the groups in this study are unified in that they are located close together in essentially one quadrant of the field diagram. According to Bales, for polarization to occur, the groups must be doing their work, but at opposing poles or vectors in opposing circles of the polarization-unification ovrlay. As can be seen in Figures 7 and 8 , the individuals at both pretest and posttest remain within the unification parameters, as do all the groups in the study. The subgroups which form do so within a relatively small parameter and within one quadrant of the field diagram. For this reason, the polarization-unification overlay is not utilized in the remaining diagrams.

The individual field diagrams yield an example of leadership dynamics in the feedback groups described by Bradford, Stock, and Horowitz (1952) as intra-group conflict, or the process necessary to precede solidarity in a group. Figures 9 and 10 represent group member Ann's (\#001) diagrams at times 1 and 2. These diagrams illustrate 


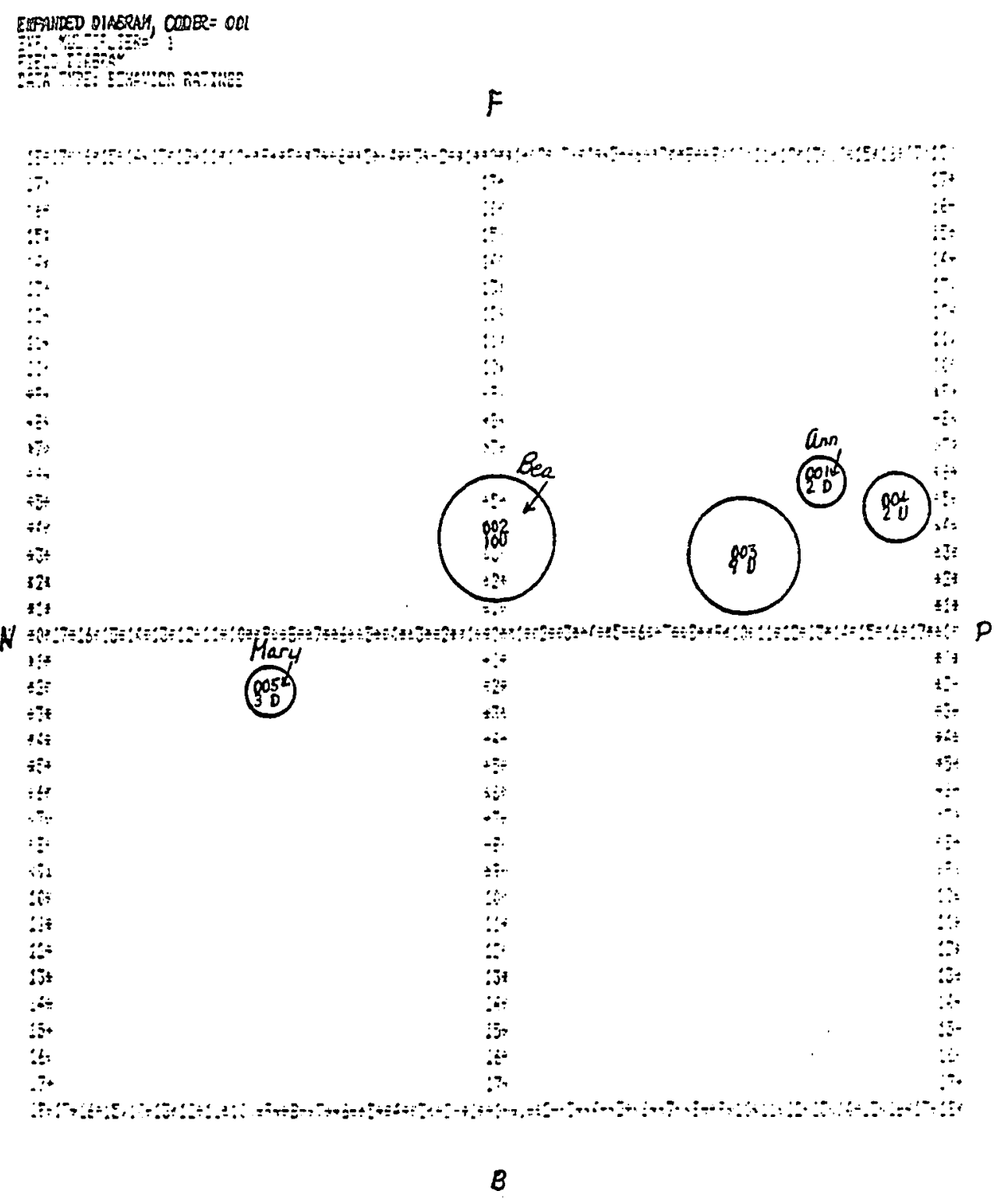

Figure 9. Individual field diagram of Ann (\#001) at 
EXPANOED DIAGRAR, CODEA 001

EXP. MUL:IIPLIEEF 1.066667

TELD DIAGRAG

DATA TYPE: BSHAYIOR RATIIES

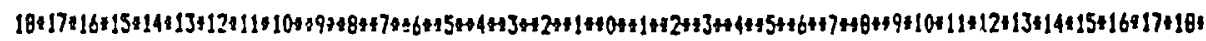

$17+17 t \quad 178$

$162 \quad 16 \%$

$154-154$

$14+144$

$134+13425$

$127 \quad 124 \quad 12+134$

$117011 \%$

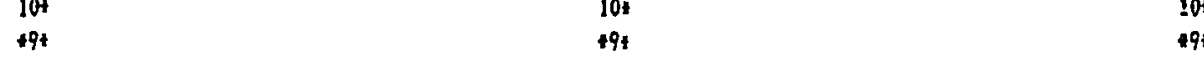

$195218+24$

$474 \quad 474$

$164+1640154$

144.44

+31
114

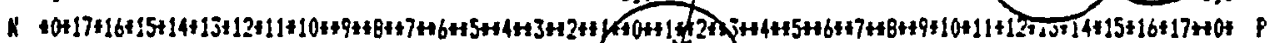

\begin{tabular}{|c|c|c|}
\hline 111 & 114090 & 414 \\
\hline+21 & $+2 t^{116}$ & +24 \\
\hline 431 & 13: & $43+$ \\
\hline 44 & 74 & 444 \\
\hline 251 & \pm 5 & 157 \\
\hline 461 & 164 & 863 \\
\hline 174 & 17: & +74 \\
\hline ABt & +87 & 284 \\
\hline 191 & 494 & 894 \\
\hline 104 & 104 & $10 i$ \\
\hline 184 & $11 t$ & $11 t$ \\
\hline 124 & 12: & 12: \\
\hline $13 i$ & 134 & $13 t$ \\
\hline 14: & $14 t$ & $14 t$ \\
\hline 15 & $15 t$ & 254 \\
\hline 164 & 161 & 164 \\
\hline $17 x$ & 178 & 178 \\
\hline
\end{tabular}

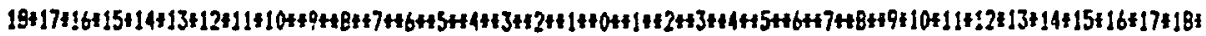

4H THE FOLLONJWE PERSOHS (OR OBJECTS1

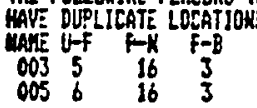

Figure 10. Individual field diagram of Ann (\#001) at 
the first occurrence of intra-group conflict. Ann placed leader Mary far to the negative, passive and emotionally expressive vectors at pretest. At posttest, Ann changed her perception considerably, placing Mary with other group members on almost opposite poles of the field diagram in UPF position. Ann noticeably rejected Mary at the initial practice session, but at the final group session perceived herself in the middle of the working group and Mary considerably more positive and dominant. Ann did not perceive Bea as moving in the group space over time, but rather placed her in almost the identical position at both pretest and posttest.

The individual perceptions of Bea (\#002) are seen in Figures 11 and 12. Bales suggests that dominant persons will clash initially in their group work (Bales and Cohen, 1979). This clash or conflict with Mary was visible at pretest and occurred in the UPF vectors. It appears that Bea perceived this activity as positive, task-oriented and dominant. On the other hand, at time 2, Bea appears to have capitulated as a result of the direct competition with Mary and was attempting to form a subgroup coalition with two additional group members, Jo and Mo.

Figures 13 and 14, the individual field diagrams of Jo (\#003) at pre- and posttest, yield yet another interpretation of what occurred in the intragroup conflict 


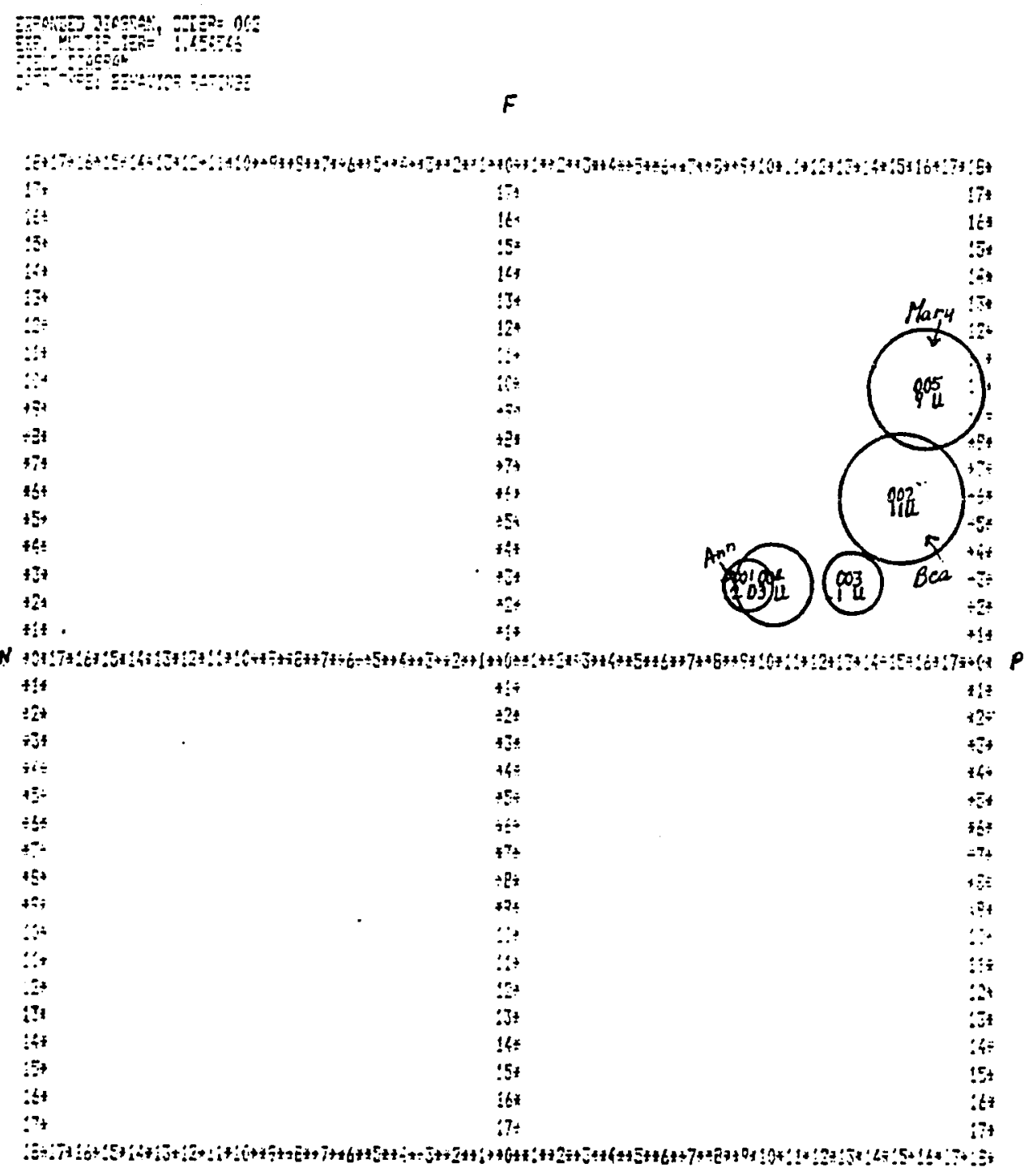

8

Figure 11. Individual field diagram of Bea (\#002) at pretest. 


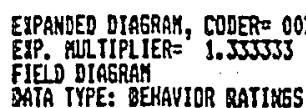

FIEID DIAGRAA

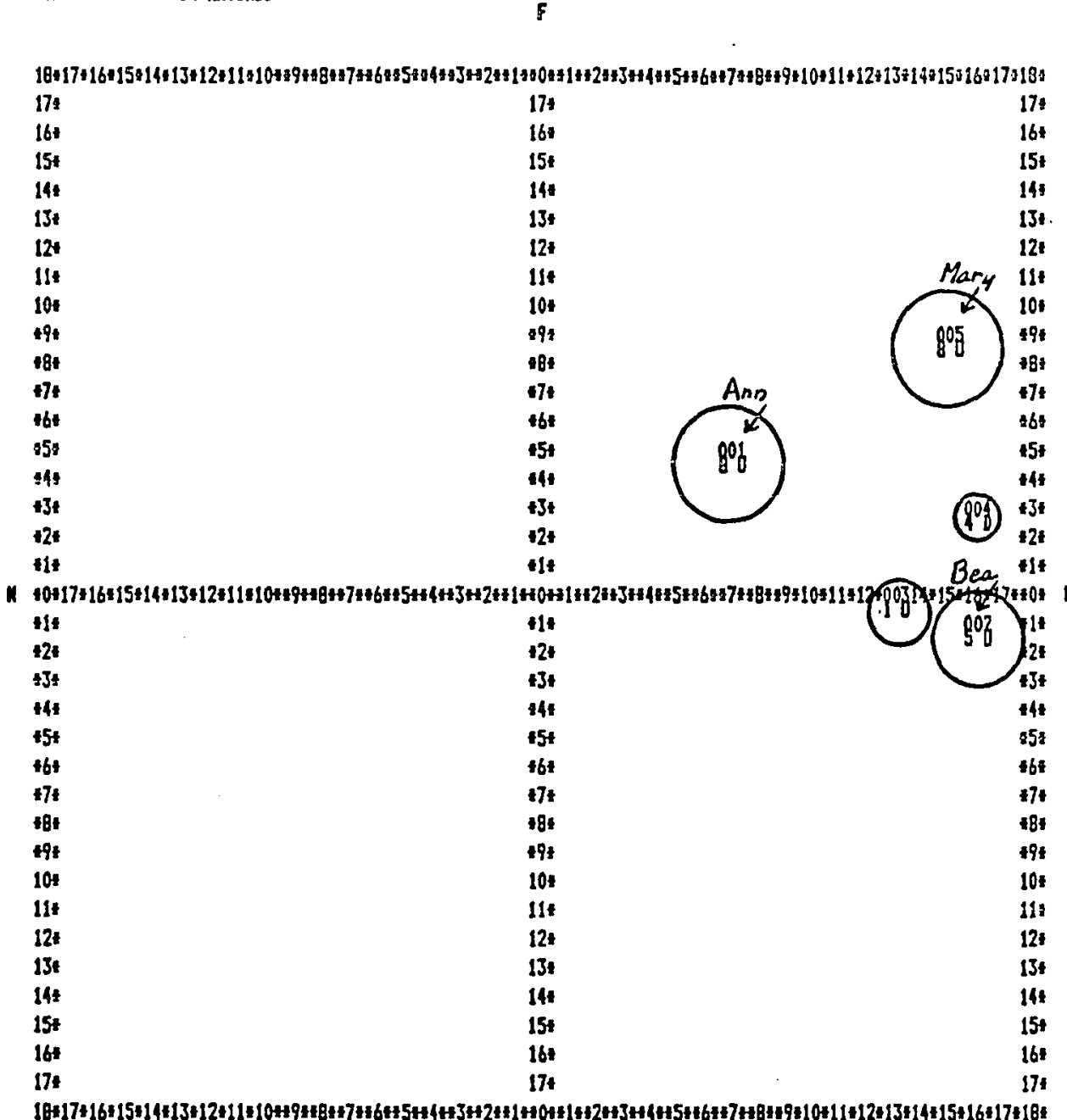

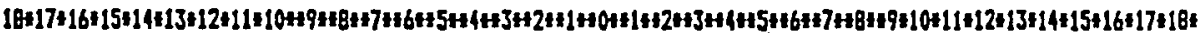

B

$\frac{\text { Figure 12. }}{\text { posttest. }}$ Individual field diagram of Bea (\#002) at 


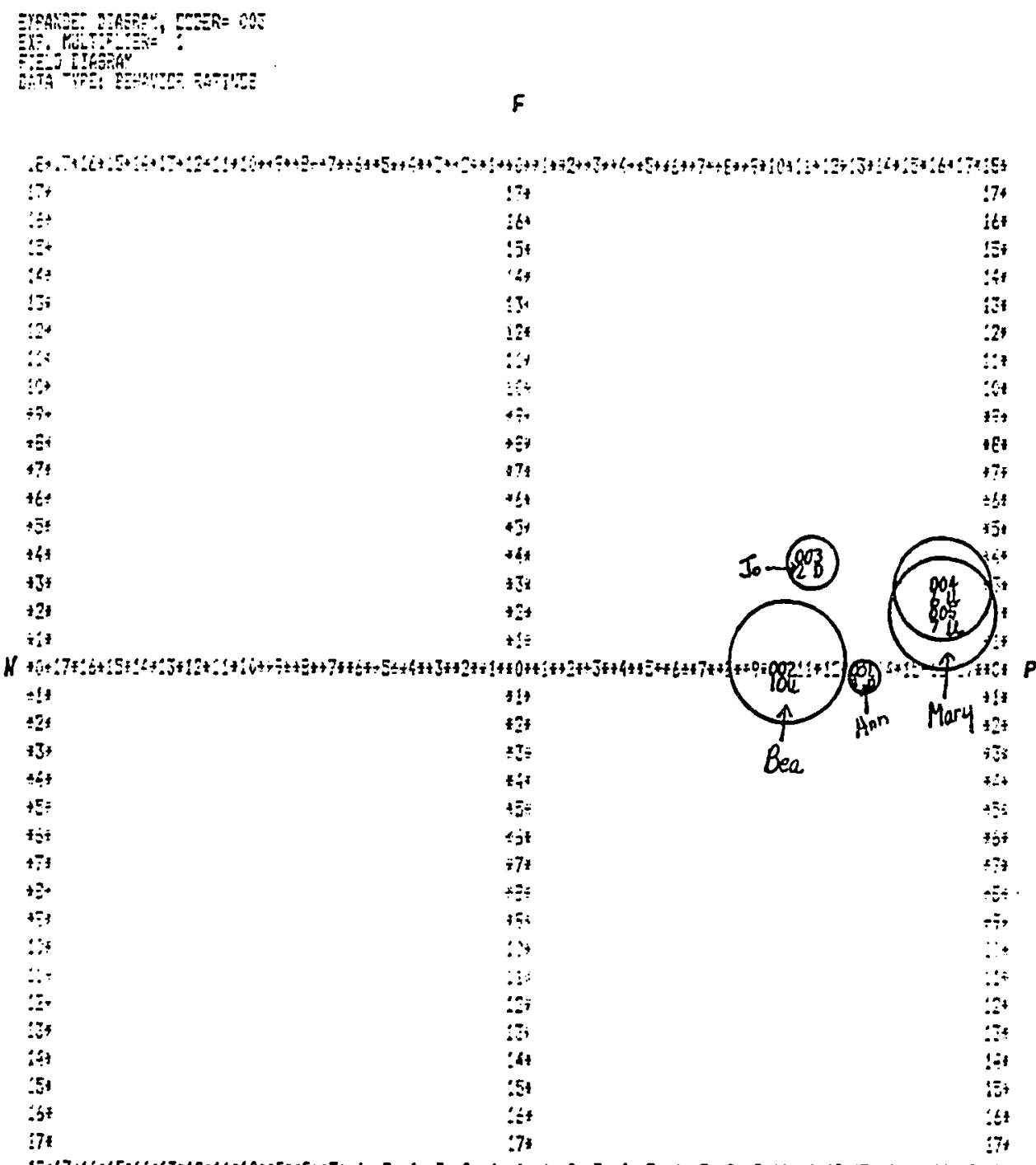

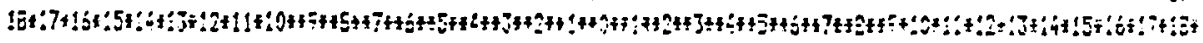

8

Figure 13. Individual field diagram of Jo (\#003) at pretest. 


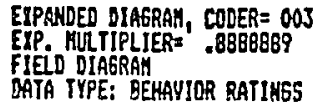

BATA TYPE: BEHAYIOR RATINGS

\section{F}

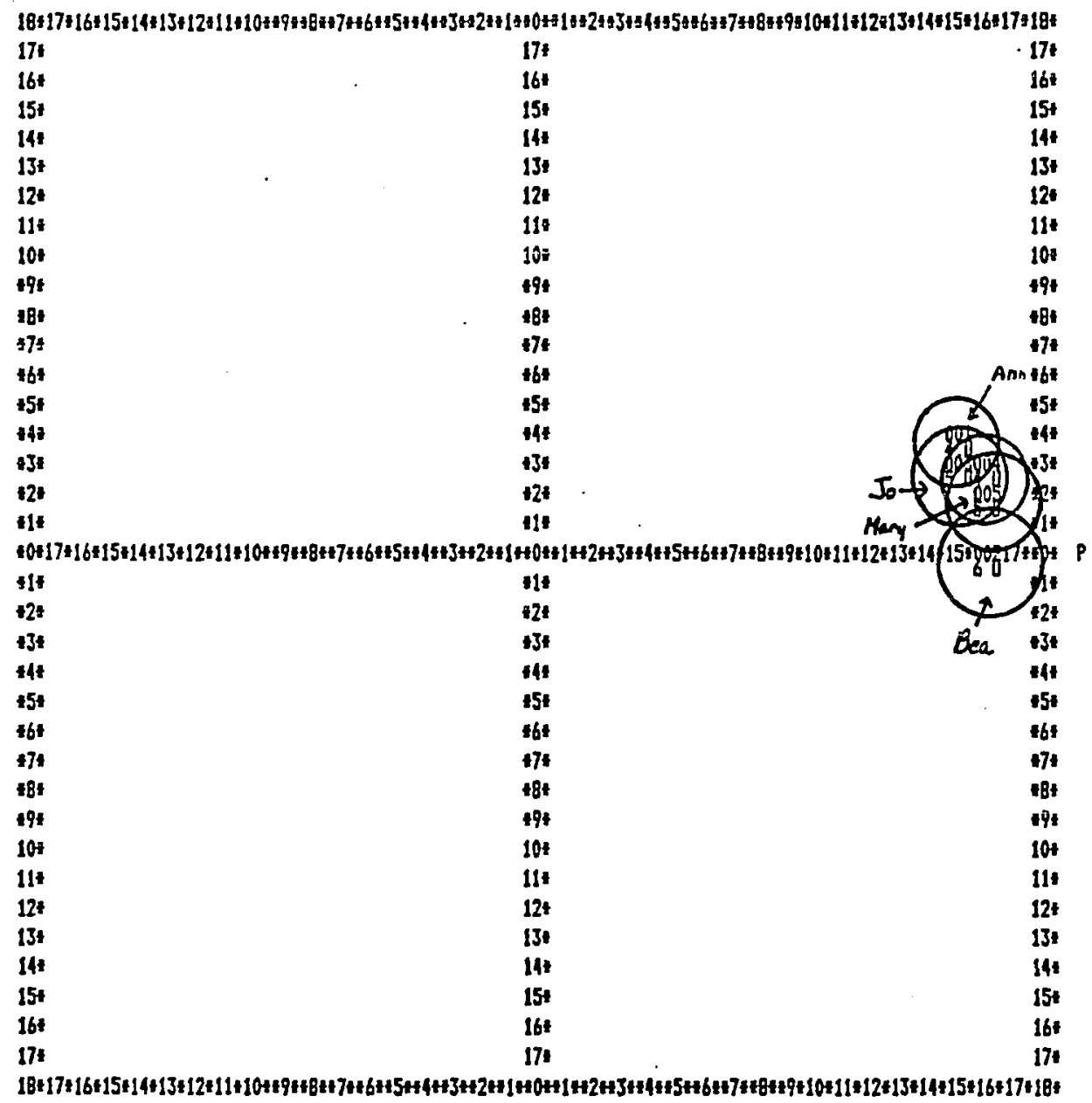

B

Figure 14. Individual field diagram of Jo (\#003) at 
and process of negotiation. Although members were somewhat distanced at the pretest, Jo perceived a solid, unified group at posttest.

Still another variation of individual perception on the same moments in time is illustrated in Figures 15 and 16 by Mo (\#004), who at pretest was aligned with Bea, but at posttest moved into a more U-F position near leader Mary. Mary remained in approximately the same position both times, but became more dominant at the posttest. This phonomenon suggests that the Iigitimate power described by French and Raven (1980) was bestowed upon Mary, which provided her with a basis for exercising the influence necessary to get the work accomplished.

The last member of the group to be diagrammatically depicted is Mary $(\# 005)$, as shown in Figures 17 and 18 . At the pretest, the emerging leader displayed tentative perceptions about herself as a leader; she described herself as moderately dominant, in a UFP position. At posttest, she perceived herself as taking more risks and coincidentally moved on the field diagram to the least positive, but the most task-oriented position in the group. This observation corresponds with Frost's (1983) study of effective military combat leaders and fire combat leaders in which he found that in both groups, the more effective leaders took more risks. 


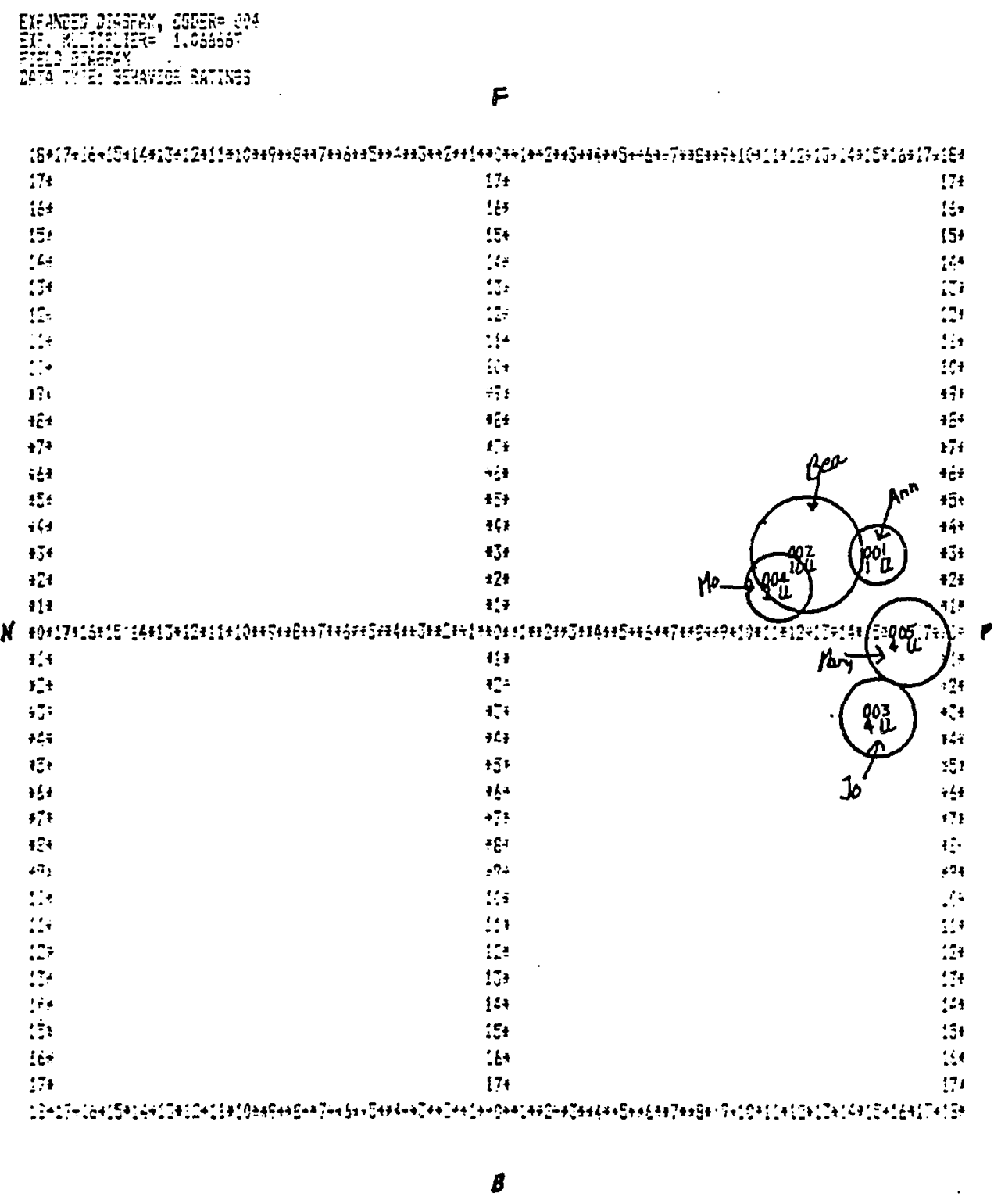

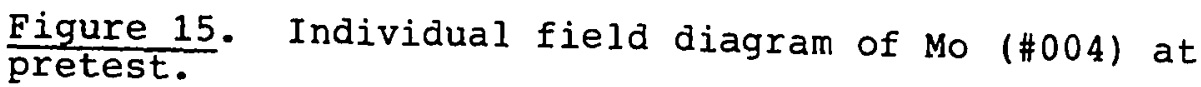




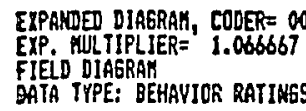

FIELD DIAGRAR

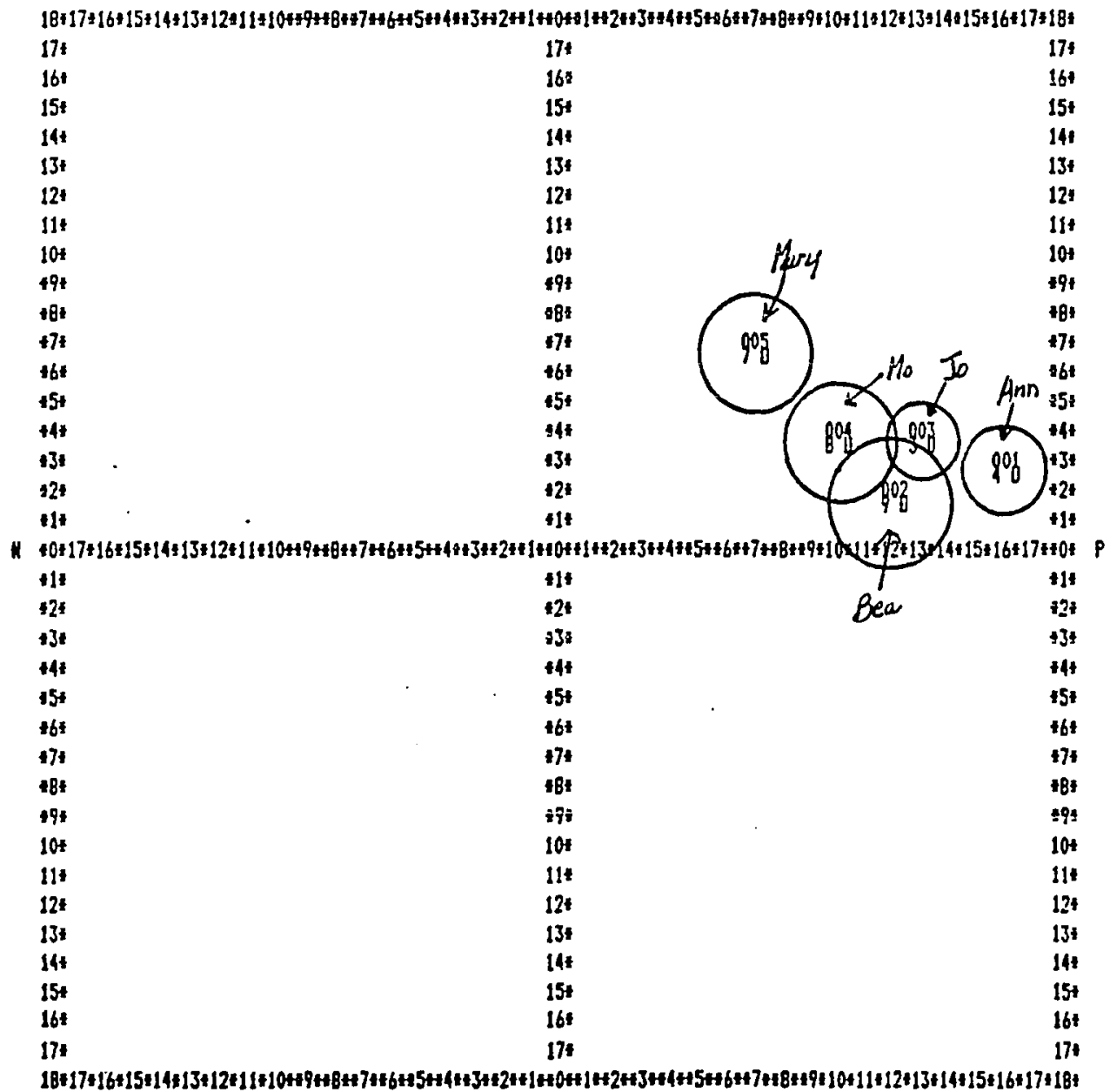

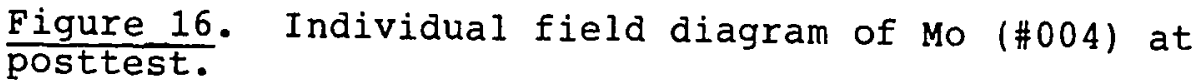




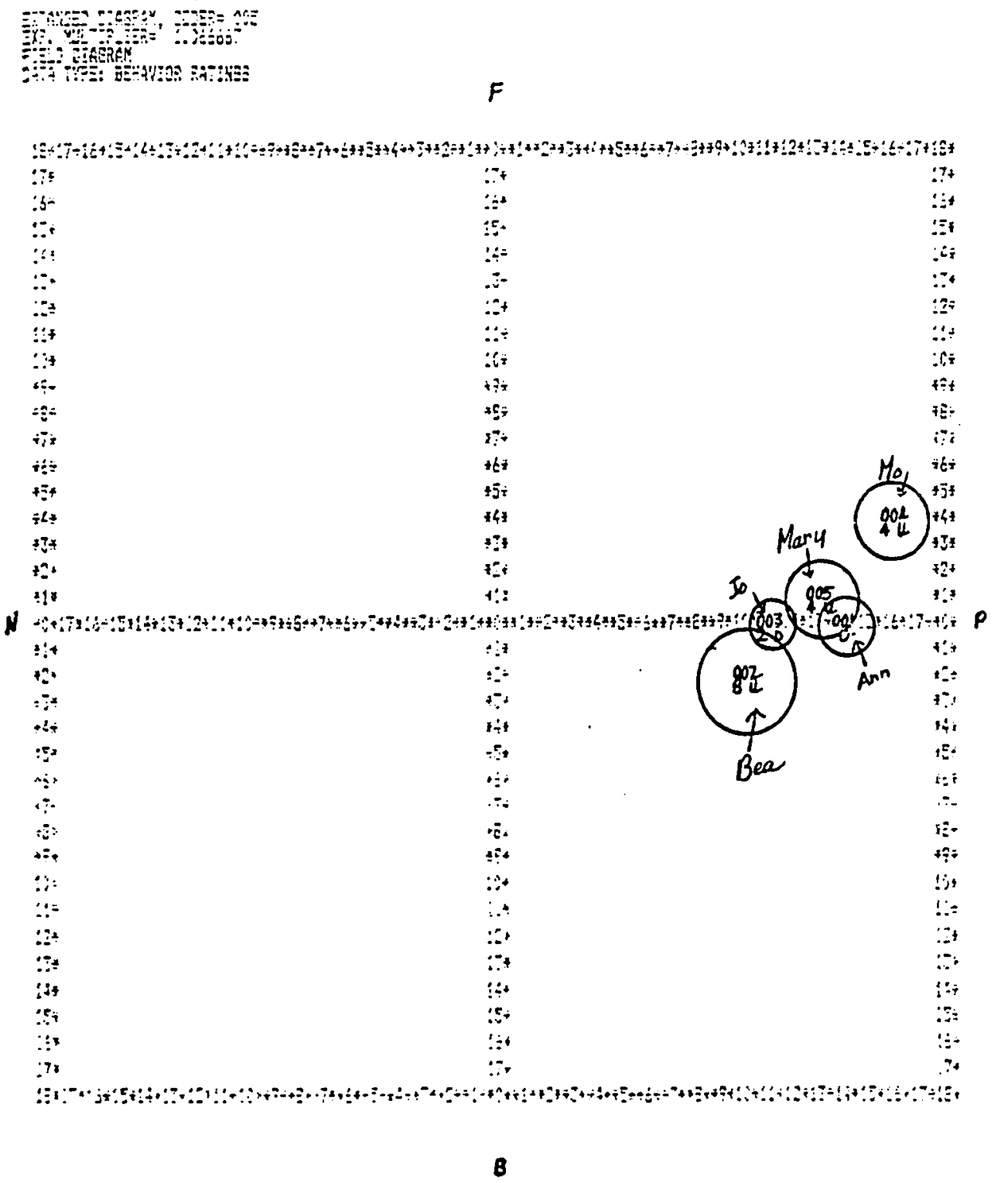

Figure 17. Individuai field diagram of Mary (\#005) at pretest. 


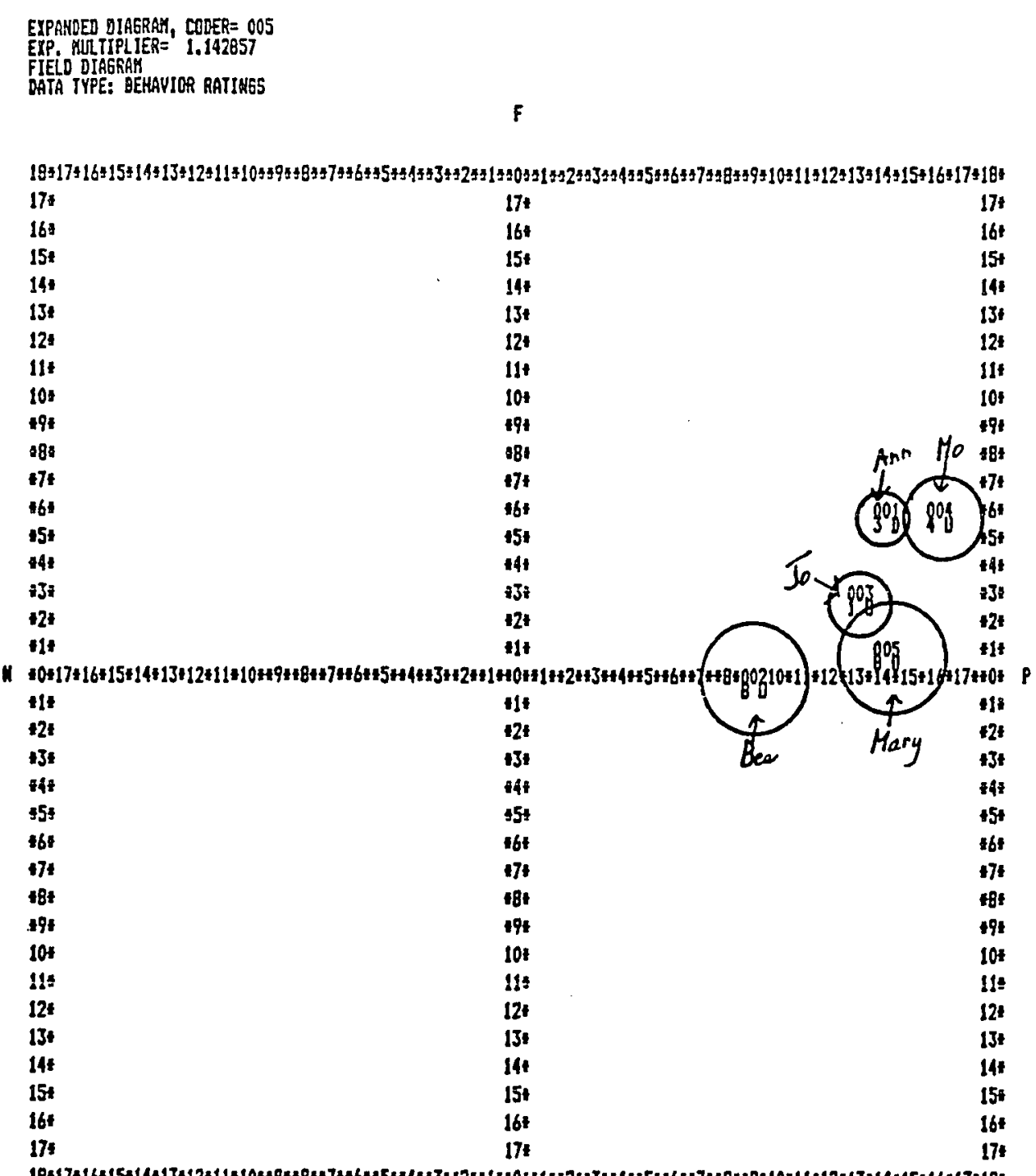

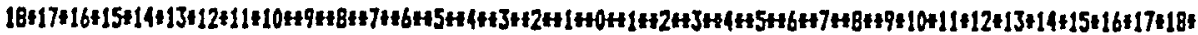

B

$\frac{\text { Figure 18}}{\text { posttest. }}$ Individual field diagram of Mary (\#005) at 
This group of five which progressed through the intra-group conflict and on to purposeful group work was one of the most successful groups in the study. It was given the "A" grade for the winning project in Term I and expressed high satisfaction with the group's work. In this group it appeared that the members Ann, Jo, and Mo were able to exert their power by diffusing the dominance of Bea and choosing Mary as their leader, which corresponds to the check and balance notion of Gibb (1954) in the democratic choice of leaders.

In addition, it appears that Mary accepted the leadership role and over time became more $U-F$ in behavior, which was her style of leadership selected for this specific situation. This approach is consistent with Fiedler and Mahler's (1979) leadership training program, which uses situational control as a way to prepare potential leaders. While the average field diagrams for this group are helpful in looking at aggregates, they do not provide the rich data that the individual diagrams display. In addition, the diverse perceptions of each individual on the leader's behavior give insight into the amount of variance tolerated by group members.

The increased satisfaction reported by this group may be related to the increased time they spent in group work, the feedback cycle which gave the group more information 
about their progress in group work, and the attention given to them (Swap, 1984). Furthermore, these groups exerted considerable control over their internal group environment, which also correlates positively with levels of satisfaction (Cartwright and Zander, 1953).

A11 of the fsidback groups followed the same pattern as that described for Group \#5: intra-group conflict at the initial task and a resolution at the final task which resulted in a more unified, solid group. The designated leaders appeared to use pretest as a period for transactional exchange, many times vying with another group member for the leadership position. The feedback process appears to have provided a high degree of satisfaction with group work and group effectiveness for these feedback groups.

\section{NO-FEEDBACK GROUPS}

The no-feedback groups differed from the feedback groups, both in terms of levels of satisfaction and in leader movement. The difference in the treatment of these groups was that no attention or information was given to the no-feedback groups which specifically related to the group work. This had an adverse effect upon the levels of satisfaction perceived by the no-feedback groups. Leaders of these groups also displayed less mobility. 
An iliustrative case study of a no-feediback group provides a clearer sense of what occurred in these groups. In Group \#4, Term II, the identified leader was Bev (\#003), who, at pretest, was positioned on the average field diagram UPF within a cluster which also included two other group members. Two additional members of the group were outside the cluster, with Nan (\#005) well outside. Figure 19 illustrates the group constellation and individuality at pretest; Figure 20 shows the same group at posttest. By posttest, the group had become more unified in its work; and Nan, who had initially been well outside the group cluster, had moved into the group space. After pretest, the leader Bev chose to remain in the same position as before, but increased her dominant behavior. This increase in the U-D dimension is consistent with that of all other leaders in the study; it is not a unique feature of the no-feedback groups (Hollander, 1978).

\section{NO-SHOW GROUPS}

The no-show groups were at a distinct disadvantage when it came to satisfaction with the group process. Without any opportunity for practice, these two groups entered the final session (posttest) under pressure to perform and were required to choose a leader with little information about individual behavior in their group. Yet, although neither 


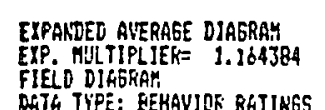

FIELO DIGGKAY

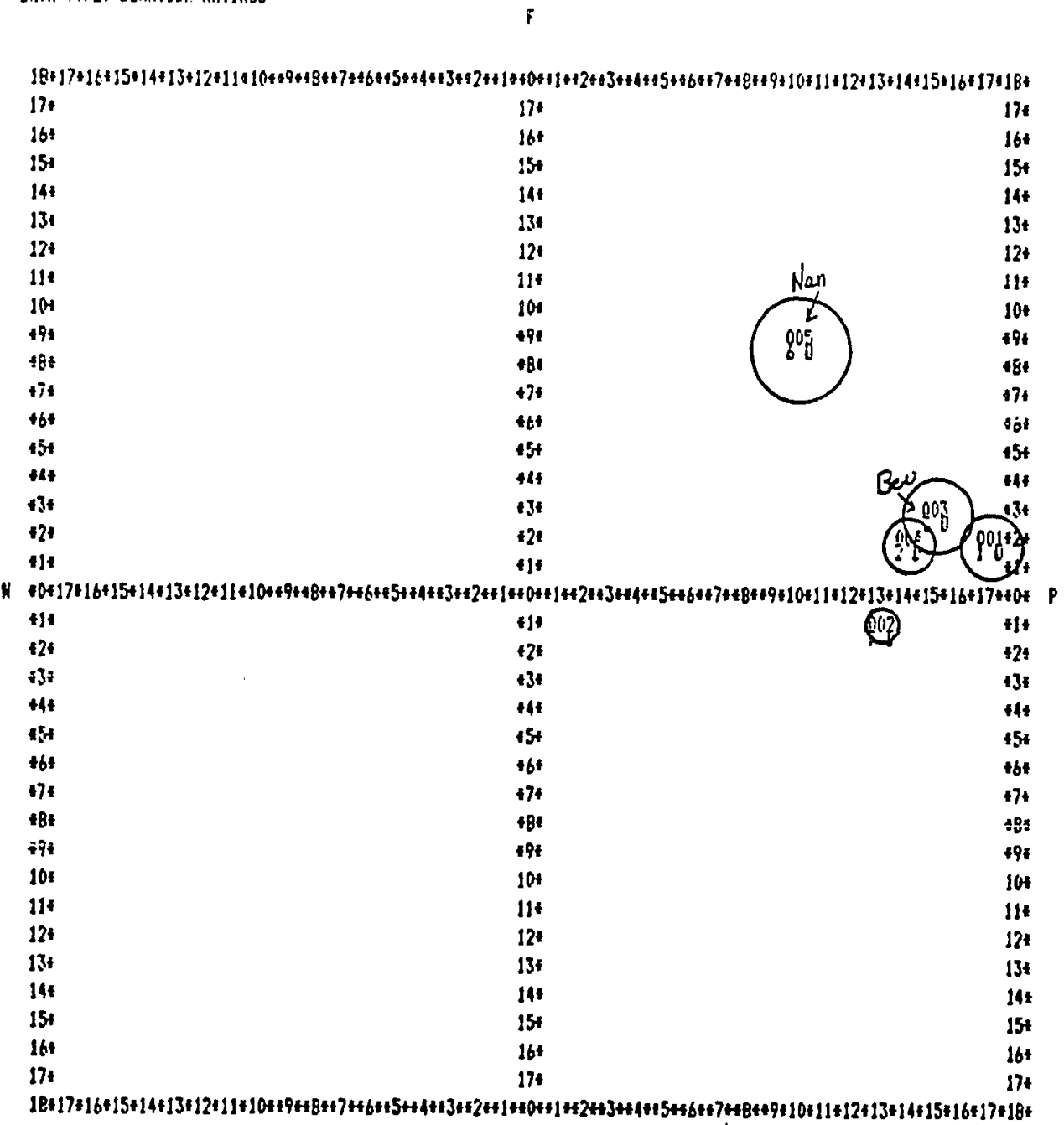

$B$

Figure 19. Average field diagram for Group \#4, Term II (no-feedback) at pretest. 


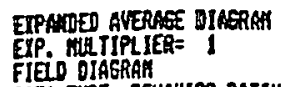

FIEID OIAGRAF̂

MATA TYPE: BERAVIOR RATINGS

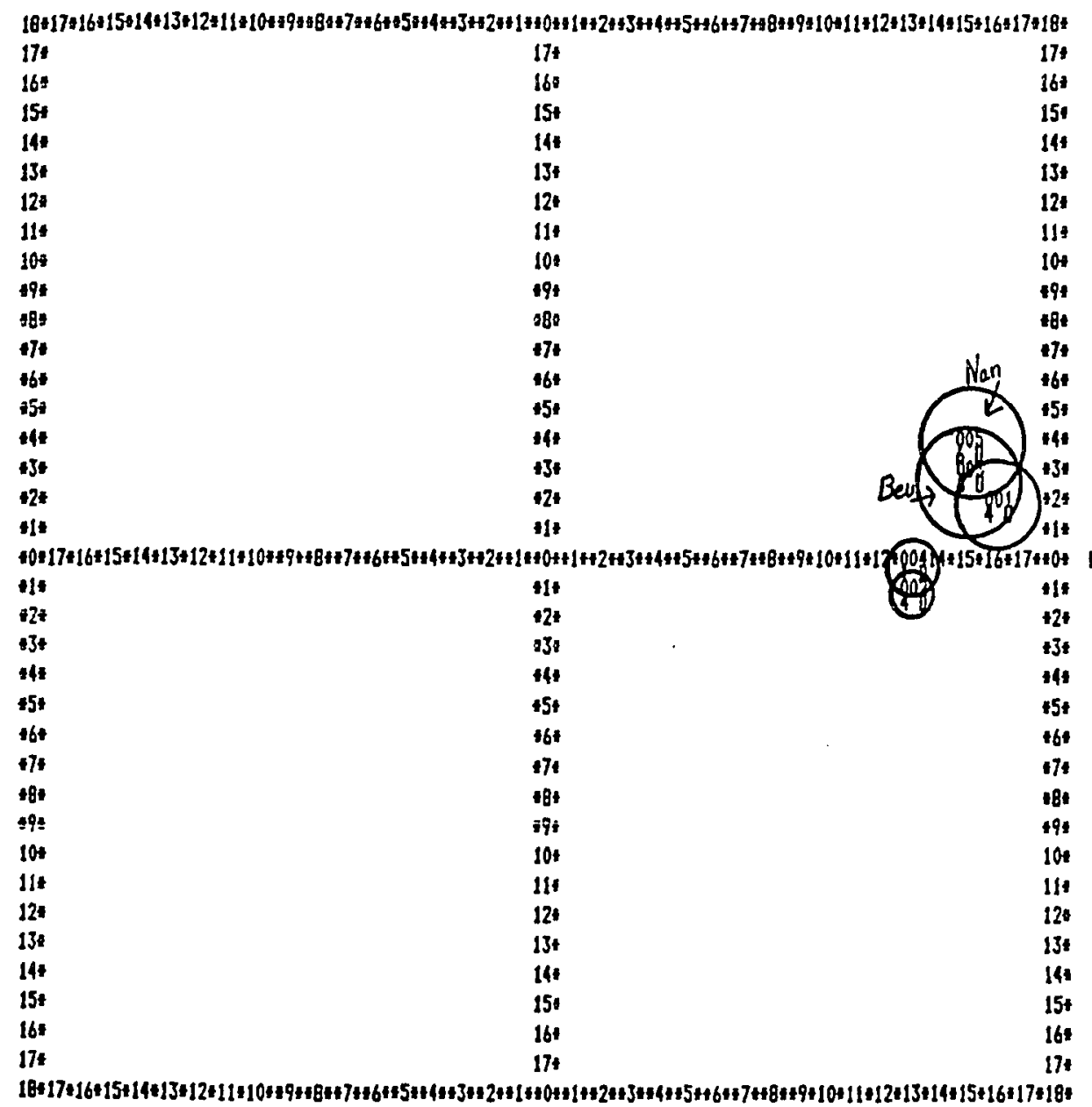

B

Figure 20. Average field diagram for Group \#4, Term II (nofeedbackl at posttest. 
of the two control groups won the "A" grade for the final project, they were rated high on performance, ranking third in the first term and fourth in the second term out of a total of fourteen. The satisfaction data indicate that these two groups were the least satisfied in the study, and the enormous expenditure of energy under pressure which resulted from lack of feedback was surely a factor (Bales and Cohen, 1979).

In Group \#7, Term II, Ter (\#002) was the designated leader. Figure 21, the average field diagram for this group, illustrates how Ter was perceived as controlling, task-oriented, dominant and less positive than any other member of the group. It appears that her leadership style was relatively autocratic, while the remainder of the group was positive, unified and passive. The field diagram for this group shows that these members were less satisfied with the group projects than either the feedback or the nofeedback groups.

Research from Argyris (1971), Hersey and Blanchard (1977), Stogdill and Coons (1957), Maslow (1970), and others delineates the leadership styles that may be employed without a compromise in outcomes. What does seem to be compromised, though, is satisfaction with the process when the leader exhibits authoritarian behavior in the group. organizations may find this information particularly useful 

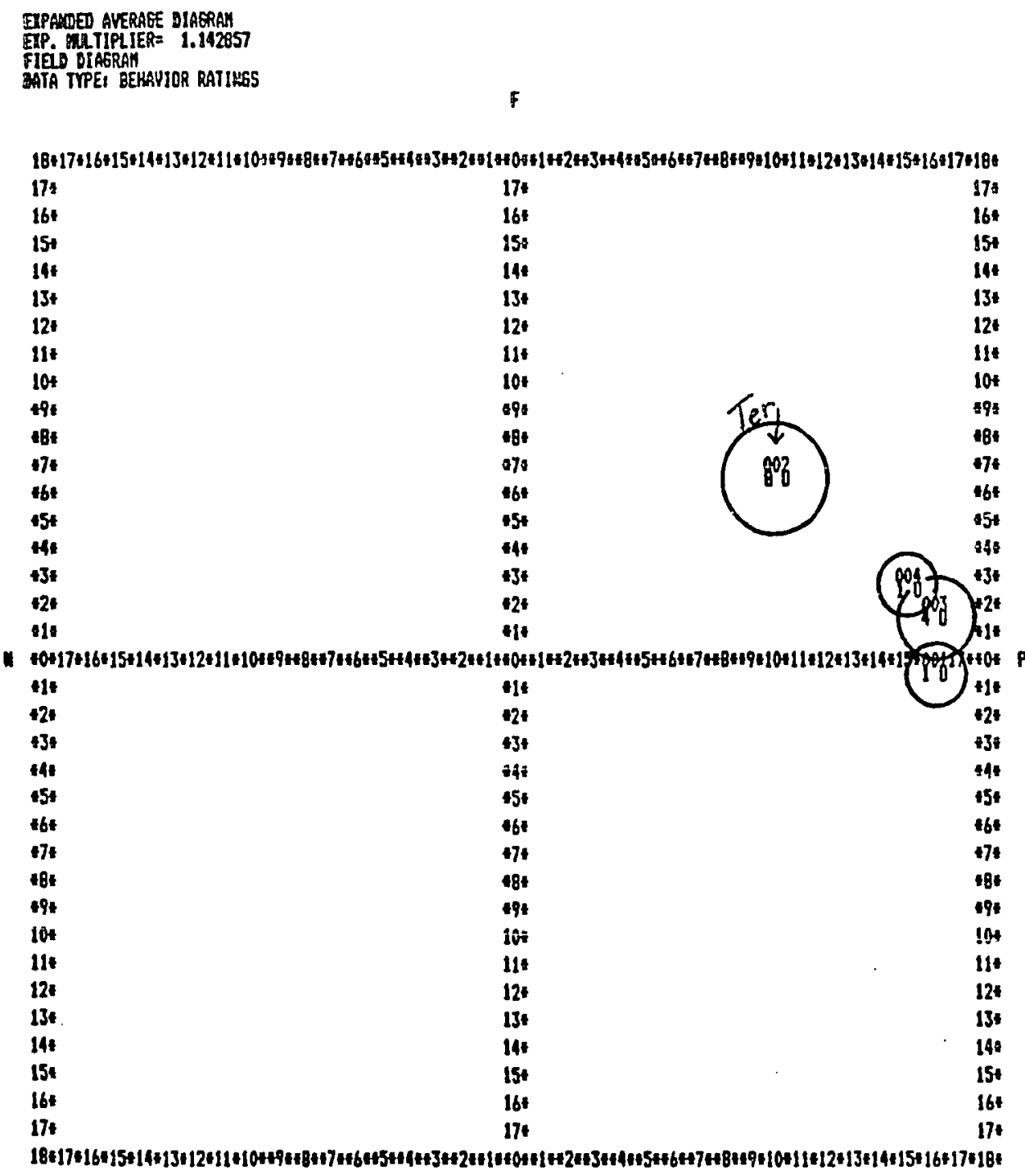

B Figure 21. Average field diagram for Group \#7, Term II (no- 
when making decisions about the division of labor in their particular work place.

Finally, the two no-show groups did not report positive correlations in their perceptions of self to the perceptions of others. The two no-show groups correlations' were not significantly different from each other; both were substantially less positive than the perceptions of the groups which worked together over the entire term. This finding does not refute the statements of Bales, Cowen and Koenigs (1986) that most persons generally see themselves as others see them, but it does raise some further questions about problemsolving groups, which are different from groups which interact without a specific task to complete. Could these problemsolving groups differ in relation to selfperceptions depending upon the various pressures of time, familiarity with the task, and familiarity with each other?

\section{THE WINNING GROUP}

The "winning group" was that group chosen each term as having given the best presentation of a group project. The feedback group discussed earlier in this chapter was the winning group during Teim I. Group \#6, discussed below, was the winning group during Term II.

Two of the four male students in Term II were randomiy placed in Group \#6. This group of two male (\#003, Don, and 
\#004, Mel! and three female students won the Term II prize for the best presentation and an "A" grade for content of the group project. As shown in Figure 22, at pretest both Don and Mel scored high in task orientation and were more positive and more dominant than the female members of the group. This position is illustrative of what the literature calls task-oriented behavior and of what was expected, but not found, in this study as the mode for group behavior. For example, Tindall et al. (1978) state that males emerge as leaders of small groups more than females because males are task-oriented, dominant and aggressive, whereas females are submissive, relational-oriented and supportive. Sue (\#005), however, who ultimately emerged as the leader of Group \#6, began in a position opposite to that of the typical leader reported by Tindall et al. Her position at pretest was less dominant, less positive and less taskoriented than that of either Don or Mel. She appears to have been mediating between the two dominant men and the two women during the pretest stage, which was a good position from which to assume ultimate leadership. This first stage scenario "predicts" the second stage very well: the two men asserted rational, businesslike behavior in the first meeting; the women assumed submissive, supportive, friendly positions; the emerging leader mediated between the two by modeling friendly behavior for the women 


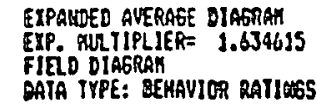

DATA IYPE: SEHAVIOR RATILOS

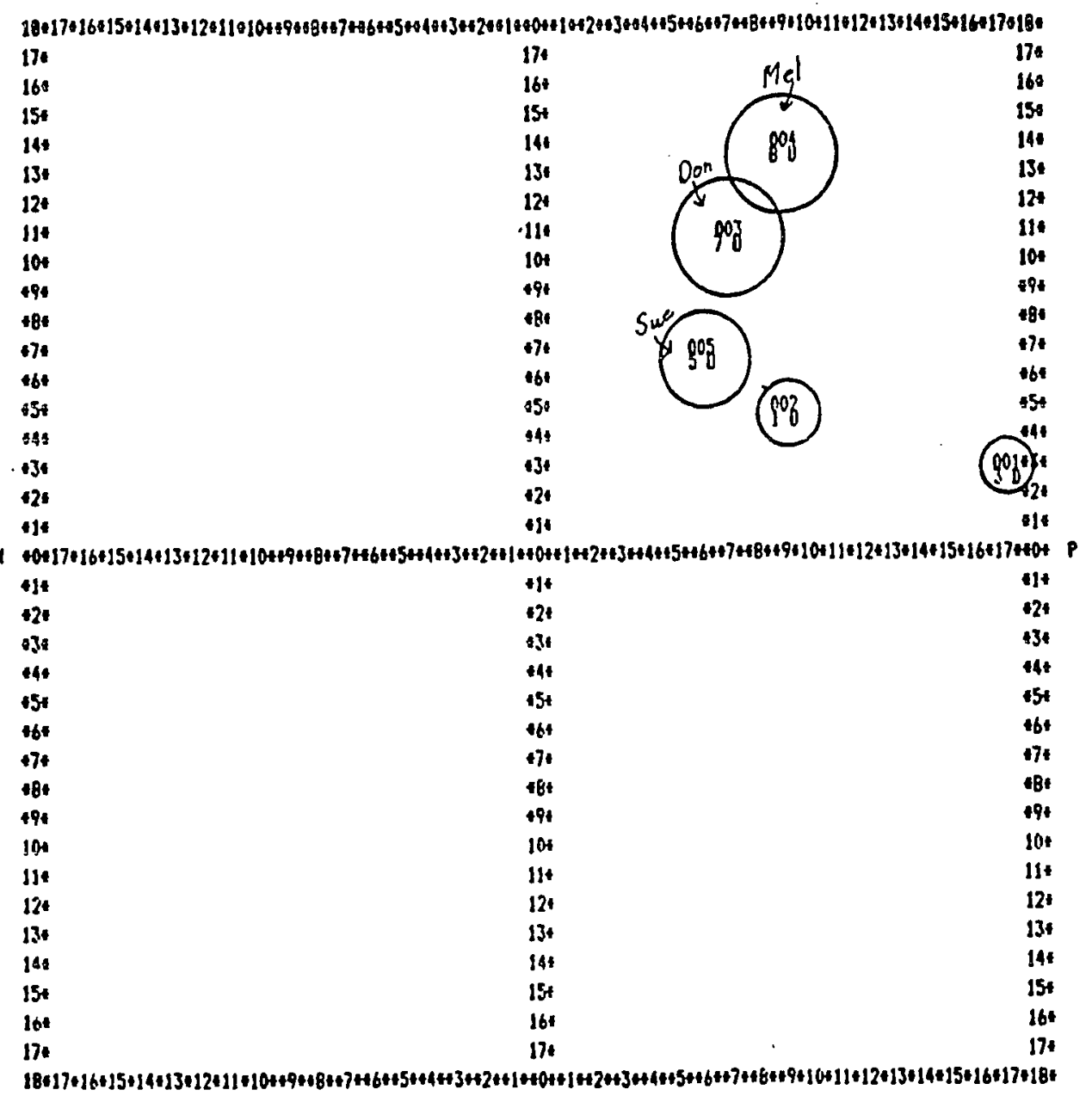

B

Figure 22. Average field diagram, Group \#6, Term II, (winning group) at pretest. 
members and emotionally expressive behaviors for the men.

As can be seen in Figure 23, which is the average field diagram for Group \#6 at posttest, both Don and Mel changed their positions in the space. As the analysis of the pretest suggests, they both relinquished their dominant, task-oriented postures and moved into a closer, friendlier relationship with the female members. Mel, in fact, became the most positive member of the group. Sue established her leadership position in this group by asserting dominance, low task-orientation, and by being perceived on the field diagrams as the most negative member. As stated earlier, this dynamic group combination was the "winning group." This winning combination is supported in Hoffman's (1965) review of problemsolving groups which suggests that allfemale groups do less well than all-male groups, but mixed gender groups are superior in task resolution to all-male groups in situations where competition for the role of leader interferes with coordination. These case studies demonstrate, through the use of SYMLOG, the versatility and utility of the field diagrams for depicting data found in this study. The illustrative case studies represented time in group work for members receiving feedback and for those receiving no feedback. In addition, depicting how one of the two no-show groups interacted in group work with its participants having never 


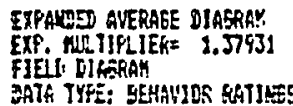

BATG TYFE: GEHAUDS SHTILES

\section{F}

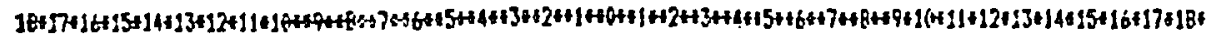

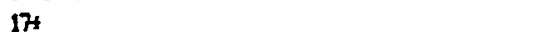

It

SSi

144

13

124

114.

$10+$

498

664

a7i

stis

45:

$4 i$

3

tat

ift

174

164

$15+$

144

$12+$

114

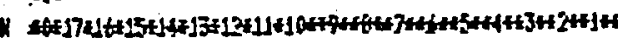

if?

424

*3:

4it'

est

46

17.

s.t.

107

IH

12:"

34:

$14 i$

164.

19.

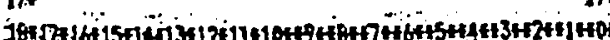

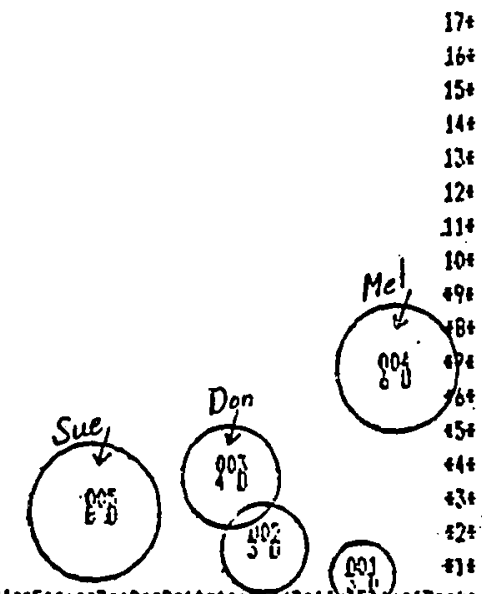

(1)

tiz

42

a

4t:

154

$+6 f$

178

+18F

$49 t$

107

I1

126

$13+$

144.

154

dis

$17+$

$+14$

4

44

45

$+4$

$+74$

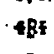

79

104

114

124

13

tet

164

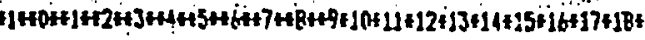
$\frac{\text { Figure 23. Average field diagram, Group \#6, Term II, }}{\text { Twinning group) at posttest. }}$ 
worked together before assisted in understanding this group's relative lack of satisfaction and self-perception. Finally, looking at the "winning group" through SYMLOG field diagrams was informational and assisted in pinpointing directions for further study. 
CHAPTER VI

SUMMARY, CONCLUSIONS AND RECOMMENDATIONS

SUMMARY

This study was designed to determine whether a feedback session employing SYMLOG field diagrams would make a difference in group movement, leader behavior, selfperception and satisfaction. The study found that feedback intervention into a course of study on leadership and management did make a difference in two of the four stated hypotheses: leadership and group satisfaction.

Designated leaders of the groups receiving feedback responded more than other group leaders to the information from the field diagrams by displaying more movement in their respective group spaces. Additionally, members of the groups receiving feedback were better able to graphically analyze their own behavior than were other group leaders, and consequently the group's work was more satisfying to them. Feedback appeared to promote the participants' perceptions of group effectiveness.

These two findings add to the literature in both the field of Organization Behavior and that of Leadership Development. In the field of Organization Behavior, the 
need for more precise intervention tools has been identifed by Berger (1981), Hare (1985), anü Eolley (1983), among others. The use of SYMLOG as such a tool could provide data for employers and employees to evaluate behavior in the work place and to identify problem areas in interpersonal relations which may lead to a positive change. In the field of Leadership Development, training modules using SYMLOG maY assist in development of skills helpful to either a potential or an established leader. The fact that potential leaders can view their own behavior in relation to that of others in a group is, in and of itself, a powerful tool for diagnosing interactions. This knowledge or informational power (French \& Raven, 1980) can lead to directional movement by the leader based on the specific constellation of group members.

In addition to Organization Behavior and Leadership Development, these findings add to the growing literature surrounding the use of SYMLOG in that they present data directed toward what Bales and Isenberg (1982) state as a critical need for further research using the feedback cycle as an intervention. In addition, this study has described how the field diagrams can be useful in interpreting data in a descriptive manner to augment quantitative data on small group interactions. Finally, this study adds to the literature using SYMLOG in the "concrete experiment" 
encouraged by Kohler (1985).

The remaining two hypotheses were not supported in this research. First, the movement of groups as a function of feedback was not significant. What movement did occur was in one dimension and by a group which was identified as an "inherent outlier" (Barnett and Lewis, 1984) in its proportion of males to females. Secondly, correlations of self-perceptions with perceptions by others were apparently not influenced by the intervention of feedback in this study. Self-perceptions were highly correlated with others' perceptions in task-orientation and in dominant-passive behaviors, but were never significantly positively correlated in perceptions in the negative-positive dimension.

This congruity in two of the dimensions and lack of congruity in the third dimension remained stable over time and was not influenced by feedback intervention. It appeared that simply being together in the groups over a period of time was a positive factor in self-perceptions since the two control groups did not experience this familiarity and were the only groups in the study which demonstrated negative correlations in self-perception related to that of others in their group. Since this study was conducted during a course on leadership and management, those groups receiving feedback 
had the full range of opportunities available to students which included the feedback session with the field diagram. This increased time to develop and sustain behaviors is supported by Berger's (1981) research which suggests that time actually spent on organizational behavior interventions may be a factor in sustaining behaviors. These groups received two hours of feedback using the field diagrams, in contrast with the other groups, which received none. The diagrams were the conduit for direct feedback to each individual on self-behavior which distinguishes this type of feedback from other, more general types.

Although positive findings are reported in two of the hypotheses tested, application of these results should be tempered by the fact that these data which support the findings were from one health care institution of learning. The sample was predominantly female, and the students were from one professional school of nursing. In addition, this study did not have an equal number of feedback to nofeedback groups, which may have influenced the results. Nevertheless, the study has shown the importance of SYMLOG as a significant intervention for use in leadership training and for influencing group satisfaction.

The findings in this study indicate that the small problemsolving groups receiving feedback in the form of SYMLOG field diagrams are more satisfied with their work 
than those groups not receiving feedback. In addition to satifaction, feedback on group interactions clearly increases movement patterns in designated leaders of the small groups.

The groups in this study appear to have established space in a conceptual field which held fairly constant over time and which did not appear to be influenced by the introduction of feedback intervention.

\section{RECOMMENDATIONS FOR FUTURE RESEARCH}

1. A follow-up study of small groups should be designed to determine what effect gender has on taskoriented behavior in groups.

2. A follow-up study should be designed using other professional groups or a more stratified sample of problemsolving groups to explore the positioning of group space in relation to identified role.

3. Further exploration into the use of feedback should be made using an equal sample size of feedback and nofeedback groups.

4. The impact of designated leaders on performance should be explored through the use of feedback as an intervening variable.

5. Self-perceptions related to perceptions of others in problemsolving groups under varying stress conditions 
should be explored.

\section{CONCLUSIONS}

The findings in this study indicate that groups receiving feedback in the form of SYMLOG field diagrams are more satisfied with their work than those groups not receiving feedback. This increased satisfaction can contribute to a healthier work place. In addition to satisfaction, feedback on group interactions appears to assist the leader in determining movement patterns.

Groups seem to establish a space in a conceptual field which is held fairly constant over time. In this study, groups surprisingly located far down on the task-oriented vectors. Even though the groups held fairly constant in the group space, the dynamics within a group were varied and diverse. Further study into the intra-conflict that occurs when a group is formulating would be another suggested topic for further study.

When groups have the opportunity of working together over time, self-perceptions are close to those of others in the group. Even though groups seem able to perform a shortterm task successfully, the toll is costly in terms of group satisfaction. another identified area for further study is the effect of this "one shot" group work on sustained performance. 
The SYMIOG system used as a conceptual tool and a method for analysis is a powerful system for the study of groups. It provides data which can be used for qualitative and quantitative research designs in a way that can be communicated to the scientific community, as well as the lay population in a pragmatic manner. 
Allport, F. (1924). Social Psychology. Boston: Houghton Mifflin.

Anscombe, F. J. (1960). Rejection of outliers. Technometrics, 2, pp. 123-147.

Appelbaum, R., E. Bodaken, E. Sereno and K. Anatol (1974). The Process of Group Communication. Palo Alto, Ca: Science Research Associates.

Argyris, C. (1971). Management and Organization Development: The Path From XA to YB. New York: McGraw-Hi11.

Bales, R. F. (1950). Interaction Process Analysis: A Method for the Study of Small Groups. Cambridge, Ma: Addison-Wesley. Review, 32, pp. 44-50.

(1956). Task status and Iikeability as a function of talking and listening in decision-making groups, in Leonard D. White (ed.), The State of the Social Sciences, Chicago: University of Chicago Press, pp. 148-161.

(1959). Small group theory and research, in R. E. Merton, L. Broom and L. S. Cottrell, Jr. (eds.), Sociology Today: Problems and Perspectives, New York: Basic Books, pp. 292-305.

- (1970). Personality and Interpersonal Behavior. New York: Holt, Rinehart \& Winston.

Bales, R. F., S. P. Cohen and S. A. Williamson (1979). SYMLOG: A System for the Multiple Level Observation of Groups, New York: Free Press.

Bales, R. F., M. A. Cowen and R. J. Koenigs (1986). Interpersonal Effectiveness Profile. Woodland Hills, $\mathrm{Ca}$ : SYMLOG Consulting Group. 
Bales, R. F. and D. J. Isenberg (1982). Symlog and Leadership Theory in Leadership: Beyond Establishment Views, by J. C. Hunt, U. Sekaran, and C. A. Schriesheim, Carbondale: Southern Illinois University Free Press.

Barnett, V. and $T$. Lewis (1984). Outliers in Statistical Data (2nd ed.). New York: John Wiley and Sons.

Barnlund, D. and F. Haiman (1959). The Dynamics of Discussion. Boston: Houghton Mifflin.

Berger, M. M. (1981). Organizational Innovation in a Professional Schoool. Unpublished Dissertation. Portland, Oregon: Portland State University School of Urban Studies.

Berlo, D. (1960). The Process of Communication. New York: Holt, Rinehart \& Winston.

Blake, R. and J. Mouton (1964). The Managerial Grid. Houston: Gulf Publishing.

- (1978). The New Managerial Grid. Houston: Gulf Publishing.

Bormann, E. (1969). Discussion and Group Methods. New York: Harper and Row.

Bradford, I. P. (1982). Group Development. (2nd ed.) La Jolla, Ca: University Associates Publishers and Consultants.

Bradford, L. P., D. Stock and Murray Horowitz (1952). How to diagnose group problems. Adult Leadership, $1(4)$, pp. 3-7.

Brilhart, J. (1974). Effective Group Discussion. (2nd ed.). Dubuque, Iowa: William C. Brown.

Bruning, J. L. and B. L. Kintz (1977). Computational Handbook of Statistics. (2nd ed.). Glenview, Ill: Scott, Foresman and Company.

Burne, J. M. (1979). Leadership. New York: Harper Colophon.

Campbell, D. and J. Stanley (1963). Experimental and QuasiExperimental Designs for Research. Chicago: Rand McNally and Company. 
Cartwright, D. and A. F. Zander (eds.) (1953). Group Dynamics: Theory and Research. Evanston: Row, Peterson and Company.

Collins, B. and H. Guetzkow (1964). A Social Psychology of Group Processes for Decision Making. New York: Wiley.

Crandall, R. (1975). A new column: On group dynamics! SASP Newsletter, I(4), pp. 1-2.

Davis, k. (1981). Human Behavior at Work: Organizational Behavior. New York: McGraw-Hill Company.

Deutsch, M. (1954). Field theory in social psychology, in G. Lindzey (ed.) Handbook of Social Psychology. Cambridge, Ma: Addison-Wesley.

Fassheber, P. and B. Terjing (1985). SYMLOG rating data and their relationship to performance and behavior beyond the group situation. International Journal of Small Group Resarch, 2(1), pp. 97-108.

Festinger, E. and E. Aronson (1968). Arousal and reduction of dissonance in social contexts, in Dorwin Cartwright and Alvin Zander (eds.), Group Dynamics: Research and Theory (3rd ed.), New York: Harper \& Row, pp. 125-136.

Fiedler, F. E. (1967). A Theory of Leadership Effectiveness. New York: McGraw-Hill Company.

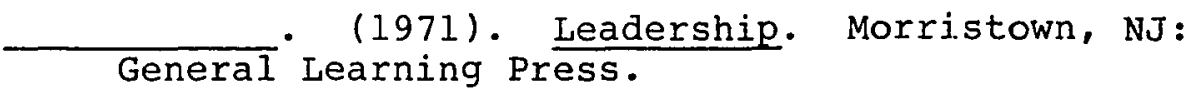

- (1973). The trouble with leadership is that it doesn't train leaders. Psychology Today, 92, pp. 23-29.

Fiedler, F. E. and L. Mahler (1979). A field experiment validating contingency model leadership training. Journal of Applied Psychology, 64, pp. 247-254.

Fine, G. A. (1976). A Group Space Analysis of Interpersonal Dynamics. Unpublished thesis, Harvard University, Department of Psychology and Social Relations.

French, J. R. P. Jr. and B. B. Raven (1980). The basis of social power, in D. Cartwright (ed.), studies in Social Power. Ann Arbor: University of Michigan Press, pp. 118-149. 
Frost, D. E. (1983). Role perceptions and behavior of the immediate superior: Moderating effects on the prediction of leadership effectiveness. Organization Behavior \& Human Performance, 31, pp. 123-142.

Frost, D. E., F. E. Fiedler and W. Anderson (1983). The role of personal risk-taking in effective leadership. Human Relations, 36(2), pp. 185-202.

Gibb, C. (1954). Leadership, in G. Lindzey (ed.). Handbook of Social Psychology. Cambridge, Ma: Addison-Wesley Publishing Company.

Gibb, J. R. and L. M. Gibb (1967). The group as a growing organism, in Leland P. Bradford (ed.), Group Development (1982). La Jolla, Ca: University Associates Publishers and Consultants.

Goldberg, A. and C. Larson (1975). Group Communication. Englewood Cliffs, NJ: Prentice-Hall.

Gouran, D. (1974). Discussion: The Process of Group Decision Making. New York: Holt, Rinehart and Winston.

Gulley, H. (1968). Discussions, Conferences and Group Processes. New York: Holt, Rinehart and Winston.

Hare, P. A. (1973). Group decision by consensus: reaching unity in the society of friends. Sociological Inquiry, 43(1), pp. 75-84.

- (1976). Handbook of Small Group Research (2nd ed.) New York: Free Press.

(1982). Creativity in Small Groups. Beverly Hills, Ca: Sage Publications, Inc.

(1985). The significance of SYMLOG in the study of group dynamics. International Journal of Small Group Research, $1(3)$, pp. 38-50.

Harnack, V. and T. Fest (1964). Group Discussion, Theory and Technique. New York: Appleton Century Crofts.

Hattink, J. (1985). SYMLOG in the classroom. International Journal of Small Group Research, 1(9), pp. 176-181. 
Haynes, W., J. Massie and M. Wallace (1975). Management: Analysis, Concepts and Cases. Englewood Cliffs, NJ: Prentice-Hall.

Hersey, P. and $K$. Blanchard (1977). Management of Organizational Behavior: Utilizing Human Resources. (3rd ed.). Englewood Cliffs, NJ: Prentice-Hall.

Hill, P. H. (1984). Decisions in corporate environment, in Walter C. Swap, Group Decision Making, Beverly Hills, $\mathrm{Ca}$ : Sage Publications, pp. 258-259.

Hollander, E. P. (1978). Leadership Dynamics: A Practical Guide to Effective Relationships. New York: The Free Press.

Hollander, E. P. and J. W. Julian (1969). Contemporary trends in the analysis of leadership process. Psychological Bulletin, (71), pp. 387-397.

Hoffman, L. R. (1965). Group problem solving, in L. Berkowitz (ed.), Advances in Experimental Social Psychology. New York: Academic Press.

Huck, S. W., W. H. Cormier and W. G. Bounds, Jr. (1974). Reading Statistics and Research. New York: Harper \& Row Publishers.

Janis, I. L. (1972). Victims of Groupthink. Boston: Houghton and Miffin.

- (1982). Groupthink. (2nd ed.). Boston: Houghton and Mifflin.

Jesuino, J. (1985). Leadership behavior in a military academy. International Journal of Small Group Research. 2(Sept 1985), pp. 155-162.

Johnson, D. (1981). Reaching Out: Interpersonal Effectiveness and Self-Actualization. Englewood cliffs, NJ: Prentice-Hall.

Kohler, Andre (1986). Seven years with SYMLOG: A review of research. International Journal of Small Group Research. 2(1), pp. 83-87.

Kruskal, W. H. (1960). Some remarks on wild observations. Technometrics, 2, pp. 1-3.

Lansdowne, J. (1986). Symlog and the theater (unpublished paper). 
Leavitt, H. (1964). Managerial Psychology. (2nd ed.). - Chicago: University of Chicago Press.

Lewin, K. (1939). Field theory and experiments in social psychology. American Journal of Sociology, 44, pp. $868-897$. New York: $\begin{gathered}(1951) \\ \text { Harper }\end{gathered}$ Field Theory in Social Science.

Lewin, K., R. Lippett and R. White (1939). Patterns of aggressive social behavior in experimentally created 'social climates.' Journal of Social Psychology, 10, pp. 271-299.

Lieberman, M. I. Yalom and M. Miles (1973). Encounter Groups: First Facts. New York: Basic Books.

Likert, R. (1961). New Patterns of Management. New York: McGraw-Hill Company.

Lippitt, G. L. (1981). Organizational Renewal: A Holistic Approach to Organization Development. Englewood Cliffs, NJ: Prentice-Hall.

Luft, Joseph (1970). Group Process: An Introduction to Group Dynamics. (2nd ed.). Palo Alto: The National Press Book.

Mamola, C. (1979) Women in mixed groups: Some research findings. Small Group Behavior, 10(3), pp. 431-440.

March, J. G. and H. A. Simon (1958). Organizaitons. New York: John Wiley and Sons.

Marrow, A. J. (1969). The Practical Theorist: The Life Work of Kurt Lewin. New York: Basic Books.

Maslow, A. (1970). Motivation and Personality. (2nd ed.). New York: Harper \& Row.

McCaskey, M. B. (1976). Collecting feedback throughout the course. The Teaching of Organization Behavior, 11(3), pp. $34-36$.

McGrath, Joseph E. (1984). Groups: Interaction and Performance. Englewood Cliffs, NJ: Prentice-Hall.

Mills, C. (1971). Feedback: The art of giving and receiving help, in Reading Book for Laboratories in Human Relations Training. Chicago: National Training Laboratory Inst. 
Miller, G. (1966). Speech Communication: A Behavioral Approach. Indianapolis: Bobbs-Merrill.

Moreno, J. L. (1953). Who Shall Survive? Foundations of Sociometry, Group Psychotherapy, and Sociodrama. (Revised edition of 1934 volume with new material added.) Beacon, NY: Beacon House.

Moscovici, S. and M. Zavalloni (1969). The group as a polarizer of attitudes. Journal of Personality and Social Psychology. $12(2)$, pp. 125-135.

Myers, J. L. (1972). Fundamentals of Experimental Design. (2nd ed.). New York: Allyn \& Bacon Co.

Napier, R. and M. Gershenfeld (1973). Groups: Theory and Experience. Boston: Houghton-Mifflin.

Patton, B. and K. Griffin (1973). Problem-solving Group Interaction. New York: Harper \& Row.

Polley, R. B. (1983). Dimensions of political reality. Journal of Applied Social Psychology, 13(1), pp. 66-7. - (1984). Subjectivity in issue polarization. (unpublished paper).

(1986). Rethinking the third dimension. International Journal of Small Group Research, 9, pp. 134-139.

Rubin, J. Z. (1984). Introduction, in Walter C. Swap, Group Decision Making. Beverly Hills, Ca: Sage Publ.

Sattler, W. and N. C. Miller (1968). Discussion and Conference. Englewood Cliffs, NJ: Prentice-Hall.

Schellenberg, J. A. (1978). Masters of Social Psychology. New York: Oxford University Press.

Sherif, M. (1936). The Psychology of Social Norms. New York: Harper \& Row.

Skinner, B. F. (1953). Science and Human Behavior. New York: MacMillan Press.

Steiner, I. D. (1975). Whatever happened to the qroup in social psychology? Journal of Experimental Social Psychology, 10, pp. 94-108.

Stogdill, R. (1974). Handbook of Leadership. NY: Free Press. 
Stogaill, ‥ and A. Coons (eds.). (1957). Leader Behavior: Its Description and Measurement. Research Monograph No. 88. Columbis, Bureau of Business Research, Ohio State University.

Stone, P. J. (forthcoming). SYMLOG for skeptics, in Polley, R. B., A. P. Hare and P. J. Stone (eds.). The SYMLOG Practitioner: Applications of Small Group Research. New York: Praeger.

Strodtbeck, F. L. (1954). A case for the study of small groups. American Sociological Review, 19(6), pp. $651-657$.

Swap, W. C. (1984). How groups make decisions: A social psychological perspective. Group Decision Making. Beverly Hills, Ca: Sage Publications, Inc., pp. 45-47.

Tindall, J. H., L. Boyler, P. Cline, P. Emberger, S. Powell, and J. Wilson (1978). Perceived leadership rankings of males and females in small task groups. Journal of Psychology, 100, pp. 13-20.

Tubbs, Stewart L. (1978). A Systems Approach to Smal1 Group Interaction. REading, Ma: Addison-Wesley Publishing Co., Inc.

Vroom, V. and P. Yetton (1973). Leadership and DecisionMaking. Pittsburg: University of Pittsburg Press.

Walton, R. E. (1973). Quality of worklife: what is it? Sloan Management Review, Fal1, pp. 11-21.

Wang, R. and J. Hawkins (1980). Interpersonal feedback for nursing supervisors. Supervisor Nurse, 11 , pp. $26-28$. 
APPENDIX A

THE SYMLOG ADJECTIVE RATING SHEET 
U......active, doninant, talks a lot..............not often...sometimes... often P....extroverted, outgoing, positive.............not often...sometimes...often UPF....a purposeful cemocratic task leader..........not often....sometimes... often UF....an assertive business-like manager...........not often...sometimes...often UNF...authoritarian, controlling, disapproving.....not often...sometimes... often UN.... donineering,tough-minded, powrful.......... not often...sometimes...often UNB...provocative, egocentric, showB off............not often...sonetines... often UB....jokes around, expressive, dramatic...........not often...sometimes... .often UPB...entertaining, sociable, smiling, warm........not often...sometimes... .often P......friendly, equalitarian.....................not often...sometimes....often PF.....works cooperatively with others..............not often...sometimes...often F......analytical, task-oriented, problem solving..not often...sometimes....often NF....legalistic, has to be right................not often...sometimes...often N.....unfriendly, negativistic...................not often....sometimes....often NB.....irritable, cynical, won't cooperate..........not often....sometimes... often B.....shows feelings anã emotions................not often...sometimes...often PB.....affectionate, likeable, fun to be with.......not often...sometimes... often DP....looks up to others, appreciative, trustful. not often...sometimes...often DPF...gentle, willing to accept responsibility....not often....sometimes....often DF....obedient, works submissively..............not often....sometimes...often DNF...self punishing, works too hard..............not often...sometimes...often DN....depressed, sad, resentful, rejecting.........not often...sometimes...often DNB....alienated, guits, withdraws.................not often...sometimes...often DB.....afraid to try, doubts own ability...........not often...sometimes...often DPB...guietly happy just to be with others.........not often...sometimes... often D.....passive, introverted, says little...........not often...sometimes...often 
APPENDIX B

"WHO GETS THE KIDNEY"

AND

"LUNA"

TASKS 
11

\section{KIDNEY MACMIAE DESCRIPTION SHEET}

Located at Swedish Hospital in Seattle. Washington, is the tamous tidney machine. A marvel of technological ingenuity, it is the only bope of life for people with a rare idiney disease.

In actuality, the machine functions as a kidney for people who have lost the ure of their own. By connecting themselves to the machine for twenty-four hours each week, people with renal failure can remain alive indefnitely -or until they are billed by some other ailment sot conpected with their kidneys.

There are several probtems associuted with using this maction, for there are many more people who need it than there is time avaitabie on the onachine. In face, only about five people can bs placed on it at any one time. Doctors examine all potential patients and determine those who could profit most from connection to the machine. They sereen out those with other diseases, for whom the machine would be only a temporary expedient, and they tum their list of recommended patients over to the bospital actministration At present, the doctors have submitted the names of five persons for one place on the machine.

The committee assembled to make the decision has been given a brief biography of each person appearing on the list. It is assumed that each person has an equal chance of reanaining alive if allowed to use the machine. Thus, the committee is asked to decide which one of these may have uccess to the machine.

Youl are arked to act as if you were a memlex of this committee. Remember, there is only one vaciancy. and you muse fill it with one of these five people. You must aytee. unanimously. on the single persen who is to he permitted to remain ulive, und you anist decide your own criterna for inaking this choice.

The only medical inlornation you have is thist people uver forty seem to do poorer on the inachine than those under forty (ulthough they do inot neciessinily find it welessi. It is up to yosi. 
KIDNEY MACHINE BIOGRAPHICAL SHEET

Alfred: White, male. American age 12 Married for 21 years. Two children (boy 18, girl 15), both bigh scbool students. Reseanch phyxicist at University medical xchool. working on cancer immunization project. Current publications indicate that be is on the verge of a significant medical dixcovery.

On the health service seaff $\alpha$ boel university, member of county medical society. member of Rotary Intemational and Boy Soout Leader for 10 years.

Bill: Black, male, American, age 27. Married for five years. One child (girh, 3), wife six monchs pregnant. Curreatly employed as an auto mochsaic in local car deslenchip.

Attending night school and tuking courses in suromatic-transmiosion rebuilding. No community service ectivities listed Plans to open auto-banseniscion repair shop upon completion of trade xhool course.

Cora: White; female, American, age 30. Married for elevea years. Five children (boy 10. boy 8, girl 7. girl 5. girl 4 monehs). Husband self-employed (owns and operates tavem and short-order restaurant). High school gradunte. Never employed.

Couple hes just purchsed home in local suburte, and Con ts plaming the incerior so determine whether she has the talent to retum to school for courses in interior decoration. Member of several religious organizations.

David: White, male. American, age 19. Single, but receptly announced engegerpent asd plans 10 marry this summer. Presently a sophomose at large eagtern university. majoring in philosophy and literature. Eventually hopes to eam Ph.D. and become a college professor.

Member of several cumpus political unganizations an outspoken critic of the cullege "administration," was once suspencled briefly for "ugitation." Has hed poetry published in various literary magazines around the New York area. Futber is selfenployed (uwns men is haberdasivery store), mother is deceased. Ilas iw y younger sisten $(15,11)$.

Edna: White, female, American age 34. Single. presently eupploved us an executive sectrefary in large manufacturing cumpany, where she has worked sinke gradustion fruin business college. Aleminer of locial choral soxiety: wew alto solvist in Christnds production of Handel's Meraviall. llas been very active in several cturch and charitalsle groupar 
114

INSERTED FOR PAGINATION

PURPOSES ONLY 
NURSING $452-$ Spring, 1986

Group Project

YGR FSSIEREN:

Fll proposals for nursing and health care on lune will be evaluated by cicr. Schantz, comanding officer of the Luna Satellite. The least costly plan wisich guarantes effective and efficient nursing care and a healthy population will be accegtsc. artia consideration will be given to innovative approaches to health care celivery. The aplicant from the group whose proposal is accested will be rired as Ciniei Nurse (CN).

Presesels sineile incluce:

1) Objectives for health care celivery and the nursing program;

2) Specific acticns to accomplish the objectives, inclucing general job descriptions for nursing personnel (you may include healti control policies for the Luna population);

3) Designate and justify numbers of nussing personnel to be used in each category, and cescithe job tasks fo: $€$ en job descrizticn; and

6) Determine a one-year buciget for salazies.

Your proposal will be presented verizlly to your comancing cificer-you nees not witte a fcrimal cocitert. A spokesperson for each grolp should be designated. You will have 10 minutes to succiretly gresent your proposal.

IIRia Buciost_Dromasal

Competing group presentations to reviewers. Limited to 15 minutes per groxp. Presentations critigued, wiming group announced anci awaroded prize on that day. A grade will ultirately be assigned to each group dejencing upon perfomance.
Criteria will be:

1. Clarity of written proposal

2. Accuracy of written prososal (credibility)

3. Group represenzative's oral presentation and cief ense of buaget

4. Creativity

5. Sensitivity to client care, personnel managemient and cost containitert. 


\section{THE PROBLEM}

As a member of a group of nurse managers, you are helping a colleague plan the nursing care on Luna, an interplanetary satellite. Luna is an experimental pathogen-free space station on which the Air Force is conducting certan classified but nondangerous studies. The 400 persons who work and live on Luna are all adults. Females on Luna must agree to an obligatory birith control program, for the atmosphere has been found to impair fetal development. Of the total population, 50 percent are temale. Tours of duty on Luna are for three years. Excep: for people involved in support senvices such as lood and sanitation, most of the personnel on Luna are prolessionals.

Because the satellite is kept pathogen-free and all adults are healthy on arrival, there is little if any disease on Luna. Moreover, as a result of reduced gravity and strict regulations, there is a relatively low injury rate. Typically, not more than four or five injuries require hospitalization at any given time. Most injuries require minor attention only by the nurse on outpatient duty.

Only three health problems trouble the people working on Luna:

Luna lichen: This is the popular. name given to the skin lungu's that seems to thrive in the pathogen-tree atmosphere. The con: dition is no: a serious threat to health, but it spreads quickly once contracted. Vietims are isolated al once in the hospital-clinic. and lesions are treated by scaling, scraping, medicating, and dressing four times a day. This is done with aseptic lechnique to proied the nurse, for Luna lichen is transmitted by direct skin contact. Patients are not ill with this condition, though bandages on hands and feet (common sites for the fungus) decrease their ability to manage their own care. There are usually three or four cases under treaiment at any one time. Most cases clear up in wo weeks. Severe cases are sent back to Earth on the shutite, which arives every three montiss. Luna lichen dies immediately in Earsis a:mosphere.

Space fever: Every now and then, pertiaps three or lour times a year, someone experiences a psychological breakdown, usually related to her or his plazement on the satelite. Such patients are tranquilized as neejed and returned to Earth on the next shuttle.

Health maintenance: (1) Mituscle wasting: To counteract the redused gravitational force, each person on Luna is given a requited daily exercise program based on weight and age. The froblem is that people co: bored with trait exercises and tend to cheat, even though exe:cise time is inciuded in the six-hour work day. As a result. muscle wasting is a potential problem for the population. (2) Immunity maintenance: Nursing musi plan also lor delivery of a monthly injection to every member of the conniunity. The serum given miainiains the ar:ibodies needed upon return 10 Earth. 


\section{THE TASK}

The Air Force has agreed to accept as chiel nurse the manager who provides at lowest cost tie most satislactory plan of nursing for Luna. The following conditions apply to all proposals.

There is one physician on Luna. His work is primarily research. Ho will cos notionte in an omormonery or in oes shlich a pian $n$

care. He will see a patient only on the recommendation of a registered nurse.

All nonnursing tasks of the hospital-clinic are provided by other personnel. Nursing, however, cannol save on is budget by assigning health-related tasks to other persons.

All personnel on Luna work seven days per week in six-hour shitts. There are no "days off" or "holidays" during the three-year tour of duty.

You may use RNs, LPNs, or NAs in whatever numbers you choose. The tasks assigned mus! be appropriate to the leve: of education. Siaff members come from typical education programs. RNs are eligible regardless of their basic education program in nursing.

Chiel Nurse (CN)

Salaries for Luna duty (per yea:; are

Regislered Nurse (RN)

$\$ 45,000$

Licensed Prastical Nurse (LPN) $\quad \$ 15,000$

Nurse Aide (NA) . $\$ 10,000$

In addition, it costs the Air Force an exira $\$ 3,000$ per year for each emsloyee for fringe benefits. On call duty is granted for RNs only, ano need not be used at all. On call bonus is $\$ 10$ for a sixhour shith, whether called or not. Luna works on a regular 24 . hour day. 


\section{XIDNEY AAACHINE PSYCHOLOGICAL REPORTS SHEET}

Re: Patients for Kidney Machine

From: Hospital Psychological Steff

In routine preadmistion interviews the following patients were exemined and eval. usted as per the following data:

Re: Alfred-He is pesently distraught about bis phyical coodition and reports that it interieres with bis work. Seems very committed to his work and eppears to be legiimately on the verge of an important cancer discovery. It was hard for the staff to get bim to talk about his work in terms that they could underntand.

Family relations seem strained and bave been for sane dime because of his commitment to his work. The anf feels that he is a firt-rate seientist and utolar who bas contributed much and could contribute more to medical reveareh. But they also believe him to be s mentally disturbed individual wha, to time, will probubly noed poychiatric help.

Re: Bill-He is a well-orieated Negro, who does not appear to be swayed by the blandishments of black extremist groupa Hie bx angly devoted to his family and appears to be an excellem husband and father.

Bill: capucity for grouth in his chosen oxcupation. however, werns limited His high chionl record was poor, atthough he had no jecord of delinguency and was 11 .

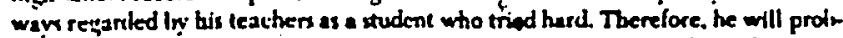
abiv nut auceed with bis lxwiness plans and will reunio employed at a faed rate perininently.

His uife is trained as a legal sectetary. Het prognoxis for couplowment is good. althengh Bill hus dierworaged lxet from seeking wort beesuse of inutual upreement to

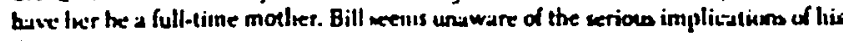
illinss.

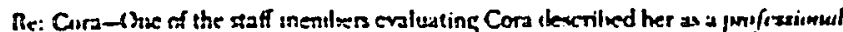

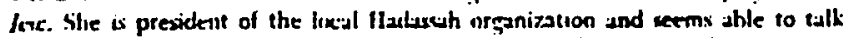

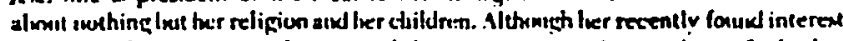
in interiow decrwating inay be a sign of change, it was nuk clear to the salf whet her this infereat was real of oxly generated artificislly when she heard of the intervieu rejuitritutent.

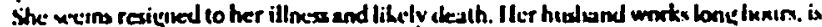

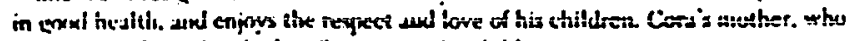

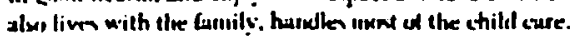

Re: David-Typical of young audent sctivists, David is a bright-almose strafght $\because A^{-1}-$ xtulent who enjoys the reppect of mox of his teachen and frienck. But he appears confused aboul bis future and demonatrates a penchunt for jeopardizing it by tnvolving himself in various tudent "caues" Iodeed, his college's dean of student efairs regards him as an iodividual who will "demonatrate for anything."

Ile is bitter. amort paranoid about his llbess. His futher has ionested a good deal of money, time, and emotion in him and has atways boped that David would becone - lawyer. His reletions with his father are presently atrained, however, and be seems ouly mildy concemed about bis two sisters, slebough they atill think bighly of bim. His fiture father-in-law, who is a bighly accestul busivesemen, expects him to enter the Eamily enterprise upon college graduation.

Re: Edna-She is a self-contained innet-directed woman and a model $\alpha$ the "careet firl." It was cleas to the state that ber natural eryessiveness and combetive tendencies millitaled againat any cort of marilal attechment, and it bs oct impouble that the hus lesbino tendencies.

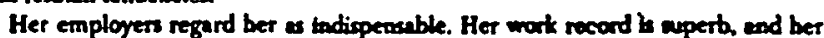
extivities in church and chariable groups bave been very afiective. Sbe bs well regarded by all who know ber, al though sile nems to have few, tf any, cloce friend she appears rexigned to her death. In fact, be lodicated that be would prefor to have comeone other than bernelf go on the machine Her ofer did not wom to the hast incincere. 


\section{APPENDIX C}

SAMPLE PACKET FIELD DIAGRAMS 
EXPAMOED AVERAEE DIAGAAM

EIP. RULLIPLIER = 1.37931

IELLO DIAERAI

DATA TYPE: BEHAVIOR RATINGS

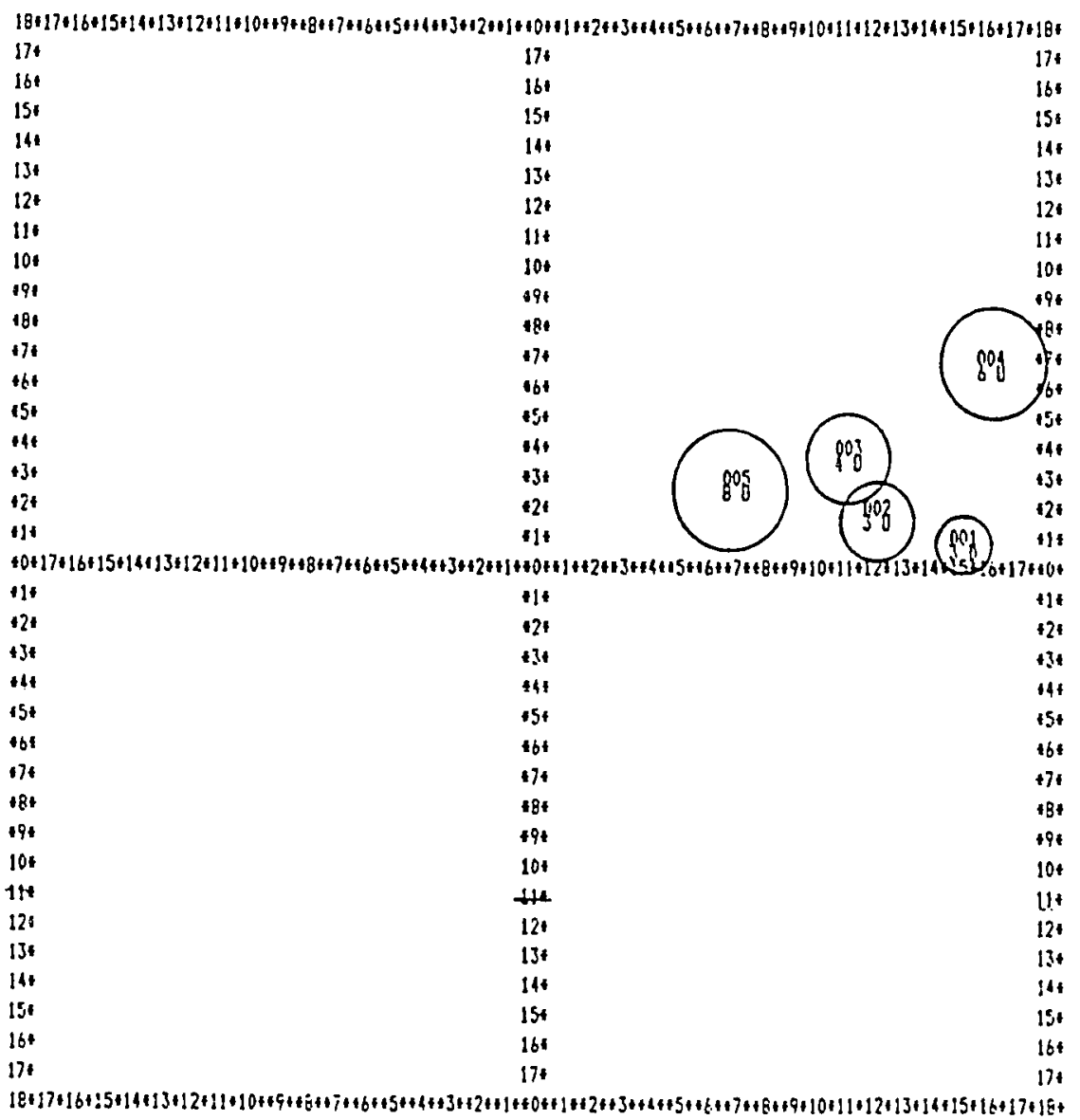




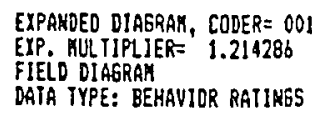

F

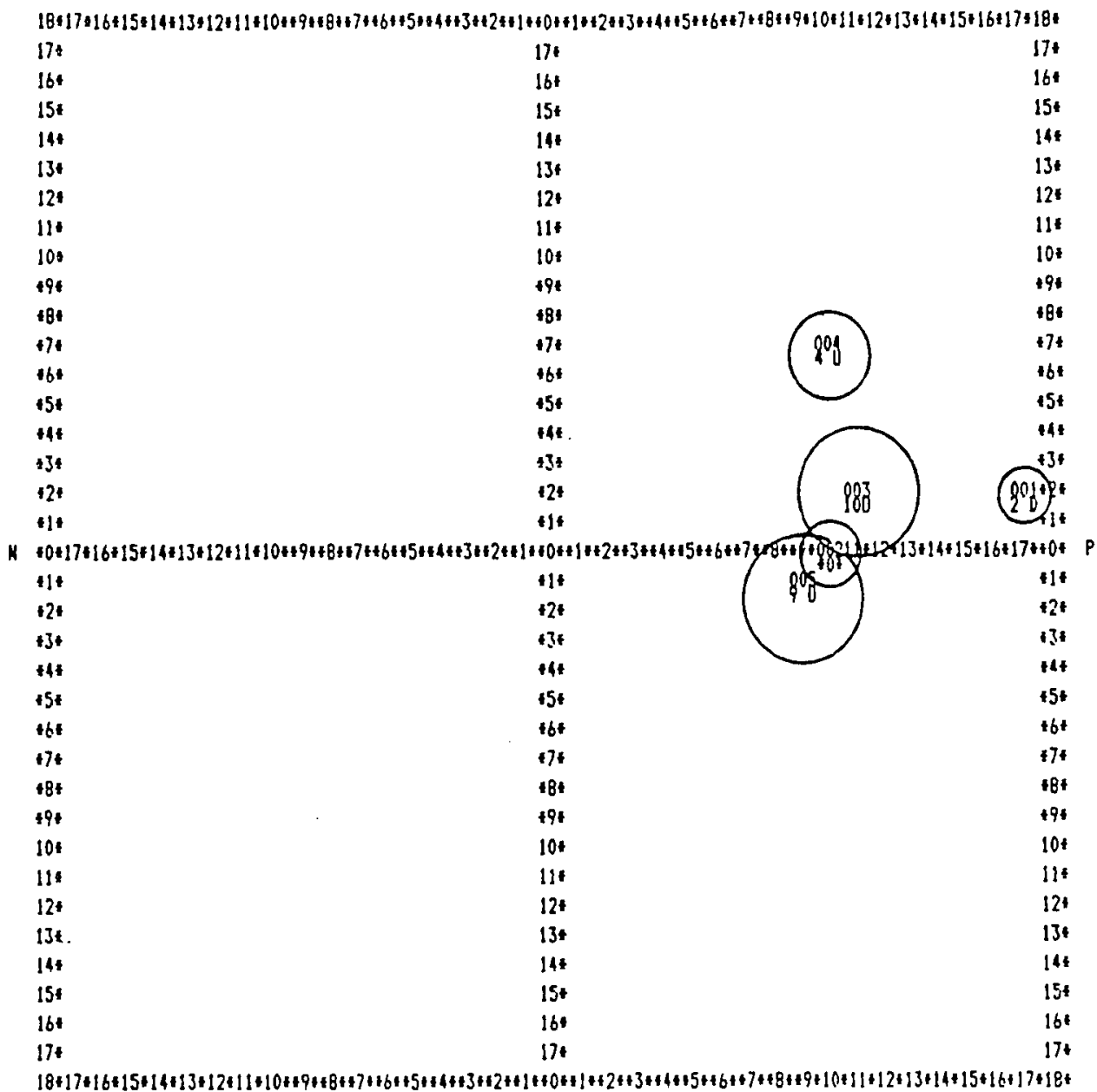

B 


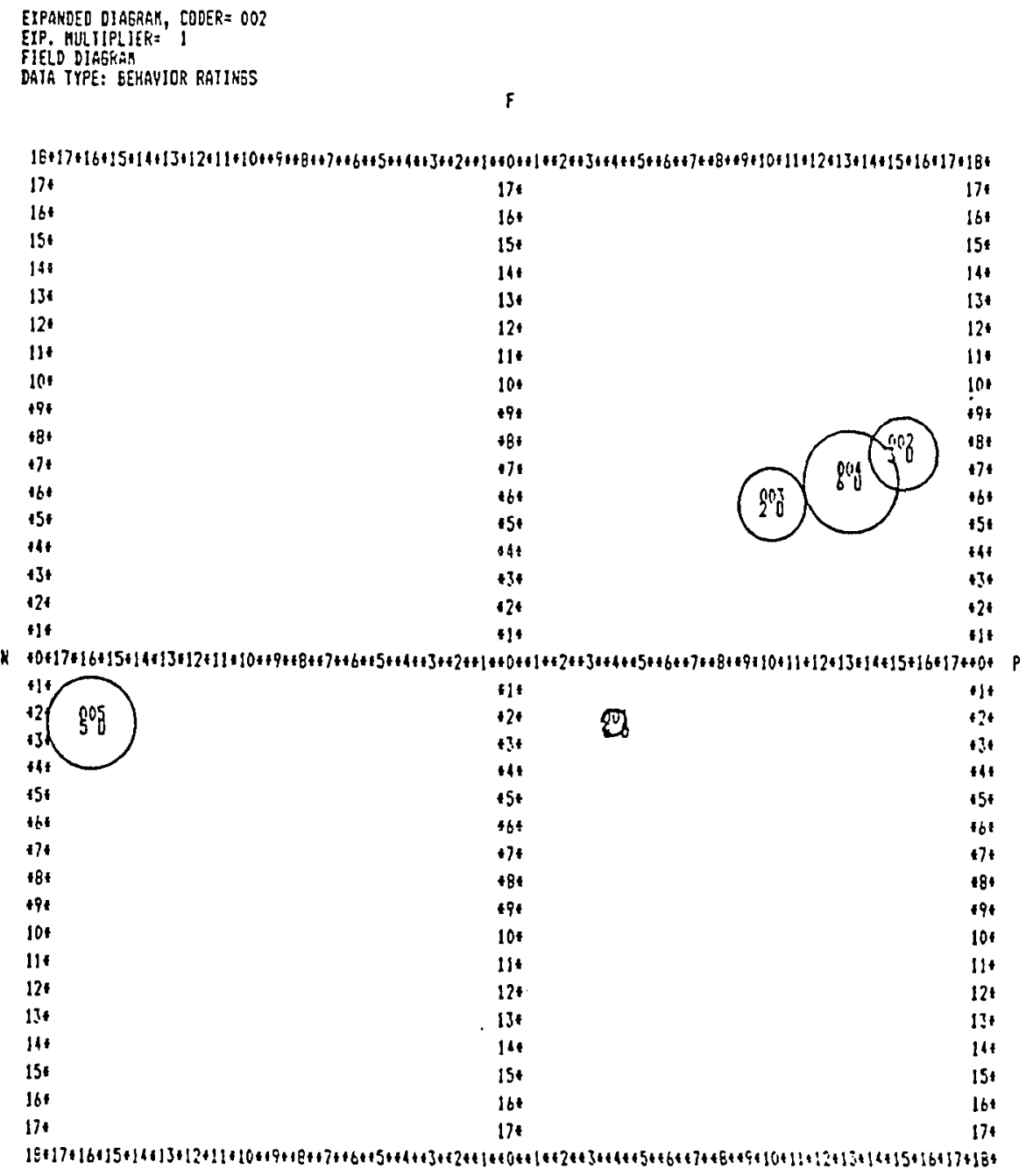




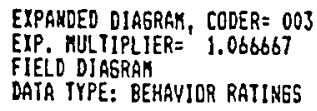

DATR TYPE: BEHAYIOR RATINGS

F

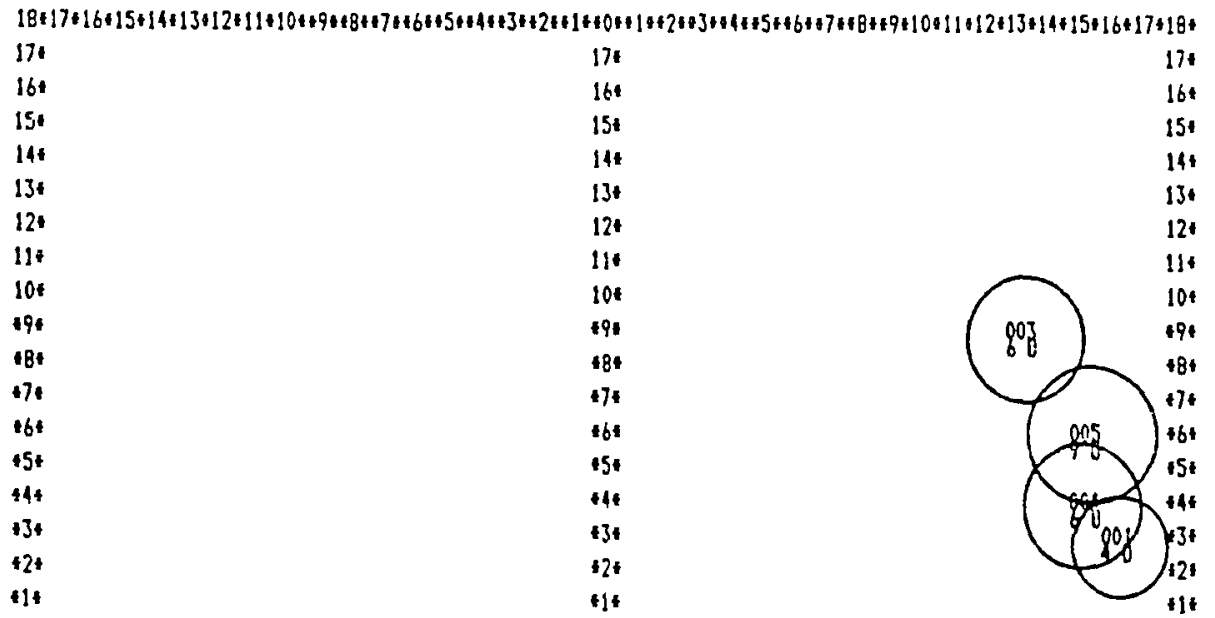

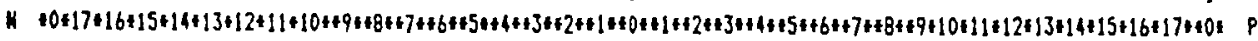

tit

24

4t

5.

$+65$

47

$4 \mathrm{~B}$

791

$10 t$

$11 *$

124

13.

146

15

164

i7s

$\begin{array}{ll}+1 . & 098 \\ +31 & \end{array}$

11t

435

14

$15 t$

$+6 t$

17

64

191

$10 t$

114

124

$13 t$

$14 t$

15.

164

174

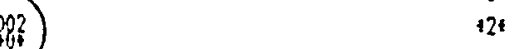

13

$+4$.

45

66

17

18

49

104

$11 t$

12.

13.

it.

154

164

$18+17+16+15+14+13+12+11+10+19++8+47+6+15+44+63+2+11+40+1++2++3+14+15+46+7++8+19+10+11+12+13+14+15+16+17+18+$ 


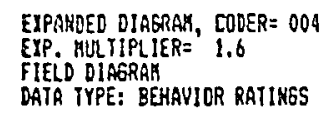

F

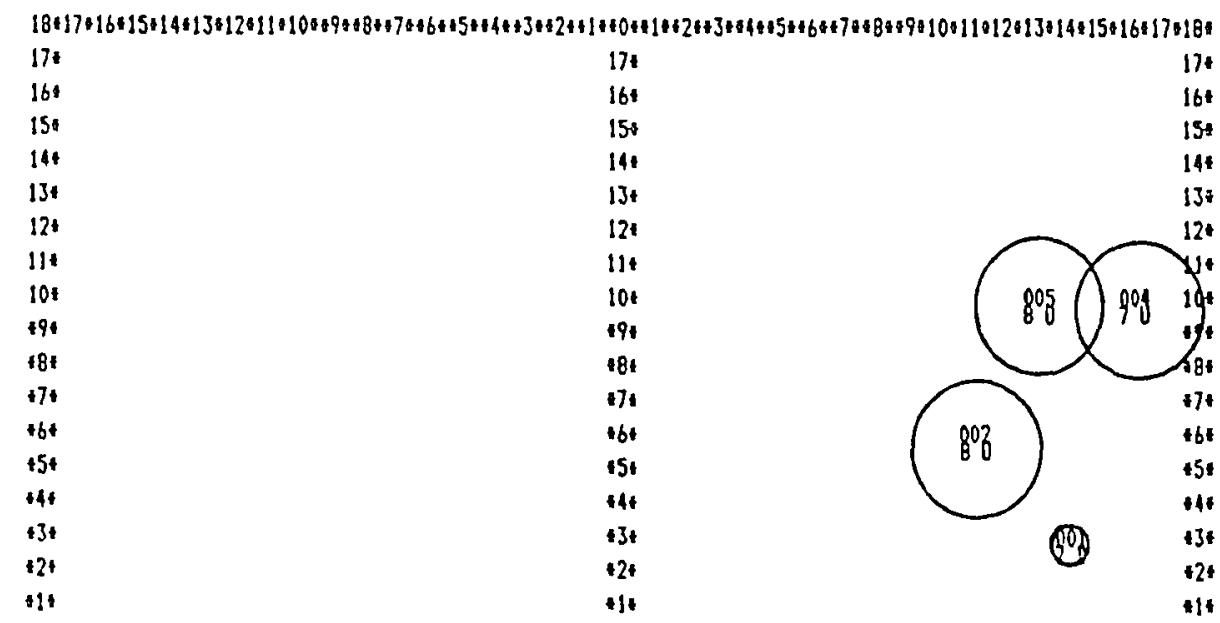

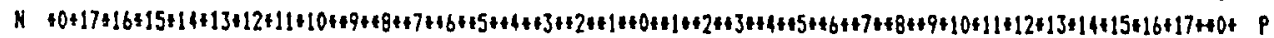
116 t1t 124.21

$13+24$

144

$+540154$

474090746

481

$19+498$

$104 \quad 104$

$11+2114$

124

$13+$

144

15

164

178

$18+17+16+15+14+13+12+11+10+19+48+47+16+45+14+3+3+2+1+1+0++1+2+13+4+4+5+164+7+48+49+10+11+12+13+14+15+16+17+18$ 4

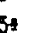
44 


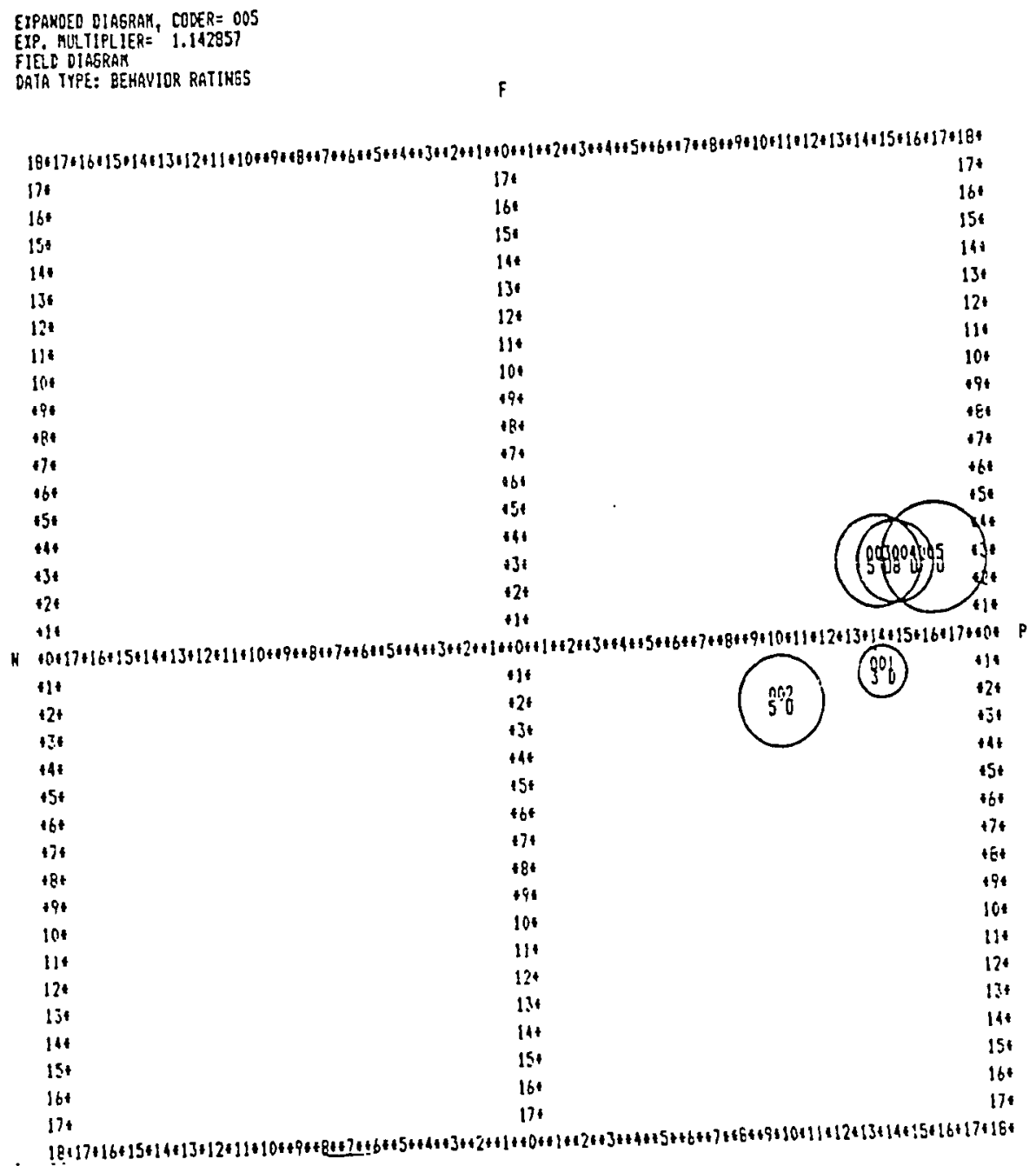


APPENDIX D

COURSE SYLLABUS 


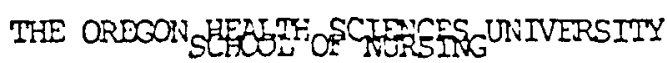

COMUINITY HEAITH CARE SYSIENS

DTPSE TIITE:

N452 Nursing Sceince VIII: MALAGEDET IN INUSING

QPEFPED:

winter, 1986

Friciay, 9:00 am - 12:00 noon

CPEDT:

Three (3) guarter hours

EDFPDUISSTIE:

Senior standing

SAgTIN:

Donna Schantz, R.N., M.S.

Pssociate Professo:

Community Health Care Systers

Mackenzie Hall, foom 3191

Phone: 225-7709

Office hours: Tuesday, 1:30 pm- 4:00 pm

COPRSE

DESCETERION:

An exploration of basic management and leaäership theories and concepts as a foundation for skill cevelopnent. These concepts can assist the nurse in efforts toward the achievement of incivicual and-orcanizational goals. The use of research and the problem-solving process is emphasized as a means of cetermining situationally appropriate actions.

CQTSE CoTforTVS:

By trie end of the course, students will be able to

1. trace the acirancerient of ranagement science anc its influence on nursing practice;

2. analyze elements of the internal and externel environment for their inwact on patient care;

3. collect database to support the assessment and diagnosis of a problem in the organizational context;

4. analyze the problen-solving process usec to efiect a sroup change;

5. conoust a group study to propose ano evaluate a nursing program as an exarple of professional accountability. 


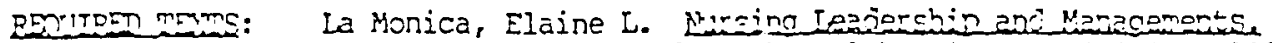
Monterey, Calif.: Wacssorth health Sciences Vivision, 1983.

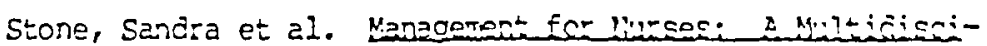

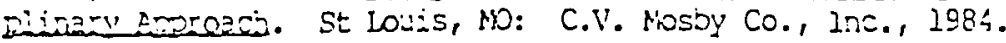

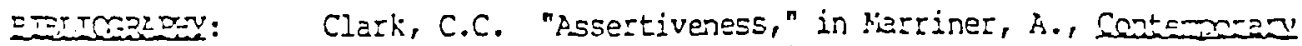

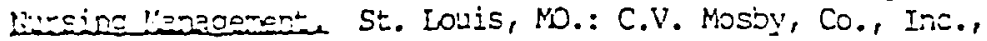
2982.

* Davis, Carolyne F. "The Federal Role in Cnanging Hesith Care

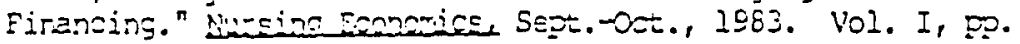
$98-205$.

Fine, puth. "hoplicktion of Lezcseship Tneory: Integrating

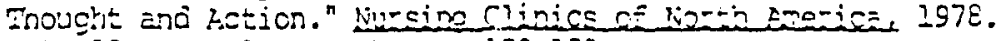
Vol. İ: lio. 1: Hezin, DP. 135-is3.

Fine, Pyth. "Crezting a Work Plzce for the Protessioral

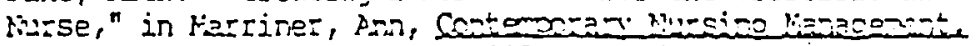
SE. Louis: C.V. Hosby Co., 1982, 叉2. $90-109$.

*Erosbe, Lozis. "The liarketing Frocess," in lazrinez, a.n.

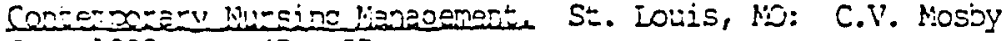
Co., 2962, ‥ $47-57$.

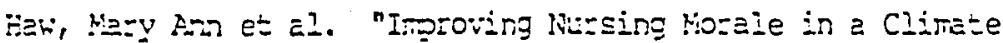

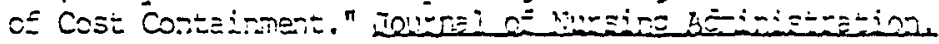
liov. 1984, F. $10-1 \equiv$.

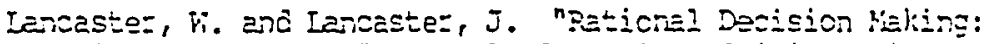

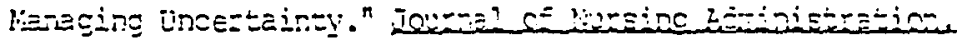
$S \equiv \pm$. I I 982, , $2.23-28$.

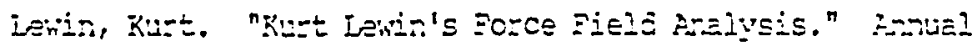

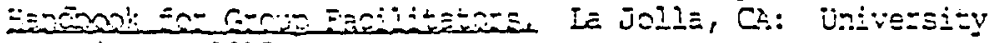

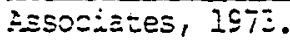

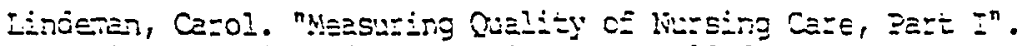

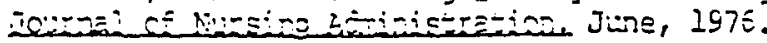

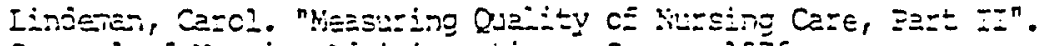
Iن

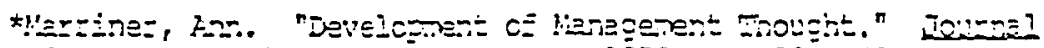

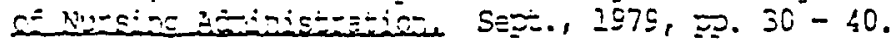

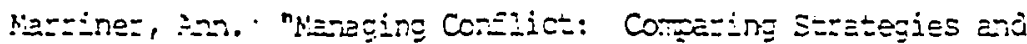

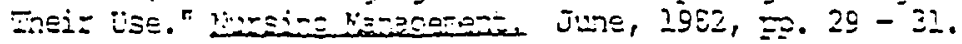

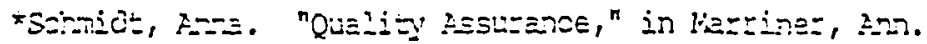

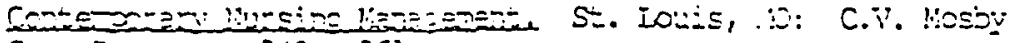

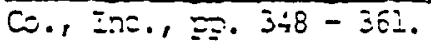

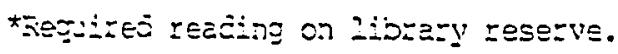




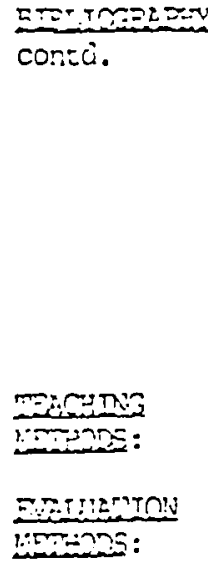

Spracley', B. "karacing Cnange Creatively." Tropterican

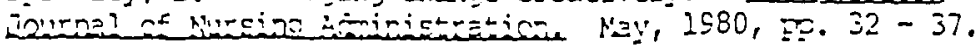

Veninga, Robert L. "Competcray: Unoerstanding the Causes ct

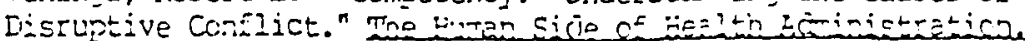
Englenood Clifss, lij: Frentice Hall, 2p. $196-2 i 9$.

Veninga, Robezt L. "Cometency': Lnoerstancing the Qiture of

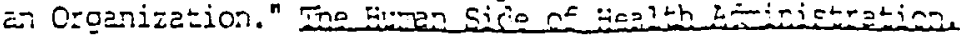
Englewood Cliffs, N: Prentice HEII, Dg. IE - 45.

Iazive, ciscussion, croup activities, kritten assigratent and exariazions.

Pagress in this course will be eveluated by kizitLen assigrents and exzinations which ixcrizorate concezts and theories learaes from assigned reacings, leztures, ciiscussicns ano class activities.

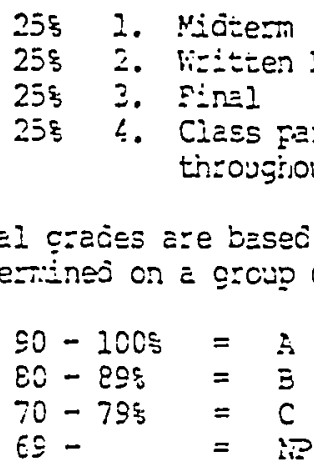

Wieek VI

hise? $\mathrm{X}$

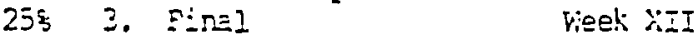
tincougious tine ter...

Sirel cazciss are besec on cunilative scozes and rill be ceteritines on a grou curve rougrily gouiveient zc: 
WEEK I Januarir 10

1. Define course objectives anả expectations

2. Discuss the relationsnip of rinagetent and nursing
1. Course overview anỏ expectations

2. Menagerient process
1. Videotape: "In Search of Excellence"

VIEEK II

Ianiagr 17

1. Define leaderership and ranagement.

2. Comare the nursing process with the manace-

_. ment process.

3. Compare and contrast the problem. solving method with the intuitive maje

1. Concepts of leac- 1. The one rinute liamader ership and ranagerent.

2. Iarionica, PP. 1-18 $\mathrm{Ch} . \mathrm{I}$ - "The Managerrent Solving Process and the Froblem Solving Method" of thougit.

4. Iöentify roles anò functions of the nurse nanager.

WEST III

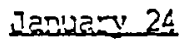

3. Stone et 21, po. $62-70$ "lianagenent and liodes of Trougint"

1. Explore the his- 1. tory of raiagetient science curing three eras: tracitional, hutian relations, contingency.

1. Theory for leacie:- 1. Larionica, DD. 21-34 ership ano ranage- Cnap II, "ineory fo: nert Nursing Leabe-ship and Nenagemen:"

2. Marriner, EP. 30-40 "Development of Menagement Fiougten (Library reserve)

2. Compare the three eass kit th nursing care delivery modeis

3. In class: Groug Eomation Expe:iential Buscise Pert I, Exe:cise in Lelionica. 
3. Discuss general systems theory as a model for nursing practice

4. Discuss the group dynamics laboratory and its relationship to leade: ship training

5. Letermine how motivation theory is a conceptual franework for leadership and mianagement

WEERK TV

Janueri 31

1. List the major corronents of leaōership benavior

2. Assess personal leacersinip style

3. Discuss trencis in leaciership theory

4. Combare anä contrast fiersey anả Blanciaró's Situizional Nodel with Fiedle:'s Contingency Model

5. Discuss leacisshi? resporsibili=ies essociatea kitis nursing menagerent positions.

6. Iciertify elenents of the decisionmaking process

7. Compere anò contrast resionel and nometive decision making.
1. Leacier responsibilities
1. Lakionica, FP. 41-99

a. "Diagnosing SeIf"

b. "Diagnosing tine Syster:"

c. "Ieader Behavio: Tneory"

c. "Dizgnosing the Task"

e. "usplying lieragenent Process and ProblenSolving lietinocs"

2. Store, et 2I, pp. 55-EI "The social liature of Leaöe:ship"

3. Lavicnica: Complete Exercise I: pp.10z-108 mon in Initiating enci Considezation sco:es for $s \in l$ ind ioeal leacier at begining of ciass.

4. Lalionica: kead the case stubies in Exercise 2 and 3 for class ciscussion. 
WEEK V

Eebruary 7

1. Define how comunication affects ranagerient style and effectiveness

2. Letemine how leacie:s companicate

3. Liagnose group problens

4. Analyze own interactions within a stall

5. List the major research activities in cominuication and siall group cynatics

\section{Communication} Group Dynamics

1. Lakionica: pp. 127-159

a. Communication process

b. Purposes of communication

c. Types of comminication

ò: How leacers comunicate

2. Stone et al, $20.81-117$

a. "Straight from the Snouloer: Leveling on the Job"

b. "Model for Better Comunication"

c. "So You Don't Like Your Boss"

c. "How to Diagnose. Group Prcilens"

e. "Cogs Ladier: A Nooel for Group Growtin"

f. "A Cognitive Iransactionel Approach to Comrtunication"

3. Ialionica: Self-Stud Assigninent: Exercise 1, .. 237

4. Ereia Bales: snitos In-Class experiential exercise on group òvranics

INER VI Eevivard 14

1. Synthesize 1. NIDTIR! EXAN lezrneà concepts of leaciersinip and

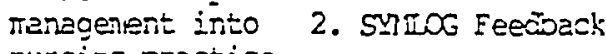
nursing practice

2. Discuss research fincings of srall group anel :sis

1. In-class, closeả book exam on assigned rezíings and classroom activities up to February 14

2. Feerisack session of Bales' SNIIOS exercise 
1. Icientify learning 1. Teaching neeòs anò teaching 2. Power priorities in a

3. Assertiveness rianagenent

situation

2. Determine learning principles ano instructional monies for teaching strategies

3. State the types, sources and use of power in professional nursing

4. Define the comonents anà apsropriate use assertiveness in rursing practice

5. Analyze self behavior in reletionship to powe: anci assertiveness sizuetions

\section{Managenent Experiential Exercise: in-class, STEII grouns
5. FeEcback on grcip assertivenss iiven

VEER VIII

Eekruen: 28

1. Define the con- 1. Crange cept of elanned 2. Conflics criange as an essertial strategy resclution

2. Iojen:ify the aziving and accozcing to Lewin's theory in a case examie
1. Lavionica: po. 160-194

a. Learning neeàs and teaching strategies

b. Types and use of porier

c. Assertive behavior in rursing

2. Stone et 21, Pp. 9-23 and $\mathrm{EP} .7 \leq-80$

a. "Nurse Power for the 80's

b. "The Powerful homan"

c. "Power Principles"

d. "issertiveness Issues for Nursing Aäinistrators anỏ Nianagers"

3. Lahionica: Exercise 14, pg. 217-4 $\bar{B}=i n g$ comesesion r-ap score to class icr recorcing and araly: $=$ is Exercise 16, FE. 2दे.285. Both of these exercises are selfstucy assigrnents. Bring Copassion Trap srore to class io: recorcing and analysis

1. Lakionica: po. 196-222

a. Force Eielc Analysis

b. Leveis of change and the change process

c. Strategies of change

i. Conzlict resolution

2. Store $\epsilon t$ 2l, Po $135-176$ and $243-252$

a. "Types anō Sources 
CEIECTITES

4. Use current manager.ent technology in communicating the change process

5. List the major types and causes of conflict and state at least three ways of resolving conflict

6. Iòentify and aralyze change in an organizational setting and framenork
CoNTreT IEARPITS ANTNTTTES

e. "Measuring Prcouctivity Through Patient Classification ${ }^{n}$

3. Learn use of a personal computer (PC) to prepare peper on "Change: Concepts into Nursing Fractice" Due in tho weeks at besinning of class (rik.Y.)

4. Use a "live" menagement problem in your clirical area (at school or at work) which is being, or has been sclvec. Refer to Obj. 6 for purpose of paper.

TEEK IX

Miscin 7

1. Defire the current major economic factors affecting healti care

2. Compare and contrast the internal anó external economic environtent

3. Iist at least 5 rarketing strategies used in the health inciustizy

4. Desine the buogeting process

5. Differentiate between ZEB and increr.erital buōgeting

6. List tire ranagener: technigues useful to nurse :- zagers
1. Economic Factors

2. internal à exterral exviromment b. rarketing

2. Buoggeting

a. tine

b. monsy

c. resources
1. "Change" paper turneō in beninning of class. Written on XC stationery double-spaceo, using ADA fomat. No mo:e than ten pages in text. Use of figures and tables encouraged.

2. Larionice: פg 223-235

a. Frizlosopioy of titie

b. Time trenagernent process and techniques

3. Froebe: "The Niarketing Process" (0.: I Iserve in Iij:ary)

4. Stone et al, Do 219-239

a. "Wriat is the Executive's Role in Buageting for

b. "Some thougits on the تutien Bice of Bucineting"

c. "Living vitin cost Contairitent"

6. "Zero Base Sucgeting for Nursing Services" 
COUPSE

OUTLRE:
CaTrunts $\cos 2 \sin$

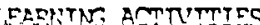

5. Davis: The Federal Role in Cuanging Health Care Finanaing" (On reserve in library)

6. IUNS Assignment handout for firal examination project

(see directions below)

Final Examination Project

Forn your original group and follow the directions on the hanciout. At the firal examination, one representative frot: each group will hand in two (2) copies to ne of your proposal and then give an oral presentation and defense not to exceed 15 minutes. Your groun will be competing for scarce resources, an A gracie and also a surprise prize for the winning group.

WEEK $X$

$$
\text { Berch } 14
$$

1. Dezermine eveluation and acccintability restonsibilities

of the nurse renager

2. Detine the three basic eveluation criteria useci in assessing the performance of hceltin care

3. Irentify the elements of clinical evaluation in beneviozal objectives

4. Discuss the $\pi e^{\circ}$ : corponerts of a personnel selection process and how it relates to the inciviciual eviluation process.

\section{Evaluation of Fatient Care: Organization Depertment Inäivicual}



\author{
1. Stone et 21, pp. 193-216 \\ a. "An Integrated \\ Approach To \\ Performence Eveluetion \\ in the Health care \\ Field" \\ b. "Iroroving Clinical \\ Eveluation" \\ c. "Is the Fosition \\ Description Obsolete \\ c.. "A Moóel fo: Systerztic \\ Selection Interviewing
}

2. Scinnidt: "Quality

Assurance"

(On reserve in the Iibrayl)

$h E X X I$

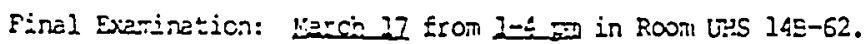


APPENDIX E

SATISFACTION QUESTIONNAIRE 
THE OREGON HEALTH SCIENCES UNIVERSITY

SCHOOL OF NURSING

COMMUNITY HEALTH CARE SYSTEMS

Nursing 452

Rate the small group experience on each statement belok, with 4 representing your greatest agreement and 1 representing your least agreement with the statement. Circie the number that best approximates your rating of the behavior exhibited by the group.

1. Group members understand the problem $\begin{array}{lll}\text { Disagree } & \text { Agree } \\ 1 & 2 & 3\end{array}$ under discussion.

2. Group members stayed on the topic.

3. Group members avoided premature closure on discussion.

4. Group members contributed equaliy to the discussion.

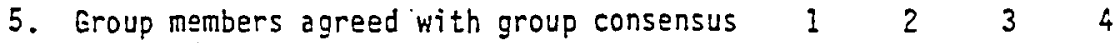
and/or decision.

6. Group members discussed their opinions

7. Group members were able to resolve confilict or discontent.

8. Group members displayed commitment to the group tasks.

9. Eroup members indicated satisfaztion with $1 \quad 2 \quad 3 \quad 4 \quad 4$ the group process.

10. Group members indicated satistaction with $1 \quad 2 \quad 344$ the group outcomes.

11. The feedback field diagrams were helpiul $1122 \quad 3 \quad 4$ to $\mathrm{me}$ in understanding my behavior in groups. 
APPENDIX F

RAW SCORES 
001001 2792011 2221110012111100000

00100212110002222100012222100010

00100322210101222200012222200000

001 004 11100001111000012222100111

00100522111001112100011111100000

602 o01 2!n2121:?232100:211100000

0. 00 ? $32110100=2-21002122110102$

10200322110101222210011221101100

0,12004400011010222200111101001000

002 cL5 !!101210 $232210011211010 ! 60$

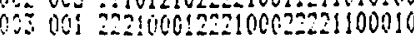

000 01000001 $=721000122721000$

100 005 $1221040 ! 3222000 ! 3222100010$

100 1004 020000012232000 2222000021

(v. 005 02110001 222100(12222100010

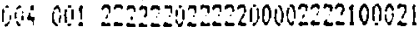

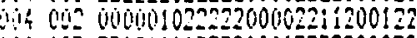

104003 nn1211012722100:2532000022

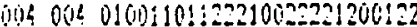

bitl 005 221112!9272220012122210021

nis tot 22106012: 2100011010000000

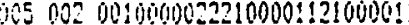

105 00j 19210101272:0001?:20000010

15 (0) 00060000!22100001?!2000!11

$00500511210001322200011110010(0) 10$

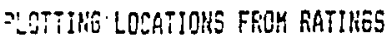

FIE KAALE: Y:STMJ.DAT

DIEXPAMEED ECORES. RRTER = 001

$\begin{array}{cccccc} & 001 & 002 & 003 & 004 & 005 \\ 15-1 & 10 & 1 & 3 & -5 & 5 \\ -1 & 0 & 15 & 15 & 11 & 5 \\ -2 & 2 & 2 & 7 & 0 & 5\end{array}$

EXRHAED EOSRES. RGTE: 001

EY. HUTTPLIEFE

$\begin{array}{cccccc} & 00 ! & 002 & 0 & 004 & 0.5 \\ 1-6 & 10 & 1 & 3 & -5 & 5 \\ 5-h 1 & 10.2 & 17 & 14.7 & 12.4 & 9 \\ 5-5 & 2.2 & 2.2 & 7.4 & 0 & 5.6\end{array}$

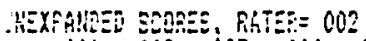

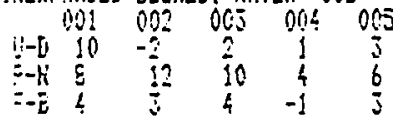

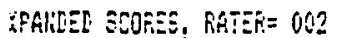

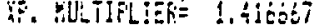

$\begin{array}{cccccc} & 101 & 00.2 & 003 & 004 & 005 \\ =-5 & 10 & -2 & 2 & 1 & 5 \\ \vdots-k & 11.3 & 17 & 14.1 & 5.6 & 8.5 \\ =-E & 5.6 & 4.2 & 3.6 & -1.5 & 4.2\end{array}$

EXPAYNED SOOFES, RATER= ONT

$\begin{array}{cccccc} & 001 & 002 & 003 & 004 & 005 \\ -5 & \vdots & -5 & 1 & -4 & -1 \\ -4 & 16 & 15 & \vdots 0 & 16 & 15 \\ -2 & 2 & 1 & 5 & 0 & 5\end{array}$

$$
\text { WIELFARIEU SCOAEE RATERT: } 004
$$

$\begin{array}{cccccc} & 001 & 002 & 00 j & 004 & 005 \\ U-D & 6 & -6 & 0 & -7 & 3 \\ F-H 1 & 13 & 10 & 12 & 9 & 7 \\ F-B & 7 & -1 & 7 & 2 & 5\end{array}$

EXPAMIED SCGRES, RGIER = 004

EXF. RUIIIFL!ES: 1.3076 ?

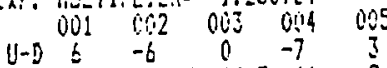

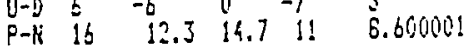

$=-8 \quad e .600001$

$\begin{array}{rrr}-1.3 & 8.600001 \\ 2.4 & 6.1\end{array}$

UHEXFAMEED SCDR:S, RATEA $=065$

$\begin{array}{cccccc}001 & 002 & 10 j & 004 & 005 \\ 4-0 & 8 & -7 & 5 & -i & 4 \\ F-N & 9 & 12 & 16 & 10 & 12 \\ F-2 & -1 & 3 & 1 & 2 & 3\end{array}$

EXFANDED SCDEES, RATER $=0.05$

EXF. MULTIPLIEK $=1$

$\begin{array}{cccccc}5.1 & 002 & 005 & 004 & 005 \\ U-0 & 6 & -3 & 5 & -7 & 4 \\ E-k & 9 & 12 & 16 & 10 & 12 \\ F-E-1 & 3 & 1 & 2 & 5\end{array}$

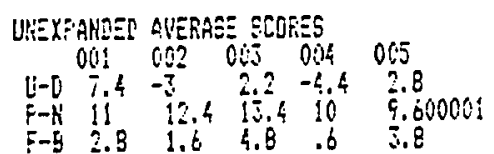

EXPHISE PVERTEE SCORE

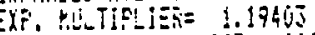

$$
\begin{aligned}
& \text { (1i1 0.2 } 000 \text { 60\% } 0.5 \\
& \begin{array}{cccccc}
1+2 & 7.4 & -3 & 2.2 & -4.4 & 2.8 \\
7-h & \vdots .1 & 14.8 & 16 & 11.9 & 1.4 .4
\end{array} \\
& \text { F-B } \begin{array}{llllll}
3.3 & 1.9 & 5.7 & .9 & 4.5
\end{array}
\end{aligned}
$$

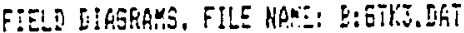

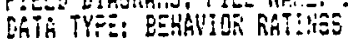

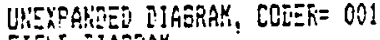

DGTA TYFE: BEHAYOA RGTINES 
APPENDIX G

PFS FILE 


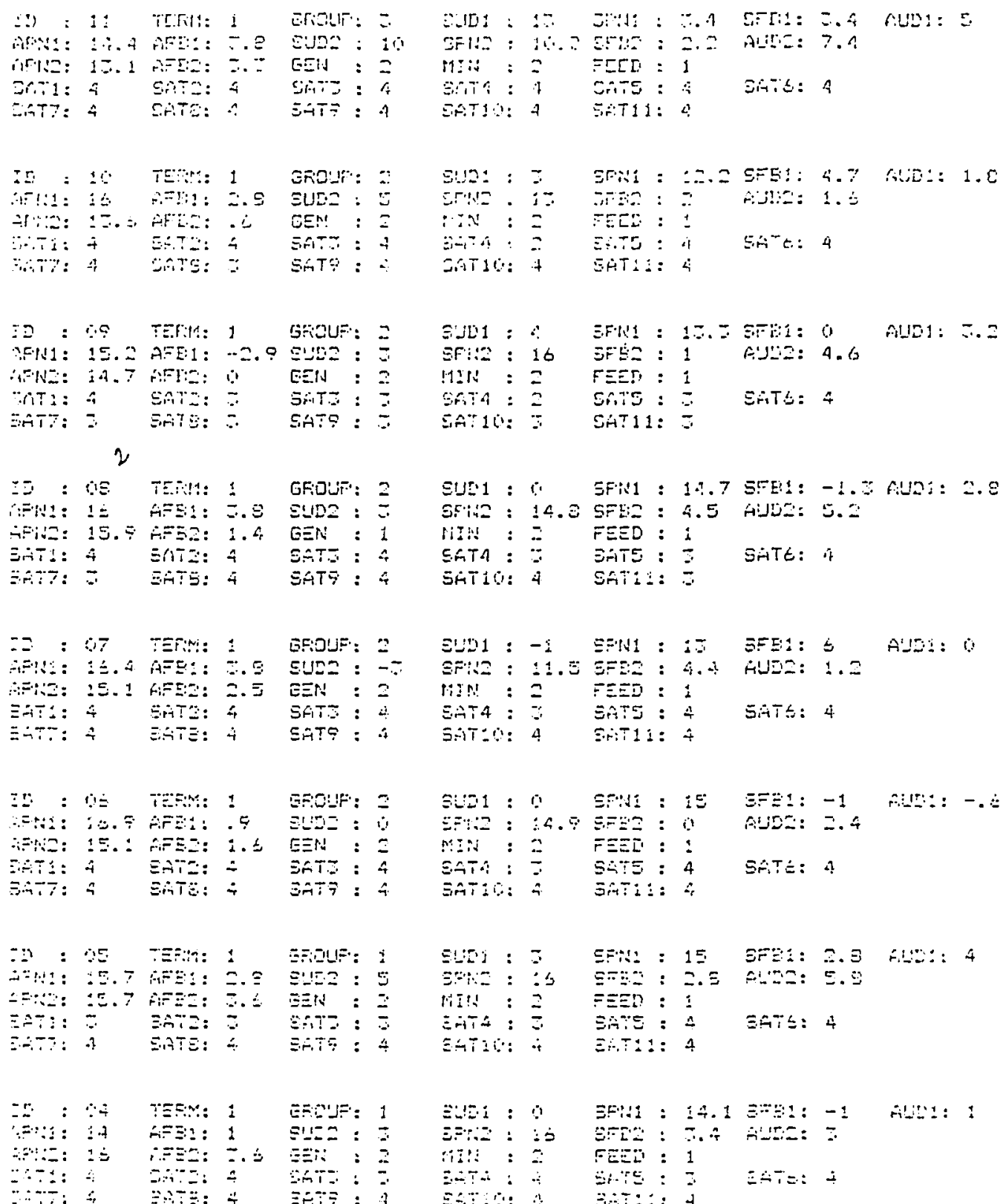


INSERTED FOR PAGINATION

PURPOSES ONLY 


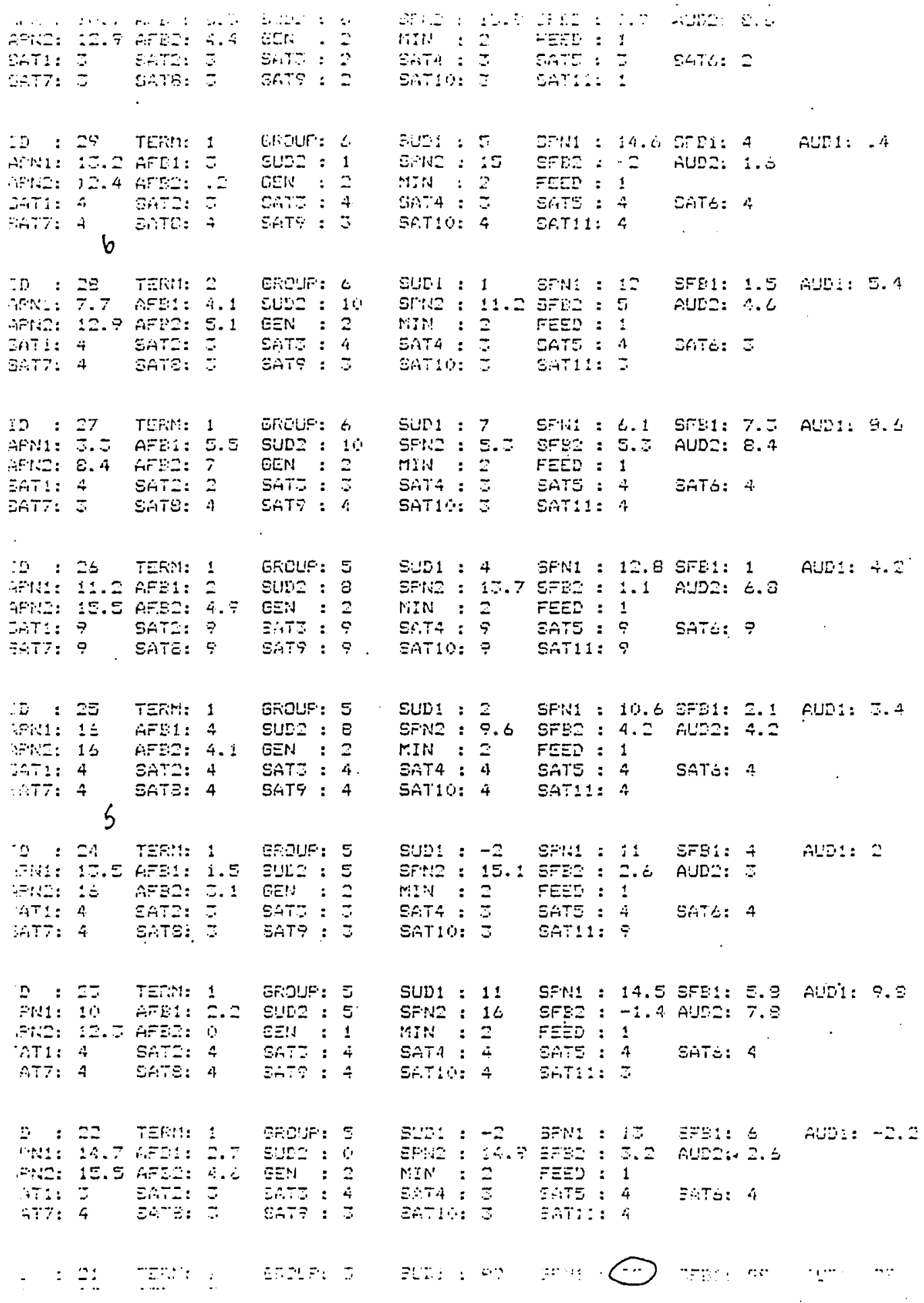




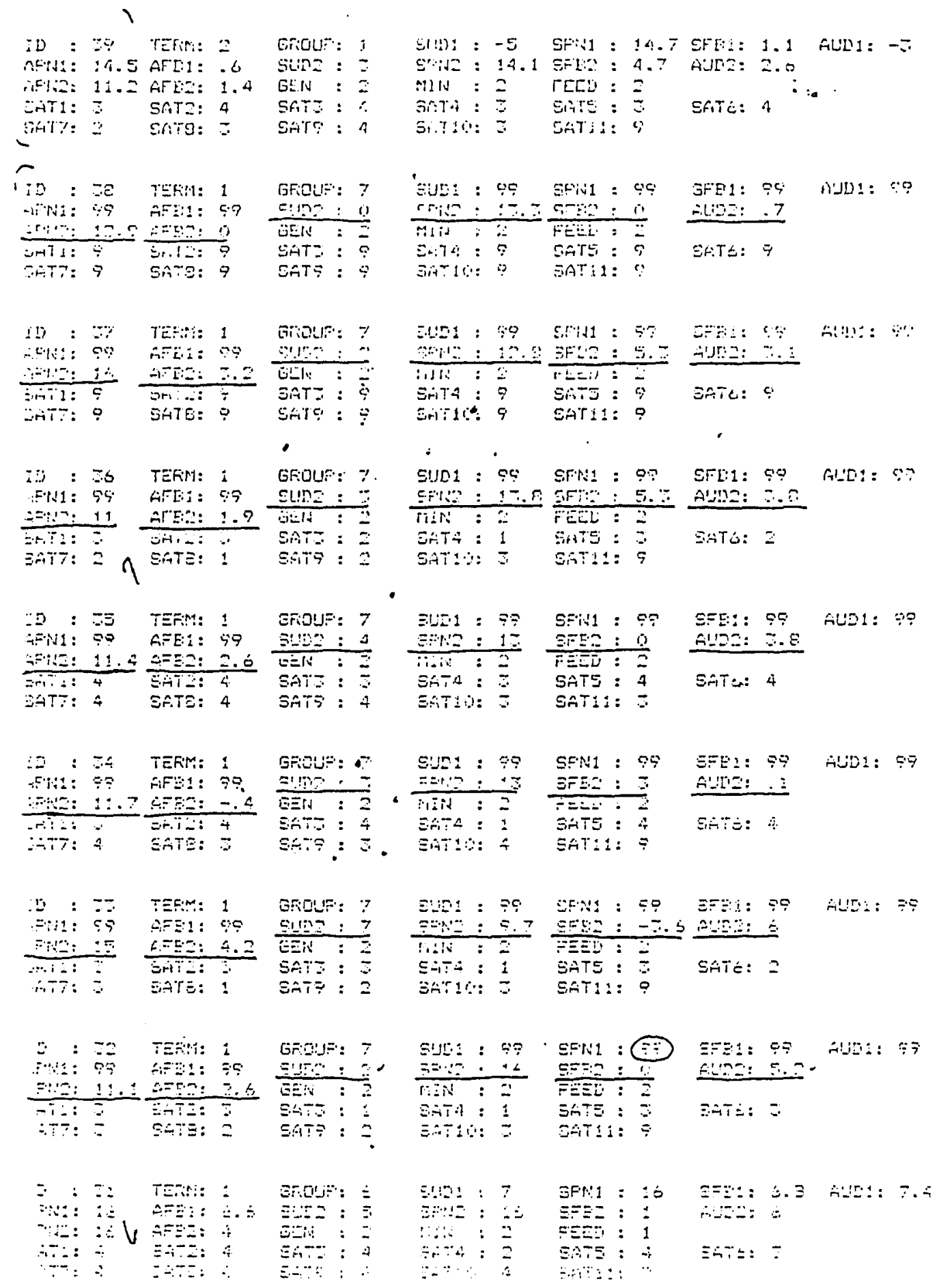




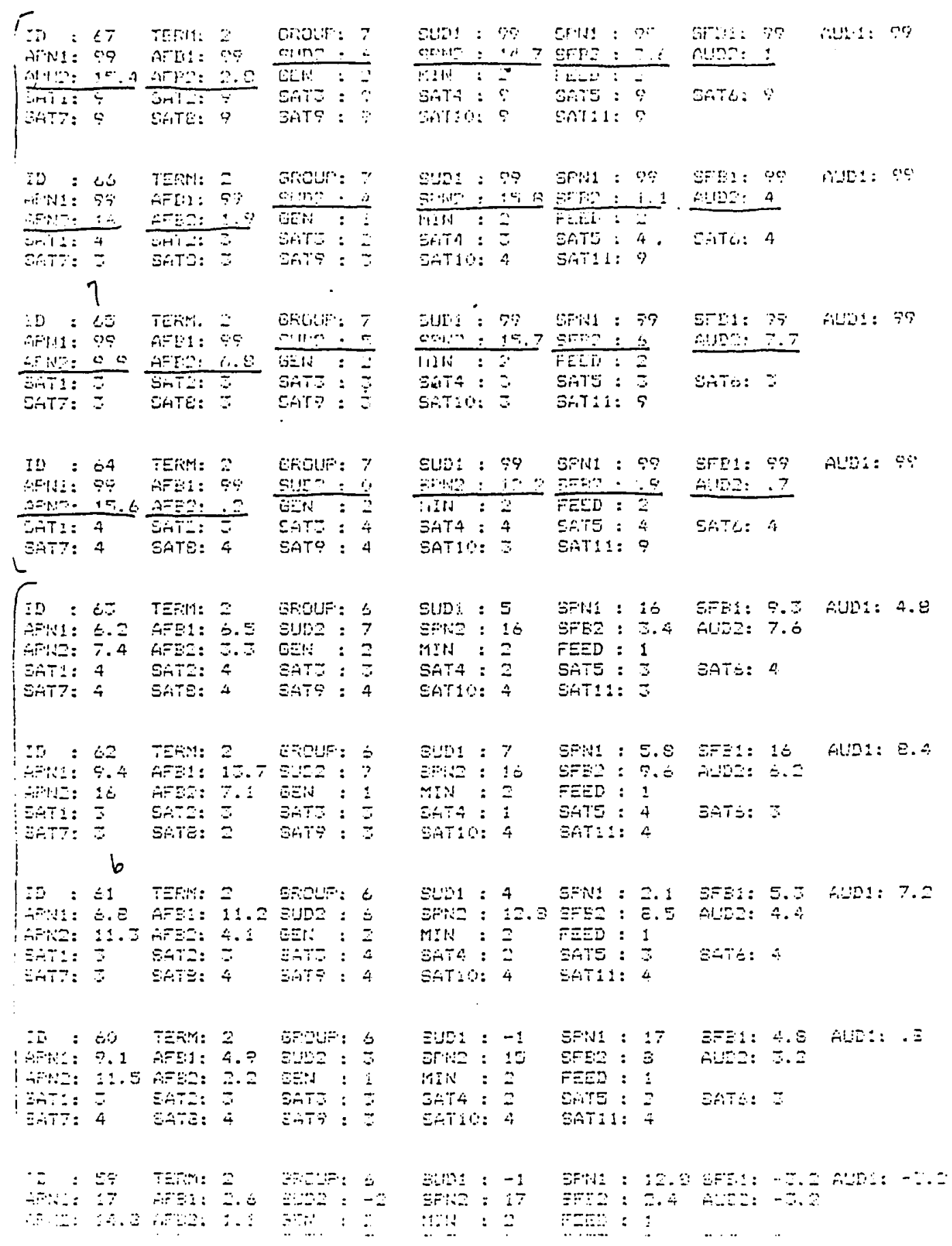


APPENDIX $\mathrm{H}$

VARIABLE LIST 
Var File: SC0723

Gr File: SG0725

Variable List

\begin{tabular}{|c|c|c|}
\hline 1. & ID & $1-67$ \\
\hline 2. & Term & 1 or 2 \\
\hline 3. & Group & $1-7$ \\
\hline 4. & $\begin{array}{l}\text { SUDl } \\
\text { SPNI } \\
\text { SFBl }\end{array}$ & $\begin{array}{l}\text { Self up-down score at time } 1 \\
\text { Self positive-negative score at time } 1 \\
\text { Self forward-backward score at time } 1\end{array}$ \\
\hline 5. & $\begin{array}{l}\text { AUD1 } \\
\text { APN1 } \\
\text { AFB1 }\end{array}$ & $\begin{array}{l}\text { Average up-down score at time } 1 \\
\text { Aveage positive-negative score at time } 1 \\
\text { Average forward-backward score at time } 1\end{array}$ \\
\hline 6. & $\begin{array}{l}\text { SUD2 } \\
\text { SPN2 } \\
\text { SFB2 }\end{array}$ & $\begin{array}{l}\text { Average up-down score at time } 2 \\
\text { Aveage positive-negative score at time } 2 \\
\text { Average forward-backward score at tine } 2\end{array}$ \\
\hline 7. & $\begin{array}{l}\text { AUD2 } \\
\text { APN2 } \\
\text { AFB2 }\end{array}$ & $\begin{array}{l}\text { Average up-down score at time } 2 \\
\text { Aveage positive-negative score at time } 2 \\
\text { Average forward-backward score at tine } 2\end{array}$ \\
\hline 8. & Gender & Male (2) or Female (1) \\
\hline 9. & Minority & Ethnic (1) Caucasion (2) \\
\hline 10 & Feed & Feedback (1) No-feedback (2) Group $7=3$ \\
\hline 11. & $\mathrm{~N}$ group & Group 7 term 1 and 2 "no show" groups \\
\hline 12. & SATl...11 & $\begin{array}{l}\text { All eleven satisfaction items rated from } 1-4 \\
\# I-7 \text { for each term }\end{array}$ \\
\hline
\end{tabular}

13. Group $1-3$ Group 1 = feedback Group $2=$ no-feedback Group $3=$ Control

14. SUD12

SPN22

SFB12

Difference between time 1 and 2 self scores on the three dimensions. Absolute value. 
Variable List contã.

15. SAUDI

SAPNI

SAFBI

SAUD2

SAPN2

SAFB2

absolute value of the self score to the average score without the self in the average at time 1 and time 2

16. STOT12

All three dimensions. Difference between total Invement of the self between time 1 and time 2 . SATOT1

SATOT2

17. DSUD12

DSPN12

SFB12

Conbined dimensions - self to aveage - all 3 dimensions of both. Movement of self cells to average cells of the group at time 1 and 2 . absolute value.

Directed, not absolute scores, vlaues of + or for self from time 2 to time 1 (time 2 minus time 1). (Computer won't 21). Separated for each dimension. Not conbined.

18. DSAUD1 DSAPN1

DSAFBI

DSAUD2

DSAPN2

DSAFB2

Again, directed values not absolute scores with + or - scores. Self to adjusted average at time 1 and 2.

to

19. $\mathrm{AAUD}(12)$

AAPN (12)

AAFB(12)

Absolute scores. Average to average from time 1 to time 2 plain average.

to

20. DAAUD (12)

DAAPN (12)

DAAFB (12)

Directed average, positive or negative values, from time 1 to time 2

Plain average.

GRPTRM

FGPSAT9

GRPSATI0

Group identification

Group satisfaction on items 9 and 10

GAUD1

GAPNl

GAFB1

GAUD2

GAPN2

GAFB2

Group average at each dimension at time 1 and then

time 2

Plain average

GFEED

Feedback 
APPENDIX I

SATISFACTION FREQUENCIES 


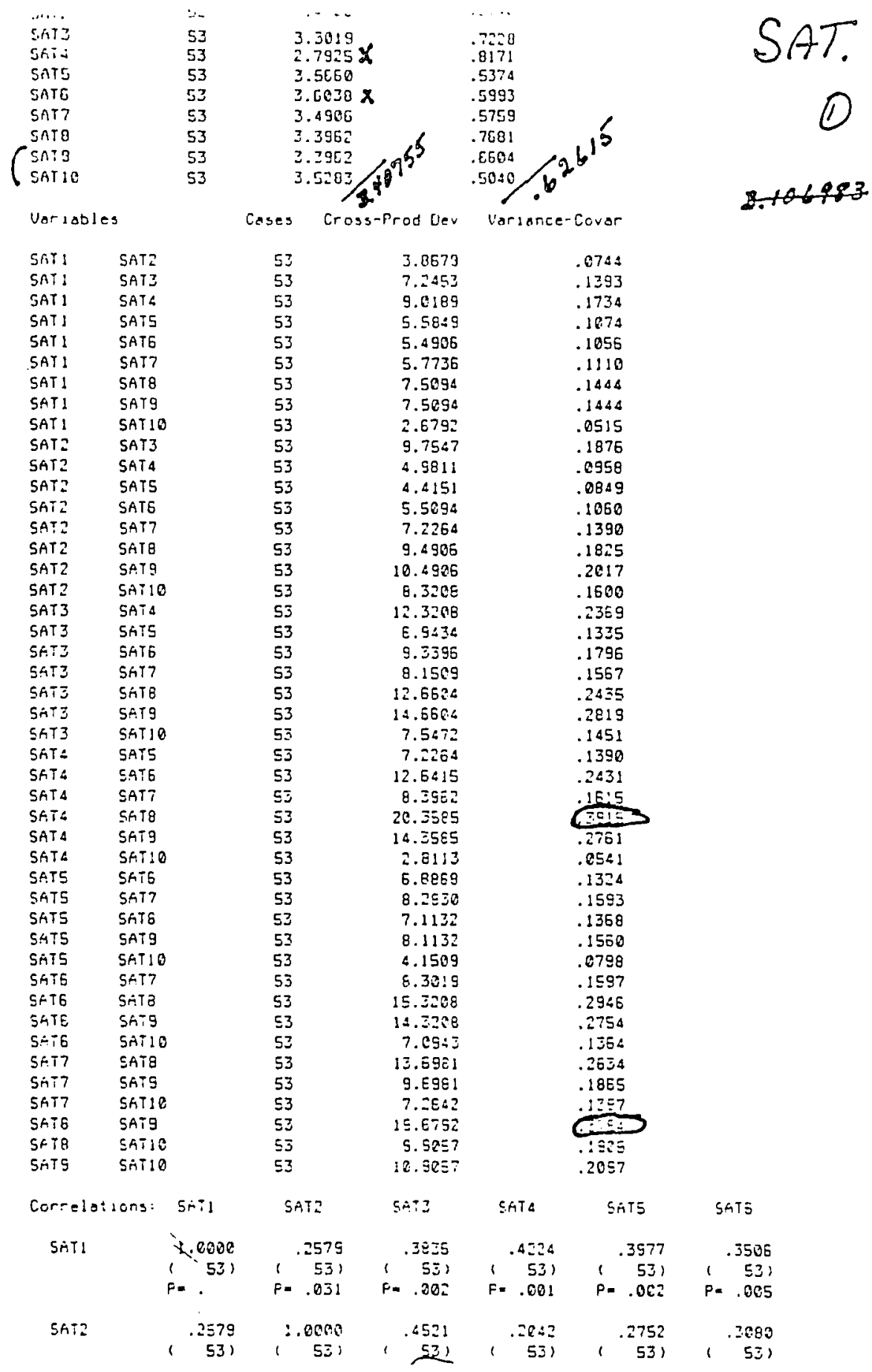




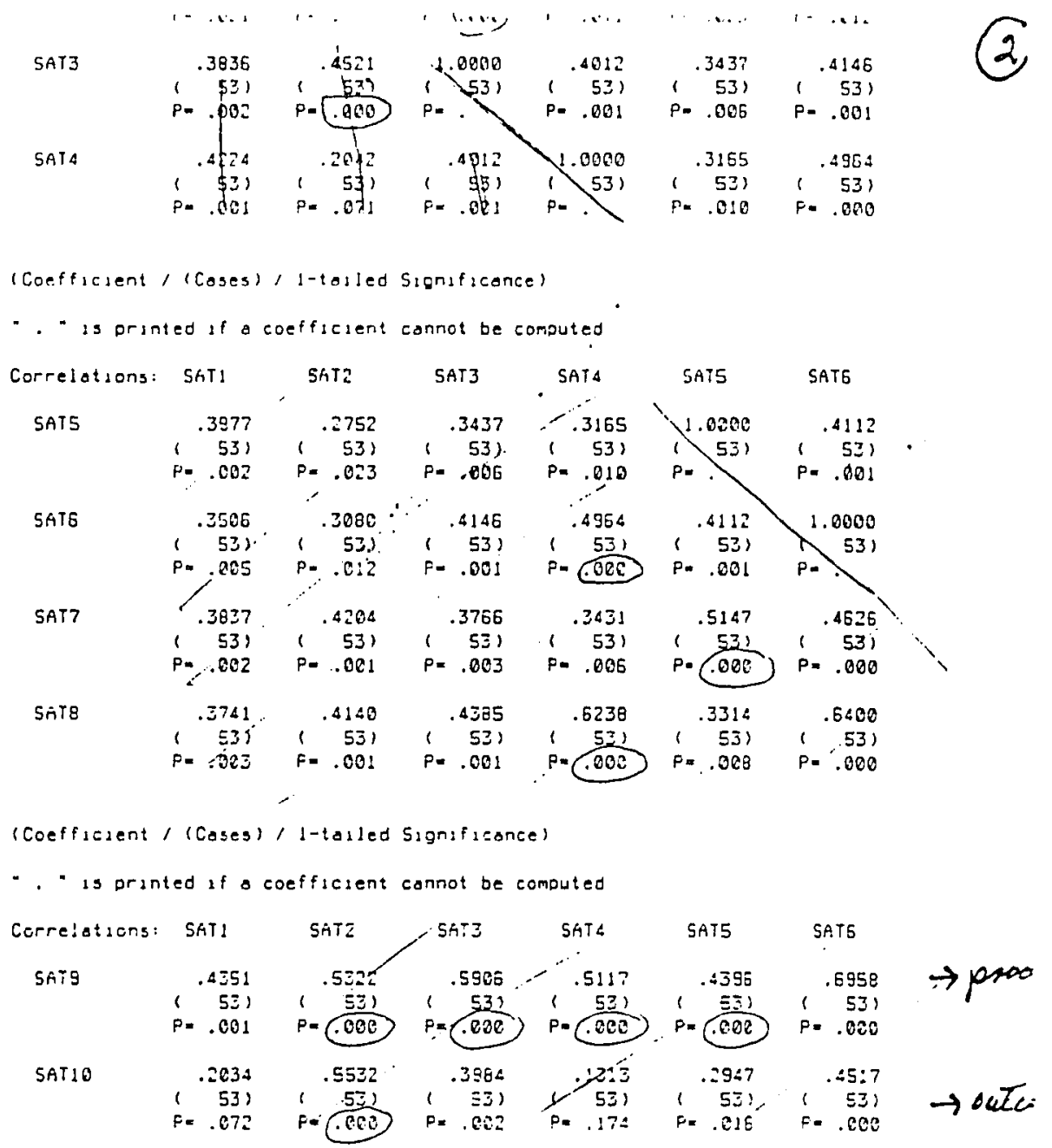

(Coefficient / (Coses) / 1-ialled Signifizarice)

- Is erinted if a coefficiens cannot be computed

\begin{tabular}{|c|c|c|c|c|}
\hline Correlations: & SAT7 & SAT 8 & SATS & SATIO \\
\hline \multirow[t]{3}{*}{ SATI } & .3837 & .3751 & 4351 & .2034 \\
\hline & 531 & 【う & (ป) & 521 \\
\hline & $P=.822$ & $P=. \operatorname{coz}$ & $F=.001$ & $P=.072$ \\
\hline \multirow[t]{3}{*}{ SA:Z } & .4234 & .2140 & .5222 & .5532 \\
\hline & ( 53$)$ & $(53)$ & 531 & 53) \\
\hline & $F=.001$ & $P=.001$ & $F=000$ & $F=.000$ \\
\hline \multirow[t]{3}{*}{ SAT3 } & $.37 E 6$ & .4385 & $.590 E$ & .3984 \\
\hline & $(53)$ & ( 53) & 1,521 & $(53)$ \\
\hline & $P=.6$ & $F=.681$ & & $F=.002$ \\
\hline
\end{tabular}




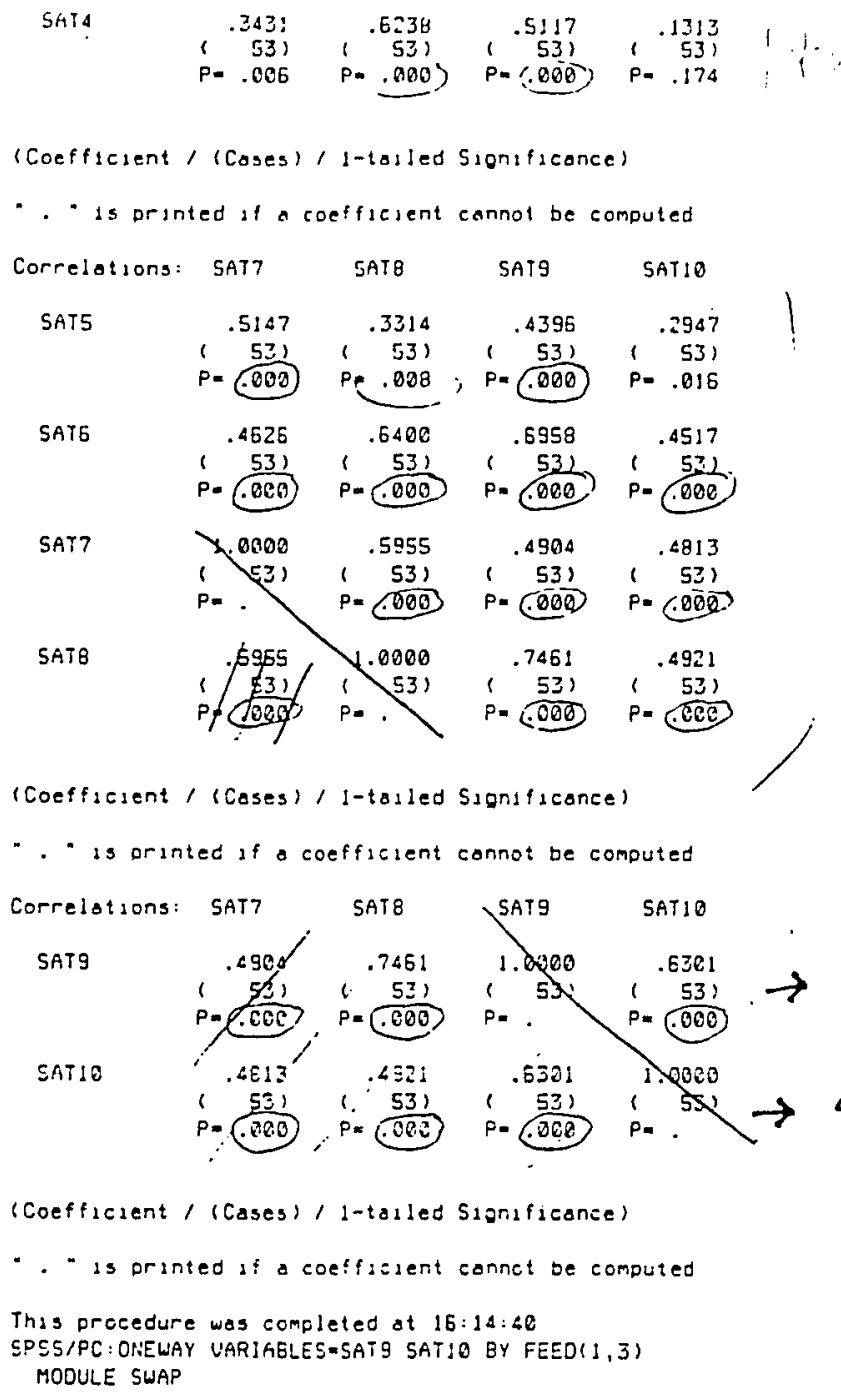

(Coeffleient / (Coses) , I-talled Sionificance)

- Is printed if a coeffiesent cannol be computed

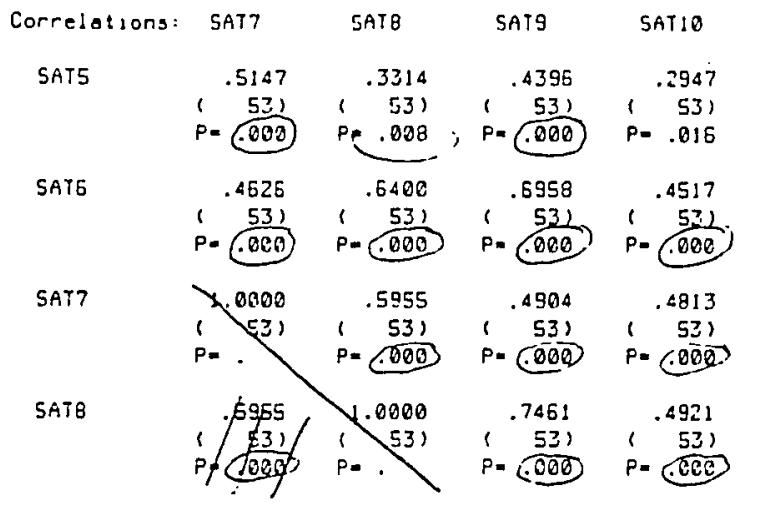

(Coefficient / (Cases) / 1-talled Significance)

". Is orinted if a coefficient cannot be computed

(Coefflcient / (Cases)/ 1-talled Sigrificance)

- " is printed if a coefficient cannet de computed

This procedure was completed at $16: 14: 40$

SPSS/PC: ONEWAY VARIAELESESATI SATIO BY FEED $(1,3)$

MODULE SWAP 
APPENDIX J

LEADER MOVEMENT 
Forward Positive Ouad

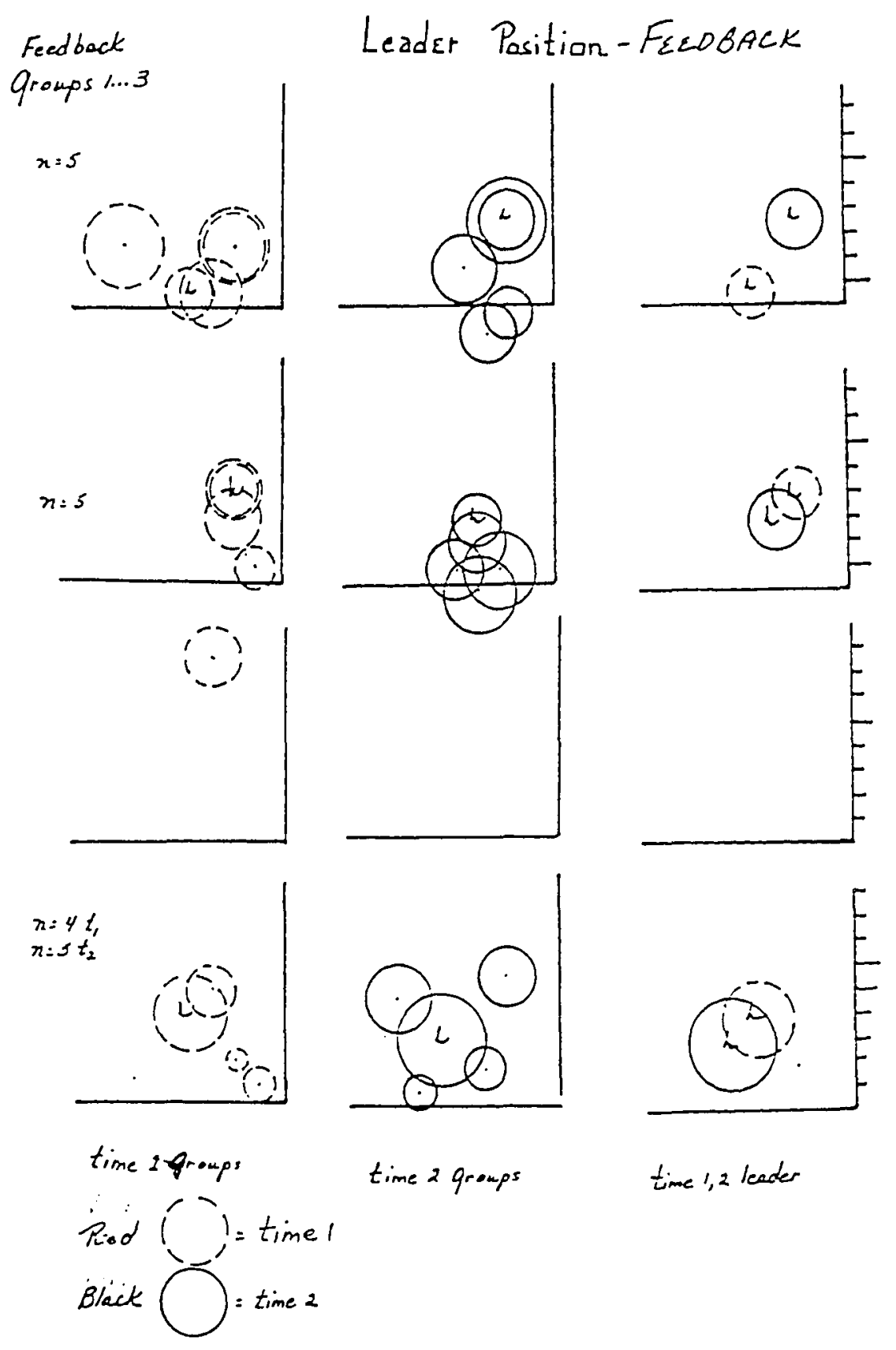


Forward Positive Quad

Feedback groups 4...6

Leader Position - FeEo BACK
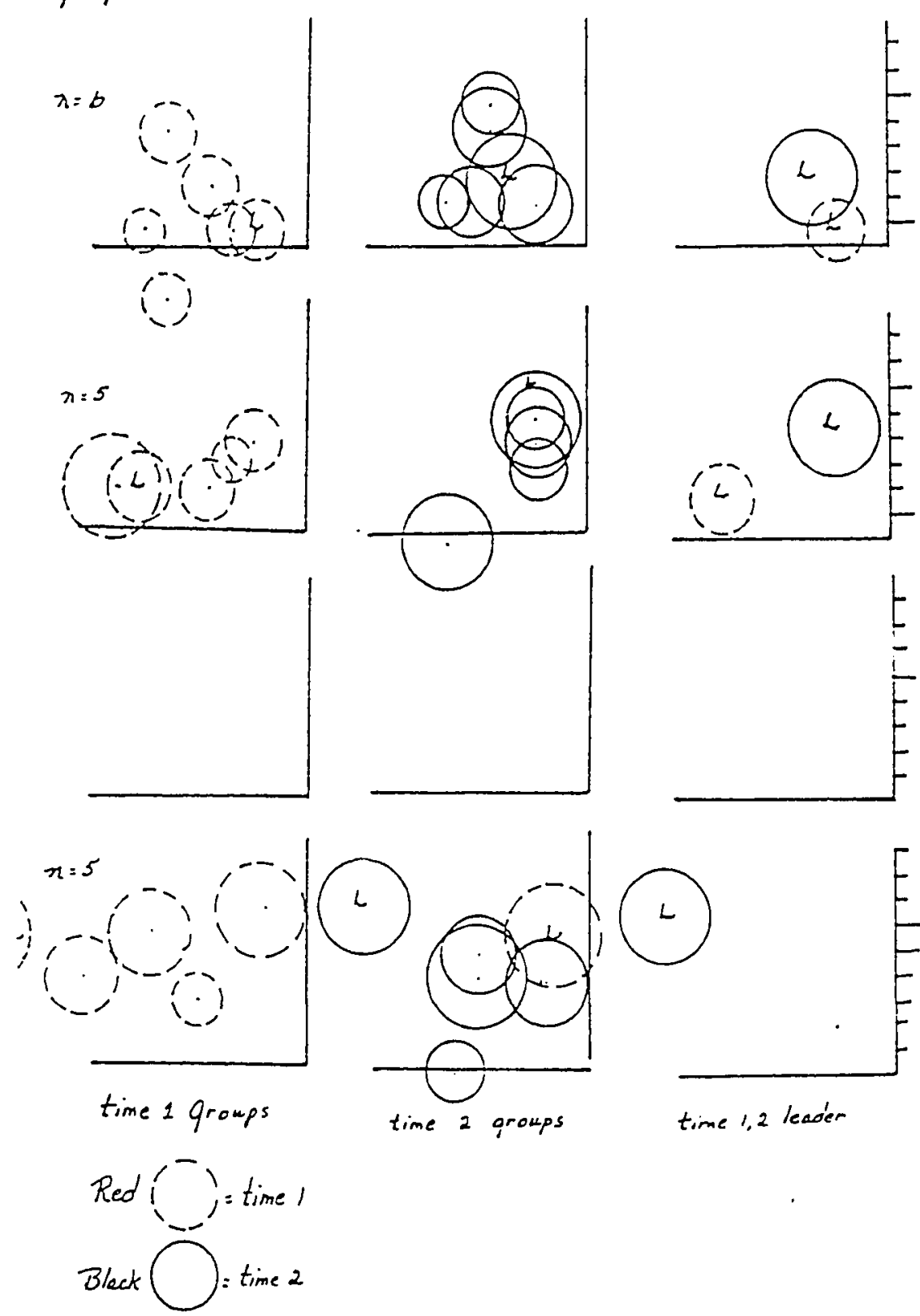


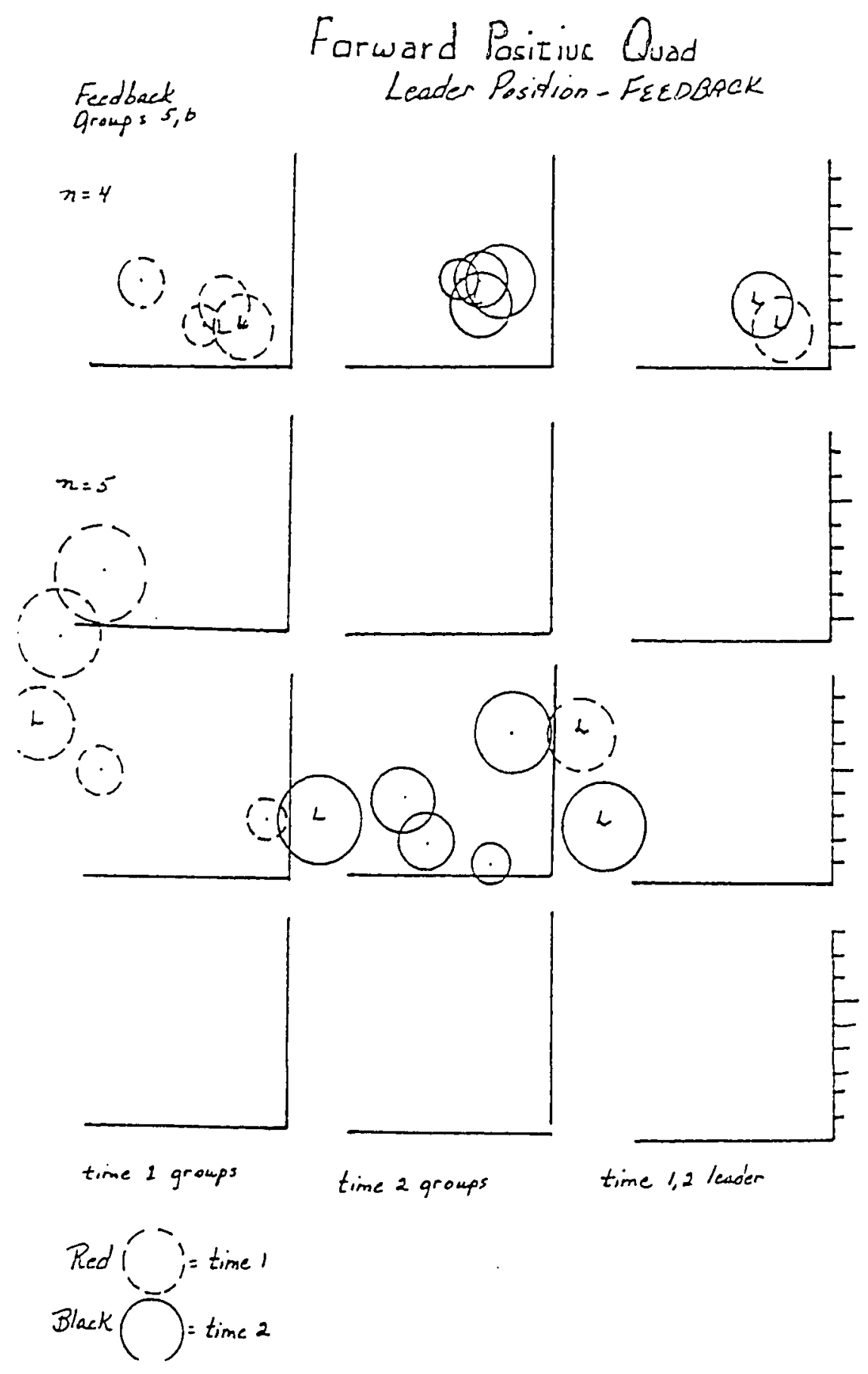


Forward-Pasitius Quad

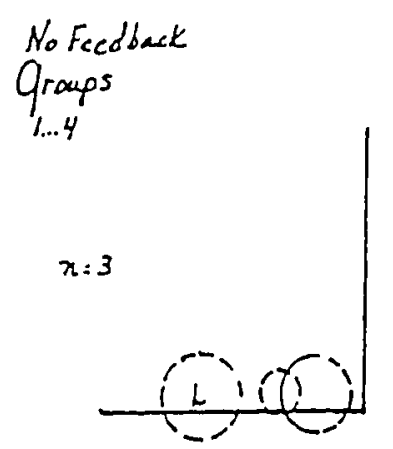

Leader Position-No Feedbact

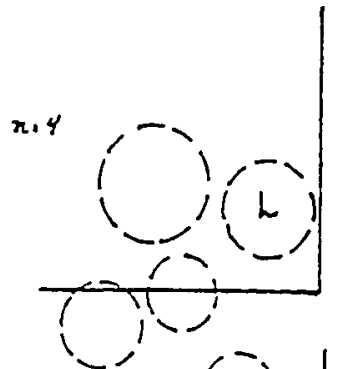

(立)

$x+4$
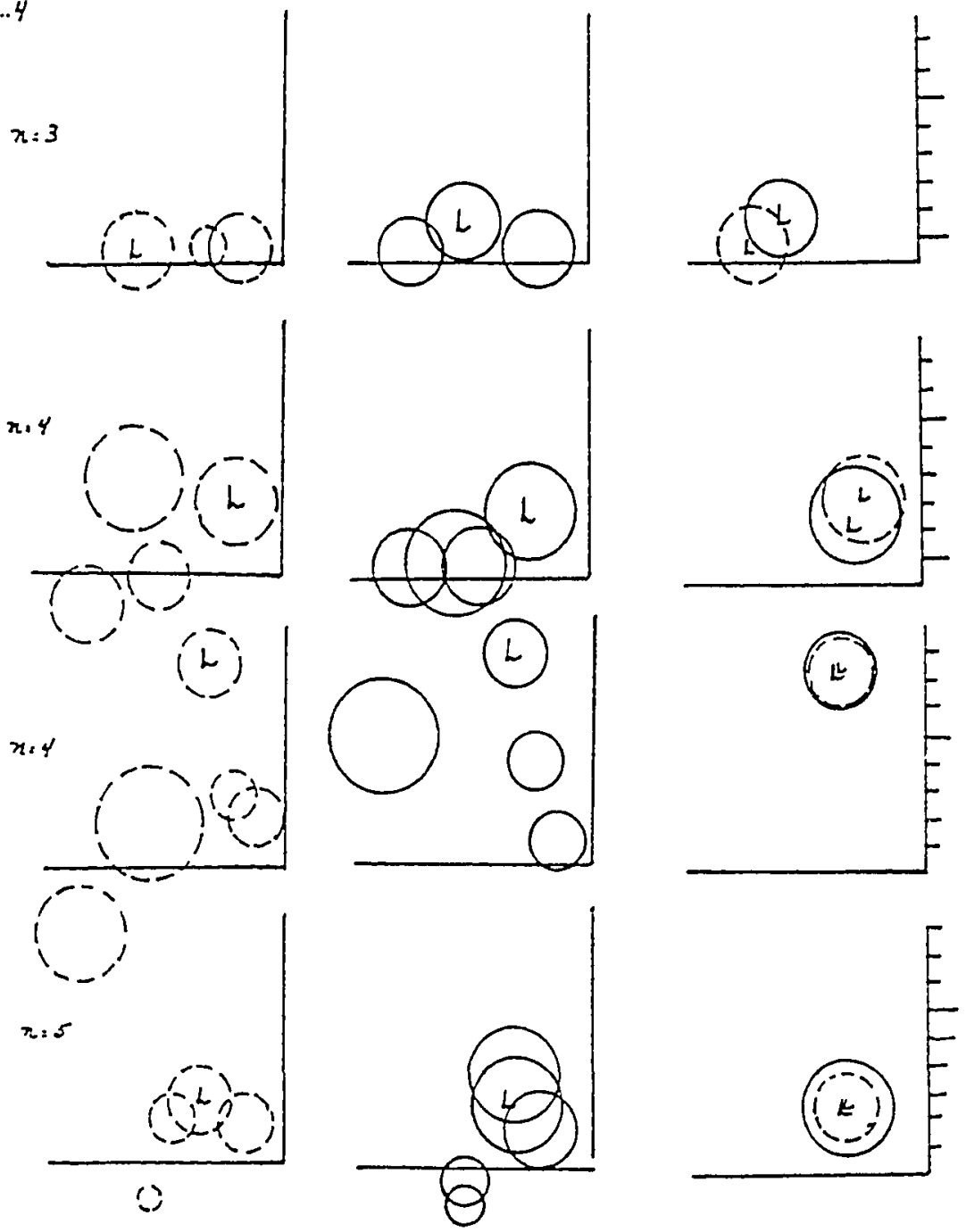

time 1 qroups

time 2 Groups

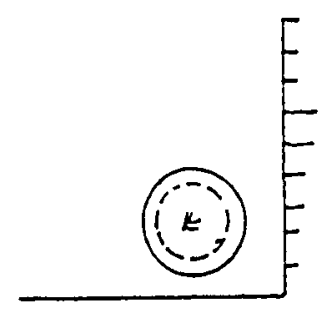

Red! ${ }^{\prime}=$ time 1

Rlock 
Forward Parituve Guad
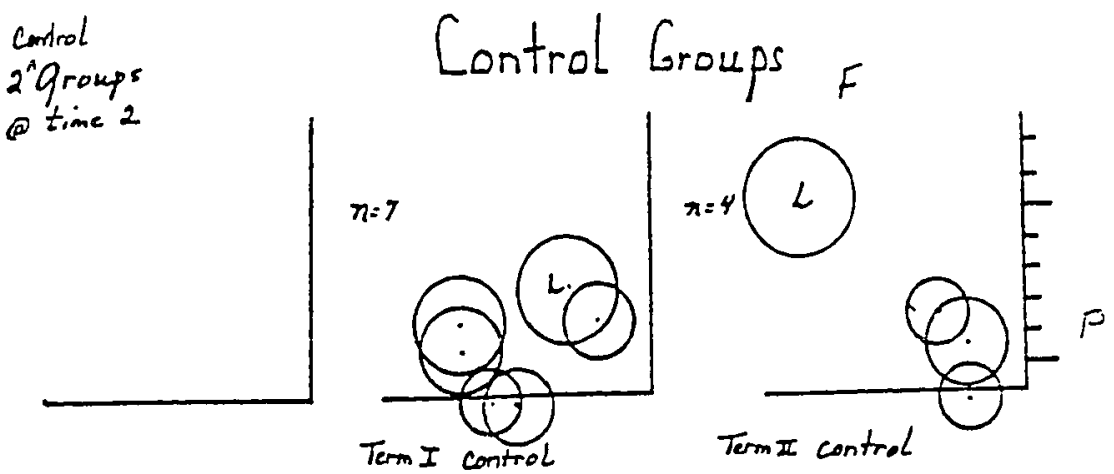